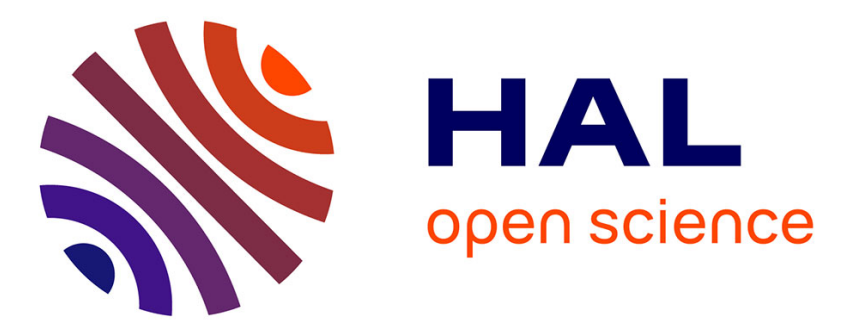

\title{
Mégalithismes en France: nouveaux acquis et nouvelles perspectives de recherche
}

\author{
Luc Laporte, Luc Jallot, Maïténa Sohn
}

\section{To cite this version:}

Luc Laporte, Luc Jallot, Maïténa Sohn. Mégalithismes en France: nouveaux acquis et nouvelles perspectives de recherche. Gallia Préhistoire - Préhistoire de la France dans son contexte européen, 2011, 53, pp.289-334. 10.3406/galip.2011.2490 . hal-02343414

\section{HAL Id: hal-02343414 \\ https://hal.science/hal-02343414}

Submitted on 19 Dec 2019

HAL is a multi-disciplinary open access archive for the deposit and dissemination of scientific research documents, whether they are published or not. The documents may come from teaching and research institutions in France or abroad, or from public or private research centers.
L'archive ouverte pluridisciplinaire HAL, est destinée au dépôt et à la diffusion de documents scientifiques de niveau recherche, publiés ou non, émanant des établissements d'enseignement et de recherche français ou étrangers, des laboratoires publics ou privés.

\section{(ㅇ)(1) $\$$}

Distributed under a Creative Commons Attribution - NonCommercial - NoDerivatives| 4.0 


\title{
MÉGALITHISMES EN FRANCE
}

\section{Nouveaux acquis et nouvelles perspectives de recherche}

\author{
Luc LAPORTE $^{1}$, Luc JALLOT ${ }^{2}$ et Maïéna SOHN ${ }^{3}$
}

\begin{abstract}
Mots-clés. Dolmen, menhir, Néolithique, mobilier funéraire, pratique funéraire.
Résumé. Le mégalithisme en France est un phénomène de longue durée, car il couvre près de trois millénaires, et d'une telle complexité que nul ne peut prétendre le résumer en quelques pages. Enrichie ces dernières décennies par de nouvelles recherches de terrain et par des synthèses thématiques ou régionales, l'étude du mégalithisme a vu ses angles d'approche renouvelés. À la lumière de ces travaux, cet article propose de faire table rase d'un certain nombre d'idées reçues, en insistant avant tout sur la complexité des pratiques funéraires et la non-linéarité de l'évolution des architectures mégalithiques. Chaque monument, aujourd'hui ruiné, est le fruit d'un ou plusieurs projets architecturaux, au sens propre du terme. Parallèlement, la mise en œuvre du chantier suppose une succession d'actes techniques qui méritent également d'être étudiés en détail, un peu à l’image de ce que nos collègues médiévistes nomment "l'archéologie du bâti ». Nous avons souhaité également mettre l'accent sur la nécessité d'aborder le mégalithisme aussi bien sous l'angle des architectures que sous celui des mobiliers funéraires et des restes humains (lorsqu'ils sont conservés), ces trois aspects étant souvent intimement imbriqués. Enfin, le monument mégalithique mérite d'être compris dans son espace, l'espace funéraire au sens large, mais aussi l'espace sépulcral. Dès lors, une multitude d'interrogations et de nombreuses nouvelles pistes de recherche apparaissent. Le mégalithisme n'est pas un sujet désuet mais novateur, pour lequel beaucoup reste à faire.
\end{abstract}

Key-words. Megalithism, France, Neolithic, grave goods, funerary practices.

Abstract. This article does not presume to summarize the immense complexity of megalithism in France over a period of nearly three millenia, but rather to contribute a few elements of reflection to the numerous research directions it inspires. It first insists on the importance of finally eliminating a number of accepted ideas; among which, the tendency to systematically classify the architecture of burial spaces in function of their "apparent" complexity, from the most simple to the most elaborate. Numerous examples show that the megalithic phenomenon is complex, not linear. Each monument, today in ruins, is the result of several architectural projects, in the true sense of the term. The construction of a site, supposes at the same time a succession of technical acts that also merit detailed study, in the same manner as that which specialists of the Medieval period call the archeology of construction. We also wish to emphasize the necessity of addressing Megalithism from the perspective of architecture, grave goods and human remains (when they are preserved), as these three aspects are often intertwined. Finally, a megalithic monument must be understood in its space, the funerary space in the broad sense, as well as the burial space. From this perspective, a multitude of question and numerous research directions appear. Megalithism is not an outdated subjet, but an innovative one, for which much remains to be done.

Près de 4700 monuments mégalithiques funéraires sont répertoriés en France, bien que tous les inventaires régionaux n'en soient pas à un stade d'avancement tout à fait égal (Soulier dir., 1998). Les zones de plus forte concentration prennent la France continentale en écharpe, de l'Atlantique jusqu'au littoral méditerranéen. G. Sauzade (2008) compte près de 3000 dolmens pour le seul midi de la France (soit près des deux tiers du corpus), dont presque 2000 se

1. UMR 6566 du CNRS «CReAAH» et Université de Rennes-1, Campus de Beaulieu, Bâtiment 24-25, CS 74205, 263, avenue du Général-Leclerc, F-35042 Rennes Cedex. Courriel: luc.laporte@univ-rennes1.fr

2. Inrap Méditerranée, 561, rue Étienne-Lenoir, F-30900 Nîmes. Université de Paul-Valéry-Montpellier-III, route de Mende, F-34199 Montpellier Cedex 5. UMR 5140 du CNRS «Archéologie des sociétés méditerranéennes», 390, avenue de Pérols, F-34970 Lattes. Courriel: ljallot@9business.fr 3. UMR 5608 du CNRS «TRACES», Université de Toulouse-Le Mirail, Maison de la Recherche, 5, allées Antonio-Machado, F-31058 Toulouse Cedex 9. Courriel: maitena.sohn@aliceadsl.fr 
concentrent sur les Causses (fig. 1). Une telle densité est à peu près équivalente à celle que l'on connaît au Danemark ou en Galice. Un même nombre de monuments avait été répertorié dans le nord de l'Allemagne depuis le XIX ${ }^{\mathrm{e}}$ siècle. Entre $80 \%$ et parfois jusqu'à près de $95 \%$ d'entre eux sont désormais détruits dans certaines provinces (Migdley, 2006). De telles destructions n'ont pas toujours été l'apanage de nos seules sociétés modernes ou contemporaines. En France, l'exemple du département des Côtes-d'Armor, où les répartitions des menhirs néolithiques et des stèles de l'âge du Fer sont globalement exclusives (Daire, 2005, fig. 54), le suggère fortement. Parmi beaucoup d'autres, le dolmen de Villedubert dans l'Aude fut assurément démantelé avant la fin du Néolithique (Duday, 2005). Il est d'autres régions où les inventaires s'enrichissent régulièrement par la (re)découverte de nouveaux monuments. Sous couvert boisé ou dans les zones un peu montagneuses, de telles découvertes ne sont pas si exceptionnelles. La Bretagne a notamment connu la publication de nombreux inventaires au cours de ces dix dernières années (Briard et al., 2004; Langouët, 2004, 2005 et 2006; Gouézin, 2007; Sparfel, Pailler dir., 2009).

En 1985, R. Joussaume commençait un ouvrage traitant principalement du mégalithisme en Europe occidentale, par le monumentalisme funéraire de ses contrées continentales et septentrionales. Cet auteur posait également la question de l'existence d'un berceau du mégalithisme atlantique en France de l'Ouest. Vingt ans plus tard, à l'occasion de la publication des actes du colloque de Bougon en 2006 (Joussaume, Laporte, Scarre dir., 2006), il prend acte des dates très anciennes désormais proposées pour certains mégalithismes de la péninsule Ibérique, dans la seconde moitié du VI ${ }^{\mathrm{e}}$ millénaire av. J.-C. En France, les rivages atlantiques tiennent toujours une place importante dans les discussions sur l'origine de ce mégalithisme. L'étude des pratiques funéraires et notamment celles liées au traitement du corps, ont fait de très larges et de très utiles progrès, prenant le pas sur les considérations architecturales dans le Bassin parisien. Dans ce domaine, la plupart des découvertes et notamment celles des dix dernières années dans le sud de la France, sont plutôt liées à des projets d'archéologie préventive et à de rares fouilles bénéficiant de recherches programmées.

Dater la construction, comme dater chaque étape du fonctionnement, d'un plus grand nombre de ces monuments mégalithiques, reste à chaque fois un préalable indispensable à des raisonnements plus élaborés. Cela demeure plus aisé pour les petits monuments construits en

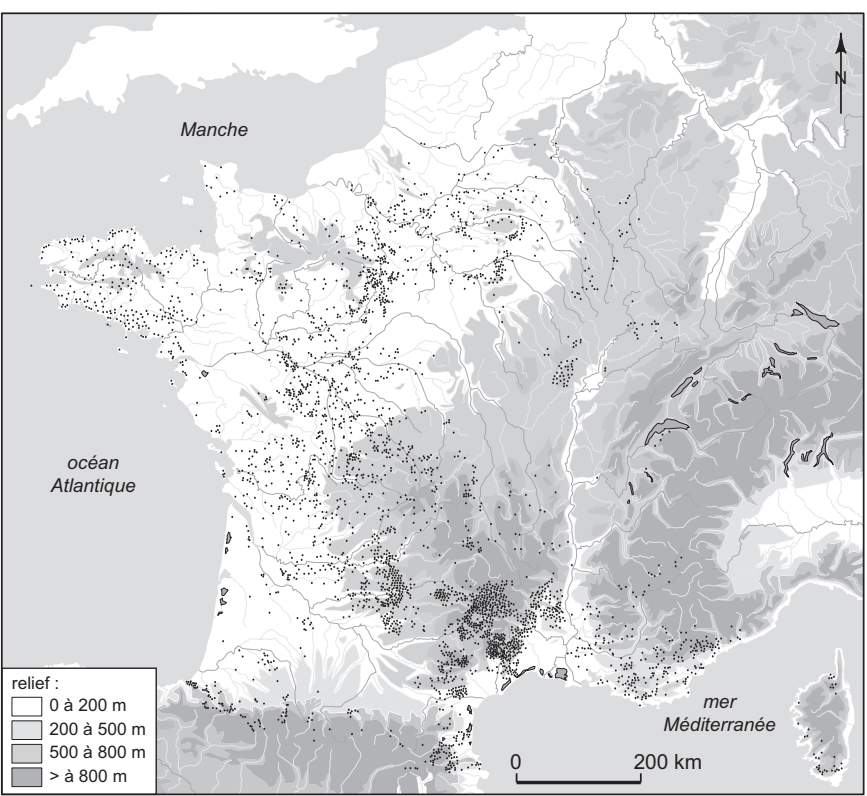

Fig. 1 - Carte de répartition des monuments funéraires mégalithiques en France d'après Soulier dir., 1998 (DAO: J.-M. Palluau, Inrap).

une seule fois à partir du vieux sol d'occupation antérieure, et contenant un seul espace sépulcral où sont retrouvés les squelettes en connexion anatomique d'un nombre relativement restreint d'individus ${ }^{1}$. Mais les rares exemples de tels contextes préservés montrent combien il est difficile d'attribuer une unique phase de construction à un monument même modeste. Chaque inhumé devrait faire alors l'objet d'une datation, de même que pour les éléments recueillis dans le vieux sol, voire dans les carrières adjacentes. Cela peut se révéler beaucoup plus difficile lorsque l'histoire architecturale du monument est complexe, ou lorsque le nombre de personnes inhumées croît considérablement sans que l'on ait jugé nécessaire, à l'époque, de respecter l'intégrité corporelle de chacun. Pour ne pas parler de la datation des menhirs isolés ou des gravures qu'ils portent. Quant au recours aux statistiques bayésiennes, comme souvent, elles ne valent d'abord que par la rigueur des hypothèses formulées au préalable.

Sans en avoir l'exclusivité en France, loin de là, la Bretagne et en particulier le golfe du Morbihan concentrent le plus grand nombre de représentations symboliques gravées sur les dalles de dolmens (Twohig, 1981; L'Helgouach et al., 1997). Dès les années 1830, la découverte de Gavrinis

1. Même dans un tel cas, disposer de tous les éléments nécessaires n'est pas si fréquent. 
joua un rôle important dans les discussions qui animaient alors la communauté scientifique quant aux capacités artistiques de l'homme «primitif». Les travaux récents sont nombreux (Cassen, 2005 et 2007; Mens, 2006; Jallot, Sénépart, 2008), mais l'inventaire systématique du corpus reste à achever, en particulier pour la Bretagne comme le faisait remarquer J.-L. Le Quellec (2006). Plus encore que le traitement informatique imposé à certains clichés photographiques, l'observation attentive d'un seul monument suffit parfois à inverser les termes du discours, comme ce fut le cas avec la découverte de très nombreuses figurations de bovidés sur la stèle de Saint-Samson, ou celle plus récente d'un grand signe serpentiforme à Saint-Macaire-en-Mauges (Joussaume, Raux, 2006). Bien loin de l'éloge de la verticalité que nous propose $\mathrm{S}$. Cassen dans son Exercice de stèle (2009), A. Gallay (2006) s'appuie sur une véritable théorie d'anthropologie générale (Testard, 2004), parmi d'autres sans doute, pour élargir encore le débat et proposer ainsi, à titre d'hypothèse de travail, une grille de lecture originale du mégalithisme.

\section{UNE QUESTION DE VOCABULAIRE}

Les études sur le mégalithisme en France ont souvent prêté l'oreille aux échos de la recherche publiée en langue anglaise, de O. Montélius à C. Renfrew, bien que parfois de façon un peu distraite; cela n'est pas toujours sans poser quelques petits problèmes de vocabulaire, plus que de traduction. Si nous insistons sur de telles confusions, c'est parce qu'elles ont contribué à forger une apparente cohérence européenne pour des théories par ailleurs contestées sur le mégalithisme français (Boujot, Cassen, 1992, repris dans Cassen dir., 2000; Cassen dir., 2009, contredit par Joussaume, 1997; L'Helgouach, 1997; Laporte et al., 2002; Scarre et al., 2003; Joussaume, Laporte, 2006; Laporte, 2010b, par exemple), mais largement vulgarisées ces dernières années dans de nombreux manuels sur le Néolithique. Quant au Petit lexique du mégalithisme rédigé par J. Arnal en 1956 (Arnal, 1956), il est resté d'un usage contestable comme l'a montré P.-R. Giot (1990).

À titre d'exemple, le terme générique de «dolmen» concerne en français tous les dispositifs de grosses pierres assemblées; dans son usage le plus courant, il s'oppose seulement au «menhir», pierre dressée isolément. Dans les publications en langue anglaise et celles d'Europe septentrionale, ce même terme de «dolmen» est traditionnellement opposé aux «passage graves». Le premier de ces deux termes concerne alors des architectures qui, en Armorique par exemple, sont pourtant qualifiées de «coffres» et en Espagne de «cistas», de par leur petite taille et l'absence d'accès couvert ${ }^{2}$. Quant au mot tholos, fréquent dans la péninsule Ibérique, il est employé occasionnellement pour décrire des monuments de plan circulaire (Tholos de la Lauve dans le Var ou Tholos de Roucayrolles dans l'Hérault) sans qu'il soit possible de restituer une couverture en encorbellement.

Ainsi, les «passage graves » du Danemark ou de Hollande, confrontés à leur traduction littérale en français de «tombes à couloir ", correspondent-elles à des formes d'architecture clairement distinctes de la plupart de ces dernières. S'il fallait alors trouver une correspondance au terme anglais, celle-ci s'appliquerait souvent en France aux monuments que J. L'Helgouach avait choisi d'appeler des «sépultures à entrée latérale», et qu'il associait aux «allées couvertes» ou «gallery graves». Cependant, une telle équivalence serait mise à mal par l'usage le plus fréquent dans les îles Britanniques, qui est d'appliquer le terme de «passage graves» indistinctement à toutes les différentes formes de chambres mégalithiques pourvues d'un couloir. Comment faudrait-il traduire le terme de «dolmen en allée couverte à entrée latérale», récemment proposé par R. Joussaume ?

Dans les îles Britanniques, la distinction entre «earthen long barrows» et «megalithic chambers» est soulignée par une partition du territoire. Vouloir superposer ces deux termes à ceux de «tertre» et de «cairn», utilisés de façon caricaturale dans une certaine littérature de langue française depuis une quinzaine d'année, serait abusif. Certes, dans les deux cas, chacun fait référence à des matériaux de construction différents. Toutefois, sur la façade atlantique de la France, «tertre» et «cairn» constituent plutôt les deux extrêmes de dispositifs monumentaux mêlant couramment la terre et la pierre à des degrés divers, recouvrant chacun des espaces funéraires de formes variées et dont la répartition géographique n'est jamais exclusive. Comme dans les îles Britanniques, chacun des extrêmes, que stigmatise ici l'emploi d'un tel vocabulaire, pourrait avoir été au moins

2. À l'occasion des relectures de cet article, J. Vaquer attire également notre attention sur les termes catalans de Cistas (tombes individuelles enterrées) et de Caixas (tombes plus grandes contenant plusieurs individus) qui se ferment toutes par le haut, s'opposant ainsi aux Cambras constituées de parois lithiques mais qui se ferment par le petit côté (situé à l'ouest). Ces dernières peuvent être enterrées, situées dans un talus ou construites dans un tumulus. Nous ferons alors remarquer que le terme de Cistas tel qu'il est utilisé en Catalogne n'est pas le strict équivalent du même terme en Castillan, tel que nous l'avons vu utilisé pour décrire des coffres au sein d'une masse tumulaire ne serait-ce que dans les Asturies, par exemple. 
partiellement contemporain. Ces mêmes termes de «tertre» et «cairn» seront encore différemment utilisés dans le sud de la France...

\section{ORIGINES ET PREMIERS DÉVELOPPEMENTS DU MÉGALITHISME AU COURS DU V $V^{\mathrm{e}}$ MILLÉNAIRE AV. J.-C.}

Les débats actuels sur l'origine du mégalithisme atlantique prennent principalement leur source dans des propositions qui furent d'abord formulées au cours des années 1930. M. et S.-J. Péquart posaient alors la question d'une filiation locale entre ce mégalithisme et les dispositifs en pierre qu'ils venaient de dégager sur les îlots de Téviec et d'Hoëdic dans le Morbihan, pour des sépultures attribuées aux derniers groupes de chasseurs-cueilleurs (Péquart et al., 1937 ; Péquart, Péquart, 1954). V.-G. Childe (1949) était plutôt frappé par la similitude de formes architecturales entre le plan des maisons des premiers colons du Rubané, et celui de quelques tumulus trapézoïdaux d'Europe septentrionale et continentale. Comme G. Daniel (1960), il ne s'était pourtant pas totalement affranchi de l'idée d'une origine proche-orientale pour ce type de construction; idées diffusionnistes que P.-R. Giot (1959) achèvera de mettre à mal, en publiant les premières dates radiocarbone du monument de l'île Carn, en Bretagne. La multiplication des études régionalistes s'attachait alors à démontrer la diversité des cultures matérielles associées à de telles réalisations monumentales (Bailloud, Mieg de Boofzheim, 1955), enterrant définitivement l'idée qu'il n'ait jamais existé une «civilisation» mégalithique. Depuis, la durée attribuée à la période néolithique n'a cessé de s'accroître; période à laquelle la plupart de ces mégalithismes sont aujourd'hui rattachés, notamment en France. Elle s'étale désormais sur trois ou quatre millénaires suivant les régions françaises concernées, là où, cinquante ans plus tôt, on ne lui prêtait guère plus de quelques centaines d'années (Guilaine, 2006).

L'association entre déplacement de très gros blocs de pierre et funérailles de quelques personnages seulement semble bien étrangère aux valeurs intrinsèques que véhicule la néolithisation de l'Europe dans son ensemble. Elle se concrétise dans des régions qui ne connaîtront l'élevage et l'agriculture que tardivement, et elle puise certainement sa source dans des représentations du monde communes à différents groupes de chasseurs-cueilleurs, déjà présents de longue date sur la façade atlantique. En revanche, l'association entre pierres dressées et différents types de constructions monumentales funéraires est assurément propre aux premiers éleveurs et agriculteurs de ces régions (Scarre, 2003 et 2007). En programmant la mort de ceux qui seront déposés par les générations futures au sein de monuments funéraires, ainsi construits en quelque sorte pour l'éternité et en imposant à leurs contemporains une perception de l'espace fluctuante suivant les points de vue, ceux qui ont conçu de tels projets architecturaux tentent ainsi d'affirmer leur emprise sur le déroulement du temps et sur la configuration de l'espace.

Le déplacement de très grosses pierres et la diversité dans les pratiques funéraires, comme dans la forme des espaces sépulcraux ou celles des constructions monumentales, doivent d'abord être traités séparément. On observe en effet un foisonnement de solutions architecturales mises en œuvre dans une étape initiale, peut-être parfois dès la première moitié du Ve millénaire av. J.-C. À partir du milieu de ce même millénaire, les espaces sépulcraux de formes architecturales distinctes (sépultures sous dalles, coffres, chambres circulaires ou quadrangulaires disposant ou non d'un accès couvert) seront associés à différents types de réalisations monumentales, chacun intégrant ou non et à des titres divers, ces très grosses pierres qui donnent leur nom à l'ensemble du phénomène.

\section{NATURE ET GULTURE: L'EMPREINTE DU MÉSOLITHIQUE}

$\mathrm{Au} \mathrm{VIII}{ }^{\mathrm{e}}$ millénaire av. J.-C., l'inhumé d'Auneau dans le centre de la France (Verjux, Dubois, 1997), portait près de $300 \mathrm{~kg}$ de pierres sur le torse, selon une mise en scène que l'on retrouvera beaucoup plus tard dans la sépulture multiple en pleine terre de Poncharraud, en Auvergne, attribuée au Néolithique moyen (Loison, 1998; Chambon, Leclerc, 2007 et 2008b). Au milieu du Ve millénaire av. J.-C. et toujours dans le centre de la France, les sépultures sous dalle de type Malesherbes participent d'un principe assez similaire; si ce n'est qu'une unique dalle, assurément mégalithique, scelle la large fosse où repose généralement le corps d'un seul individu et plus rarement ceux de deux personnes inhumées simultanément (Verjux et al., 1998). Sur le site éponyme, la dalle de grès ne pèse pas moins de dix-huit tonnes. Deux millénaires plus tard, sur le site d'Auneau, une autre sépulture sous dalle correspond cette fois-ci à une sépulture collective du Néolithique final (Verjux, 2006). La répartition en France de sépultures sous dalle, construites à différentes époques, coïncide d'ailleurs assez bien avec celle des dolmens angevins, parfois qualifiés de «Brontosaures» du mégalithisme atlantique (fig. 2). Établi très tôt, un tel 

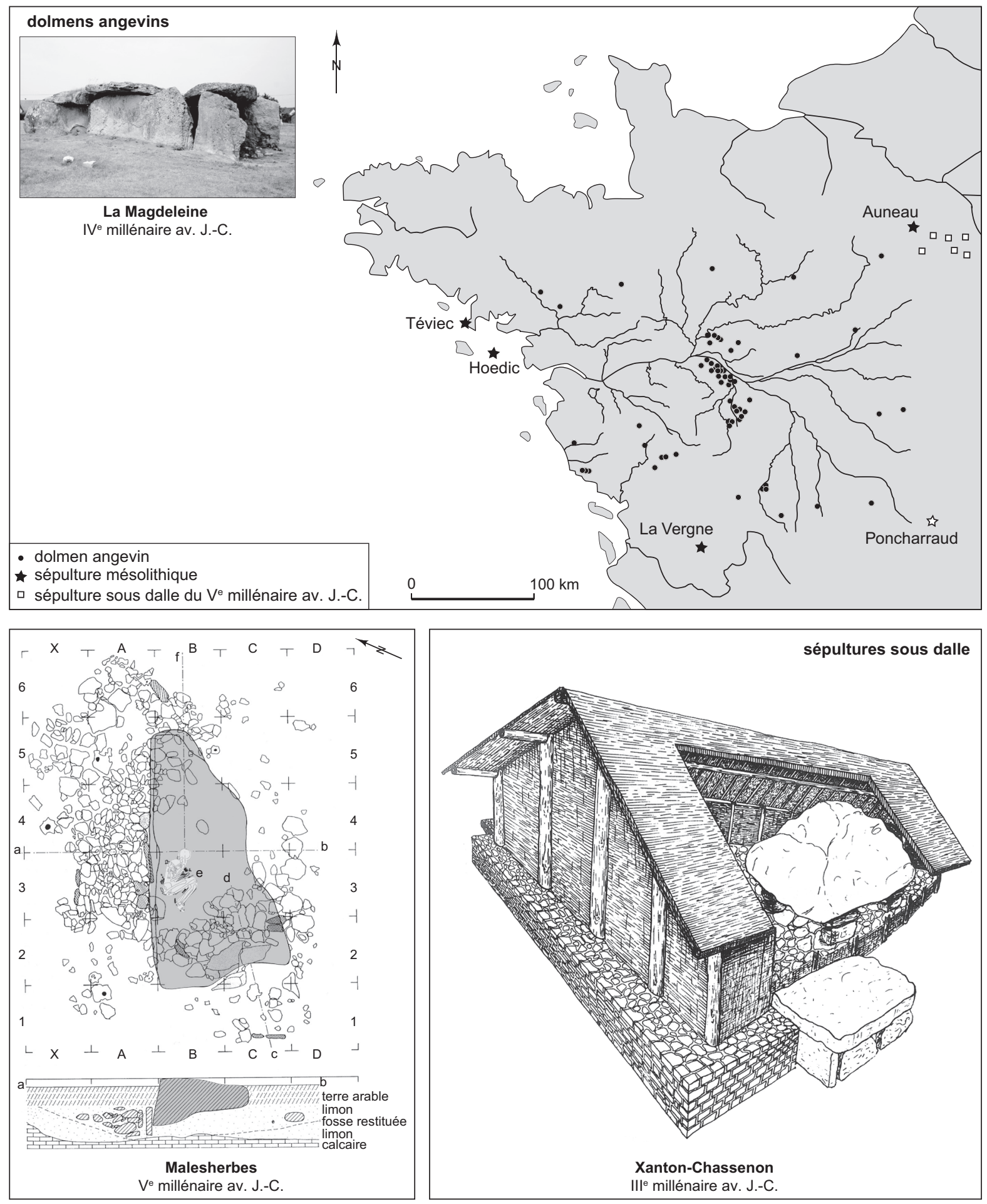

Fig. 2 - Déplacer de très grosses pierres. Sépultures sous dalle et dolmens angevins: une tradition régionale ? d'après Gruet, le Roux, 2005 ; Joussaume, 1981; Verjux et al., 1998 (cliché: L. Laporte, CNRS; DAO: L. Laporte, L. Quesnel, CNRS). 
lien entre le déplacement de très grosses dalles et les funérailles de quelques uns au moins des défunts, semble ainsi traverser toute la période du Néolithique.

Pour parler de l'héritage des derniers groupes de chasseurs-cueilleurs, il convient en effet de distinguer deux niveaux distincts: quelques tendances très générales présentes dans les architectures mégalithiques tout au long de leur développement au cours du Néolithique, d'une part, et d'autre part les modalités de transmission au moment où une telle monumentalité commence à faire son apparition en France. Paradoxalement, le premier point est le plus tangible alors que le second porte plus à discussion.

\section{POUR CE QUI EST DES PRINCIPES GÉNÉRAUX}

Tirer parti de la courbure naturelle des blocs déplacés, pour les positionner individuellement de façon à réduire la portée d'une table de couverture (Joussaume et al., 2002); façonner l'un de ces blocs dans un affleurement naturel de la roche en place, pour l'intégrer dans une construction totalement artificielle (L'Helgouach, 1962); tailler un piédestal aux monuments les plus imposants, dont les marches dans le rocher seront de dimensions équivalentes à celles des parements étagés construits par l'homme, pour insister sur la continuité des matériaux (Laporte et al., 2001); au-delà de l'économie de moyens que la mise en ouvre de telles solutions techniques représente, ces quelques exemples parmi beaucoup d'autres, rendent compte d'une attitude face à la nature profondément ancrée dans l'héritage des derniers chasseurs-cueilleurs (Scarre, 2004).

La morphologie de vastes amas coquilliers de la fin du Mésolithique a parfois été comparée au relief des masses tumulaires de tombes néolithiques, au Danemark comme dans le bassin du Tage; en revanche, aucun des amas coquilliers aujourd'hui reconnus en Bretagne ne peut supporter une telle comparaison (Dupont, 2006). Reconstituer une paroi verticale en pierre, pour former ainsi une figure de plan purement géométrique, semble avoir été une attitude totalement étrangère au mode de pensée des groupes de chasseurs-cueilleurs dans l'ouest de la France. La présence d'un parement périphérique construit en élévation est d'ailleurs aussi ce qui paraît distinguer les monuments mégalithiques de cette région de la plupart de leurs homologues ibériques. À si large échelle, les dalles calcaires finement bouchardées et assemblées en équerre des dolmens à couloir de type angoumoisin concrétisent bien le mode de pensée que l'on prête aux premiers agriculteurs de l'Europe (Cauwe et al., 2007).
De tels raisonnements, forcément trop caricaturaux, méritent cependant d'être rappelés dans la mesure où ils sont implicitement présents chez de nombreux auteurs. Dans un autre domaine, comparer les nombreux éléments de parure en coquillage provenant des sépultures mésolithiques de Téviec et Hoëdic ou de La Vergne quelques millénaires plus tôt (Duday, Courtaud, 1998), avec les milliers de perles discoïdes associées à la sépulture double de Germignac datée du tout début du Ve millénaire av. J.-C. (Laporte, Gomez, 2001), n'est pas hors de propos. Dans le premier cas, on met à profit et on se réapproprie quelquesunes des caractéristiques des objets mis à leur disposition par la nature, là où, dans le second cas, on transforme une matière en des formes abstraites, conférant peu à peu à cette dernière son véritable statut de matière première (Laporte, 2009).

\section{POUR CE QUI EST DES MODALITÉS}

Il est souvent bien difficile de dater la mise en place de quelques grandes pierres allongées, seulement fichées dans le sol. Nombre de menhirs se trouvent isolés alors que les seuls alignements du Ménec, à Carnac, en comptent plus de mille (Bailloud et al., 1995). À Beltz, des charbons de bois, recueillis dans le comblement des calages, suggèrent que quelques-unes de ces grosses pierres ont pu être dressées dès le second quart du $\mathrm{V}^{\mathrm{e}}$ millénaire av. J.-C. (Hinguant, Boujot, 2010). Les céramiques associées à l'alignement du Douhet sur l'île d'Hoëdic tendent à confirmer une datation vers le milieu du V $V^{\mathrm{e}}$ millénaire (Large, Mens, 2008). En Bretagne, des menhirs ont été érigés au moins jusqu'au début de l'âge du Bronze (Briard et al., 1995). Quelques autres sont positionnés très bas sur l'estran, voire largement sous le niveau des mers actuelles (Giot, Morzadec, 1992), et parfois organisés en files légèrement divergentes comme à Kerdruelan (Cassen, Vaquero, 2003). Est-ce ici la preuve que l'on ait commencé à dresser ces pierres dès la fin du $\mathrm{VI}^{\mathrm{e}}$ millénaire av. J.-C., comme on commence à le suspecter pour la péninsule Ibérique? Les courbes de remontées des niveaux marins présentent une marge d'erreur beaucoup trop importante (Laporte et al., 2009), pour autoriser une telle affirmation sur ces seules bases.

Le grand menhir brisé de Locmariaquer pèse environ 300 tonnes (fig. 3). Le remploi de fragments de stèles en orthogneiss souvent gravées, dans la construction de plusieurs dolmens sur les bords du golfe du Morbihan, a permis de faire le lien entre deux manifestations majeures du mégalithisme atlantique (Le Roux, 1985). De tels remplois 


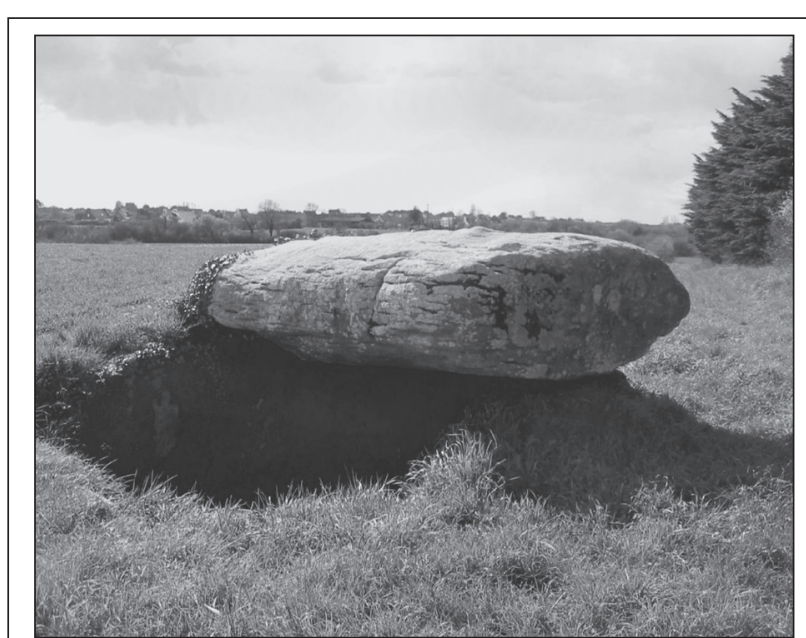

1

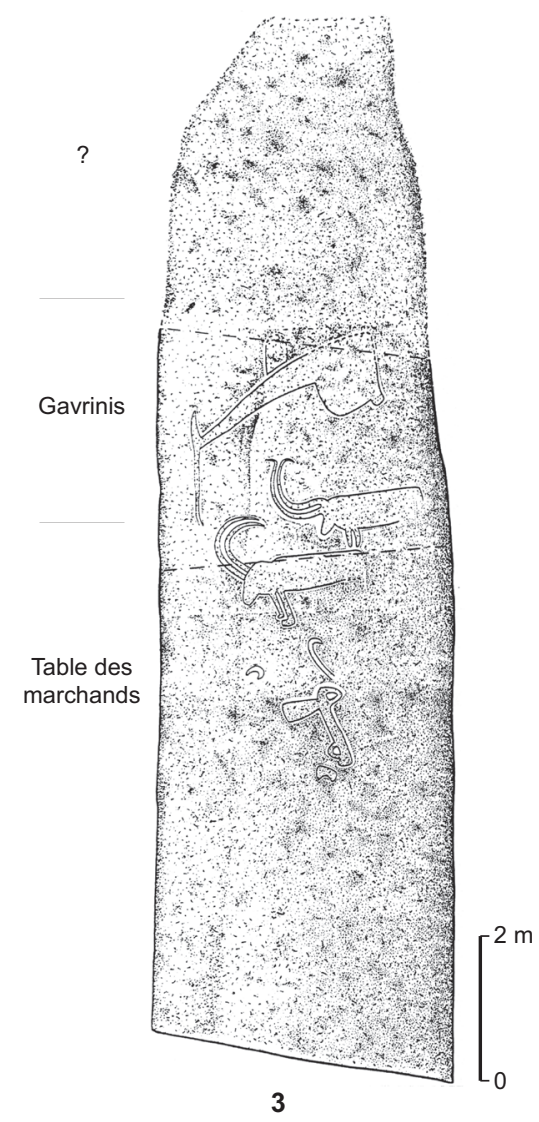

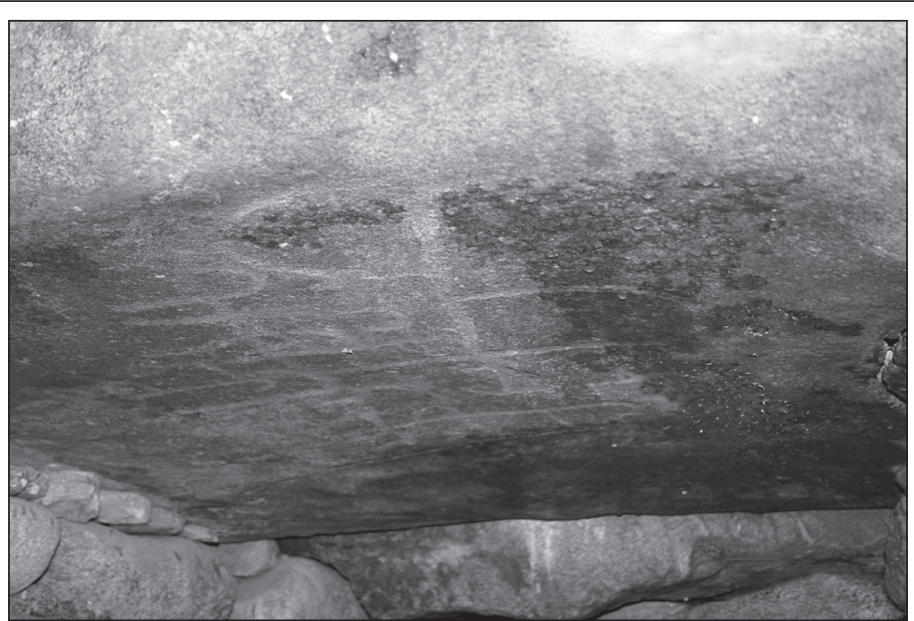

2

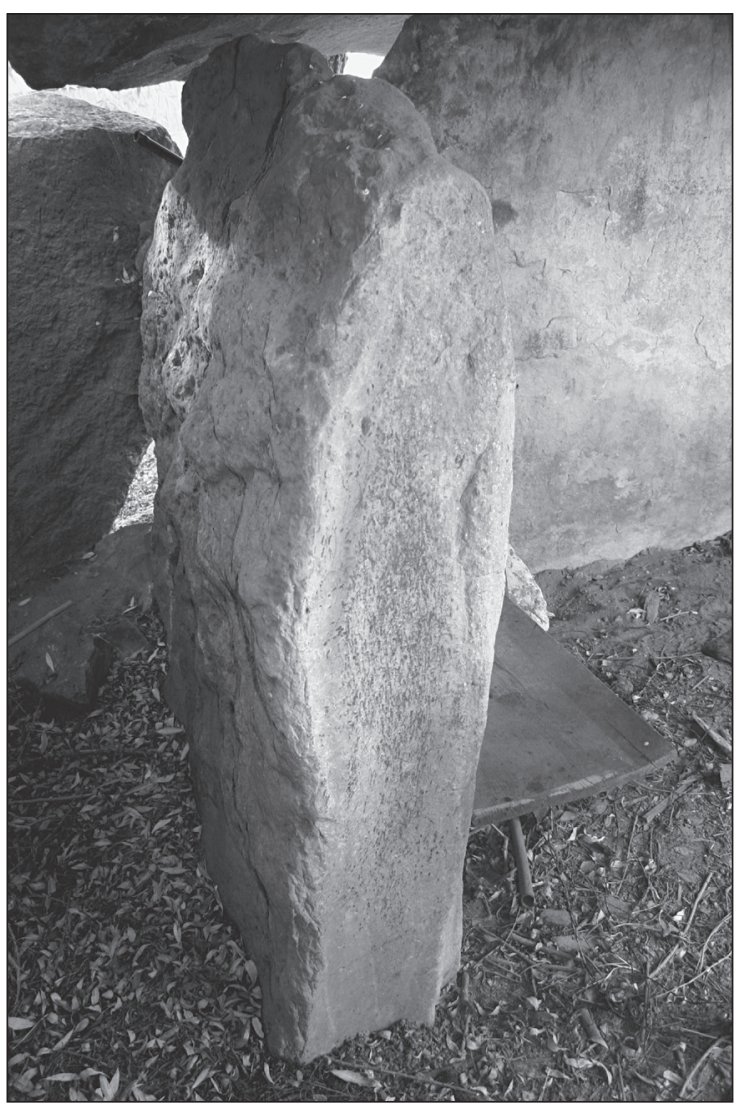

4

Fig. 3 - Dresser de très grosses pierres. La présence de fragments de grandes stèles (menhirs) en remploi dans certains dolmens du Morbihan, comme du Poitou, doit-elle systématiquement être interprétée en termes de périodisation? Tiendrait-on le même raisonnement pour des meules et polissoirs en remploi, nombreux près de l'estuaire de la Loire et en Anjou par exemple ? 1, fragment de stèle utilisé en table de couverture (Runesto, Morbihan); 2, fragment de meule en remploi comme table de couverture (Dissignac, Loire-Atlantique); 3, assemblage des fragments de stèles utilisés en table de couverture à Gavrinis et à la Table des Marchands (Morbihan); 4, polissoir dressé dans la chambre du dolmen angevin du Bois du Fau (Saint-Hilaire-Saint-Florent, Maine-etLoire) (cliché: L. Laporte, CNRS; dessin d'après Le Roux, 1985). 
sont attestés jusqu'en Poitou; le dolmen de Pierre-Levée à Poitiers présente ainsi une crosse gravée sur la face supérieure de sa table de couverture (Pautreau, Mataro i Pladelasala, 1996). De tels exemples ont conduit à proposer l'existence d'au moins deux phases distinctes: l'une qui voit l'érection de ces grandes stèles; l'autre qui correspondrait à la construction des dolmens à couloir (L'Helgouach, 1983). À moins, bien sûr, que tout cela ne participe d'un processus continu de réappropriation des lieux (Laporte, 2010a), sur chaque site indépendamment dans le temps, et qui concerne également bien d'autres matériaux: viendrait-il à quiconque l'idée de proposer l'existence d'une phase à polissoirs, antérieure à la construction des dolmens à couloir ? Dans certaines régions, leur remploi est pourtant tout aussi fréquent.

Une réinterprétation des signes gravés sur ces mêmes stèles est alors venue au secours de ce que les méthodes de datation plus classiques peinent à démontrer. On voudrait n'y voir qu'un bestiaire d'animaux sauvages, rendant compte d'une cosmogonie propre aux derniers groupes de chasseurs-cueilleurs (Cassen dir., 2000). Cependant, l'interprétation des bêtes à cornes figurées sur ces stèles comme sauvages ou domestiques est assurément conjecturale. Rappelons que les deux bovidés, probablement domestiques, enterrés dans une fosse sous l'extension secondaire du monument d'Er Grah, ne disposaient pas d'assez de collagène pour une date radiocarbone. La seule datation est obtenue à partir des charbons présents dans le remplissage de la fosse qui elle-même recoupe un foyer plus ancien (Le Roux dir., 2006). Le problème reste donc entier.

La plupart des auteurs s'accordent en revanche pour associer, d'une manière ou d'une autre, l'émergence du mégalithisme à la néolithisation de la façade atlantique de l'Europe. De ce point de vue, l'ouest de la France présente une situation singulière. Ici s'est opérée la rencontre entre courants rubanés et méridionaux, face à un substrat mésolithique qu'il serait tout aussi absurde de considérer comme uniforme.

\section{ENGRANGER QUELQUES-UNS PARMI LES ANGÊTRES - NÉOLITHIQUES ANGIENS MÉRIDIONAUX ET LES PHÉNOMÈNES D'ACCULTURATION}

Les espaces sépulcraux délimités par de larges dalles dessinant un plan quadrangulaire, et les grandes pierres dressées au-dessus du sol, semblent apparaître à peu près au même moment. En Poitou, les premières sépultures déposées dans des coffres en pierre de forme quadrangulaire, comme celles de la Goumoizière, appartiennent au deuxième quart du Ve millénaire av. J.-C. (Solers, 2007). Elles furent souvent comparées aux cistes «Chamblandes» des Alpes. Des vases à embouchure déformée leur sont associés, de même qu'à la Croix-Saint-Pierre en Bretagne; là, ils proviennent d'une fosse initialement creusée au centre d'une petite construction circulaire sur poteaux (Briard et al., 1995). Beaucoup plus au sud et vers le milieu du Ve millénaire av. J.-C., la nécropole du Camp del Ginèbre à Caramany (Pyrénées-Orientales) est composée de petits coffres en pierre au plan quadrangulaire, étroitement ceinturés par une masse de pierres sèches circulaire et parementée (Vignaud, 1994; Vaquer, 2007). En Catalogne, quelques monuments parfois plus imposants, comme ceux de Tavertet, sont tout juste un peu plus récents (Molist et al., 2007). À Caramany toujours, des foyers circulaires, bordés de petites dalles dressées, contiennent des dépôts de vases pour certains, des ossements émiettés et carbonisés pour d'autres. Ils ne sont pas non plus sans évoquer les structures décrites anciennement sous certains des tumulus carnacéens, voire au sein des amas coquilliers de Téviec et Hoëdic pour le Mésolithique (Laporte, 2005). Des fouilles plus récentes ont mis au jour ce même type de vestiges sous les terres rapportées constituant la masse du tumulus des Fouaillages à Guernesey. Ces terres ont livré quelques dates radiocarbone appartenant au second quart du Ve millénaire av. J.-C. (Joussaume dir., 1990, études en cours).

Il se peut qu'il faille y adjoindre, dans l'ouest de la France, quelques petites constructions circulaires exclusivement construites en pierres sèches (fig. 4). On y a introduit les ossements de quelques personnages décédés au milieu du $V^{\mathrm{e}}$ millénaire av. J.-C., comme dans la chambre F0 de Bougon en Poitou, ou celle de Vierville A en Normandie (Joussaume, Laporte, 2006). L'une au moins des personnes dont les os ont été recueillis sur le sol de la chambre circulaire du monument $\mathrm{C}$ de la Boixe-en Charente, date $\mathrm{du}$ troisième quart du $\mathrm{V}^{\mathrm{e}}$ millénaire av. J.-C. (Gomez De Soto, 1998). Les nombreuses datations radiocarbone désormais disponibles (antequem, utilisation, postquem) pour la nécropole de Condé-sur-Iff en Normandie, attestent d'une construction au cours de la même période (San Juan et al., 1998; Dron et al., travaux en cours).

\section{FORMES CIRCULAIRES ET QUADRANGULAIRES}

La distinction entre espaces sépulcraux de forme circulaire ou quadrangulaire, les uns plutôt couverts en 


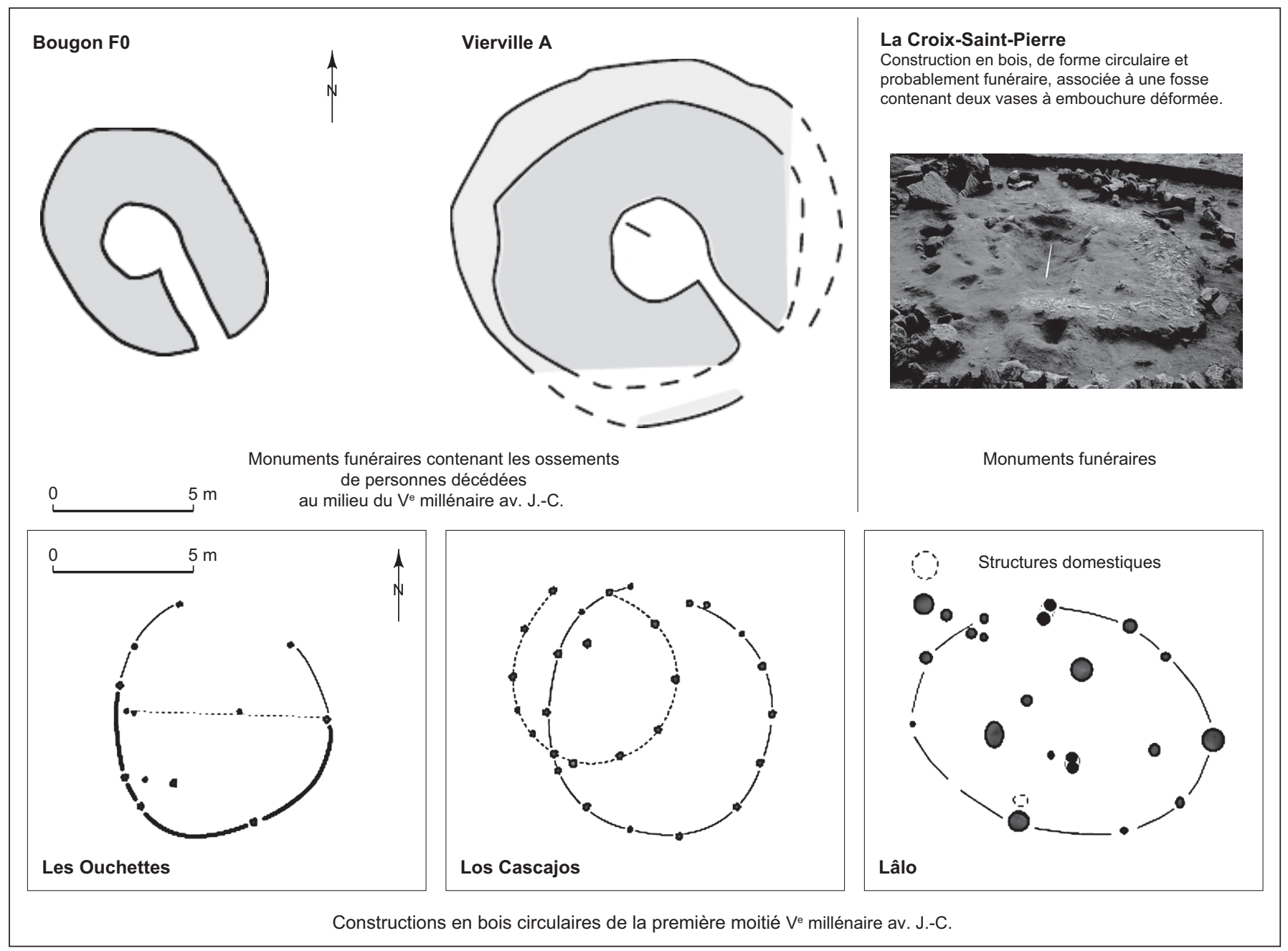

Fig. 4 - Forme des espaces sépulcraux: plans quadrangulaires ou circulaires. Les dimensions des monuments en pierre de Bougon F0 et de Vierville A, qui contiennent les ossements de personnes décédées autour du milieu du VE millénaire av. J.-C., sont comparables à celles de constructions circulaires en bois attestées dès la fin du Néolithique ancien, sur la façade atlantique comme dans le sud de la France d'après Laporte, Marchand, 2004 (cliché: J. Briard, CNRS; DAO: L. Laporte, CNRS).

encorbellement, les autres plutôt scellés par une table de couverture, a très tôt été interprétée par les archéologues en terme de chronologie relative. De par la technicité qu'implique la mise en œuvre d'une couverture en pierres sèches, W.-C. Lukis imaginait déjà que les chambres recouvertes par une simple dalle étaient les plus anciennes. Depuis, la fouille du tumulus E de Bougon par J.-P. Mohen nous a livré l'exemple contraire d'une chambre circulaire qui a été secondairement transformée en un espace quadrangulaire (Mohen, Scarre, 2002). À la suite des travaux effectués sur le tumulus très arasé du Planti, R. Joussaume imagine tout aussi bien que la mise en place simultanée d'espaces internes, aux volumes si différents, puisse correspondre à une distinction fonctionnelle (Bouin, Joussaume, 1998), comme cela est le cas pour la chambre $\mathrm{H}$ si richement décorée du tumulus de Barnenez, fouillée par P.-R. Giot et son équipe (1987).

La recherche de prototypes aux encorbellements des chambres circulaires en pierres sèches fait également partie du débat. Des photographies prises en 1902, lors de la fouille du coffre du Campet en Gironde, nous montrent qu'il était couvert par de petites dalles disposées en écaille; ces mêmes photos nous révèlent aussi qu'il était pourvu d'un accès latéral (Joussaume dir., 1990). Inversement, les parois du caveau piégé sous la masse des constructions, correspondant à ce que nous appelons aujourd'hui le 
tumulus Saint-Michel à Carnac, sont plutôt constituées de grandes dalles très épaisses, disposées horizontalement les unes sur les autres (Le Rouzic, 1932). Faut-il attribuer systématiquement une signification chronologique à de telles tentatives, sur la seule base de solutions techniques qui nous paraissent rudimentaires? Ce serait peut-être oublier que des parois exclusivement montées en pierres sèches peuvent tout aussi bien supporter une large dalle de couverture de plus de deux tonnes, comme le démontre l'exemple de la chambre III du tumulus C de Péré dans les Deux-Sèvres (Scarre et al., 2003).

\section{ESPACES SÉPULCRAUX ET FORMES DE L'HABITAT}

La comparaison avec les plans de structures domestiques contemporaines, encore assez mal connues jusqu'à ces dernières années, pourrait être plus prometteuse. Dans le sud de la France et dès le Chasséen ancien, l'une des alternatives au mégalithisme atlantique parmi les plus fréquentes sera l'inhumation d'un ou de plusieurs individus dans l'espace confiné de profonds silos (Vaquer et al., 2007). D'autres fosses étaient parfois signalées en surface par la présence d'une petite pierre dressée, comme au Gournier dans la vallée du Rhône où elles contenaient de nombreuses meules brisées (Beeching, Crubézy, 1998). Toutes sont parfois regroupées en de vastes nécropoles comme celle de Crès en Languedoc (Loison, Schmitt, 2009). Si ce choix est parfois interprété comme un geste de relégation destiné à isoler une partie de la population (Villes, 1986), pour d'autres périodes, la possibilité d'un lien conscient entre la conservation du grain et la conservation des corps a pu être démontré, notamment à La Tène ancienne (Delattre $e t$ al., 2000). Le volume interne des chambres circulaires voûtées en encorbellement n'est effectivement pas sans rappeler celui d'un silo, jusqu'à la présence d'une grosse pierre au sommet qui contribue à l'équilibre des premières et obture le second (fig. 5).

Les chambres funéraires construites en élévation réservent désormais aux ancêtres un espace protégé sur le même sol que foulent les vivants (Joussaume, 2003a). Toutes engrangeront les corps et les ossements de quelques personnages seulement (à peine plus d'une dizaine), parmi ceux décédés à chaque génération; un peu comme dans un grenier aux morts où l'on déposerait quelques semences sélectionnées, nécessaires à la production des récoltes pro- chaines (Laporte, Marchand, 2004). On pourra prélever (manipulations) dans ce stock en fonction des besoins (symboliques) jugés nécessaires à la survie du groupe; stocks qu'il conviendrait parfois de nettoyer (vidanges) ou de renouveler (réintroductions). N'est-ce pas dans la conservation des semences que réside l'opération la plus stratégique pour chaque groupe de chasseurs-cueilleurs lorsque celui-ci se décide à adopter de nouvelles stratégies de subsistance? N'est-ce pas ce qui a pu frapper le plus fortement et le plus largement l'imaginaire collectif des différents groupes humains concernés, sur le très long terme?

Constructions circulaires (enclos, greniers ?) et quadrangulaires (maisons ?) du Néolithique moyen cohabitent sur le site chasséen de Beaumont en Auvergne (Saintot, Le Barrier et al., 2009). Le bâtiment 3 se distingue par les murs porteurs de parois latérales qui débordent largement des murs pignons, assez courts, situés à chaque extrémité; à toute autre échelle, la disposition similaire des larges dalles verticales constituant les parois latérales de nombreux coffres en pierre de forme également quadrangulaire, intrigue... Une autre analogie possible réside dans la comparaison avec de grands bâtiments circulaires d'une quinzaine de mètres de diamètre, attribués au groupe de Cerny. Ils disposent d'une compartimentation interne dans leur premier tiers que l'on retrouve parfois dans les chambres circulaires de monuments mégalithiques, comme celui de la Hoguette en Normandie (Cassen dir., 2000). D'autres constructions sur poteaux présentent des dimensions plus modestes, de 7 à $8 \mathrm{~m}$ de diamètre; elles sont attestées dès le Néolithique ancien, depuis l'estuaire de la Charente jusqu'au sud des Pyrénées et dans la vallée du Rhône (Laporte, Marchand, 2004). De telles dimensions sont effectivement comparables à celles de petits monuments funéraires en pierres sèches, dont certains furent par la suite intégrés dans des constructions souvent allongées et beaucoup plus imposantes, comme sur l'île Carn en Bretagne, à Vierville en Normandie ou à Bougon en Poitou (Joussaume, Laporte, 2006).

Beaucoup des exemples précédemment cités pour la sphère domestique, mais pas tous, appartiennent à un courant de néolithisation qui s'est progressivement consolidé, d'abord dans le sud de l'Europe occidentale. En Europe continentale, là où le poids démographique de la néolithisation s'est peut-être fait le plus sentir (Scarre 2002a, 2002b et 2005), la néolithisation porte d'autres valeurs que le mégalithisme atlantique a également su intégrer. 

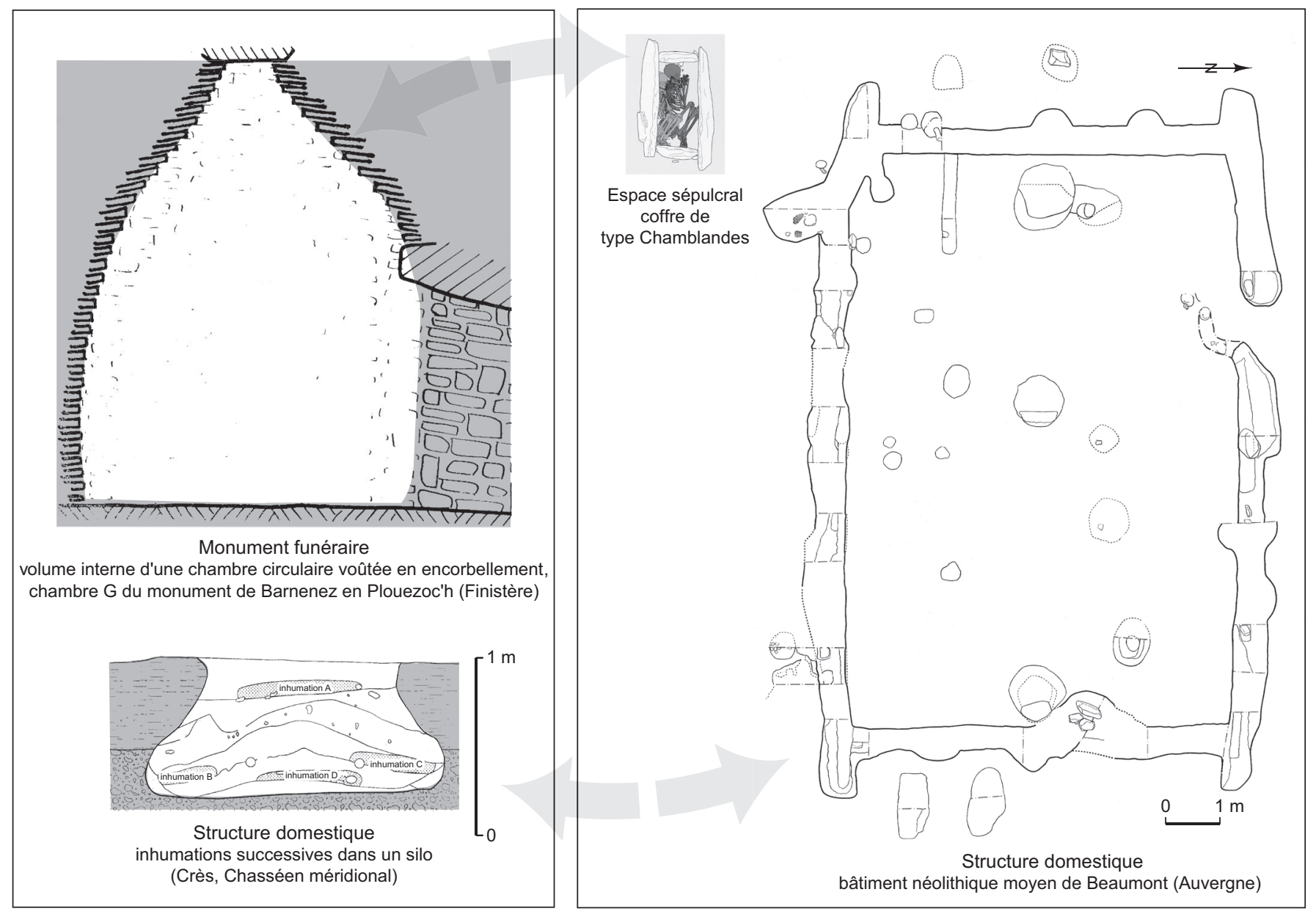

Fig. $\mathbf{5}$ - Forme des espaces sépulcraux: greniers aux morts ou maisons des ancêtres? d'après Giot, 1987; Moinat, Chambon, 2007; Loison, Schmitt, 2009; Saintot, Le Barrier et al., 2009 (DAO: L. Laporte, CNRS).

\section{UNE TENTATIVE POUR DOMESTIQUER LE TEMPS ET L'ESPACE - NÉOLITHIQUES ANCIENS CONTINENTAUX ET L'EXPANSION DÉMOGRAPHIQUE DU NÉOLITHIQUE}

Dans le Bassin parisien, les structures de type Passy ont souvent été présentées comme un terme de passage vers l'émergence d'une monumentalité funéraire (Demoule dir., 2007), bien qu'elles soient largement contemporaines des débuts du mégalithisme atlantique (Joussaume, 2008). Quelques sépultures individuelles en pleine terre, axiales, sont associées à un enclos allongé parfois sur plusieurs centaines de mètres. Le fossé périphérique semble rendre compte de dispositifs en élévation assez variés: talus externe ou interne, voire construction tumulaire couvrant tout ou partie de l'aire circonscrite, ou simple calage d'une palissade (Duhamel, 1997). Sur le site éponyme, la superposition de structures de type Balloy, plus courtes que les précédentes, avec le plan de quelques maisons de la culture Blicquy-Villeneuve-Saint-Germain (BVSG), a été un argument fort pour inscrire un tel processus dans l'héritage du courant rubané (Mordant, 1997). Ces structures sont attribuées au groupe de Cerny, et datées pour la plupart du troisième quart du $\mathrm{V}^{\mathrm{e}}$ millénaire av. J.-C. Le corps n'est plus déposé directement au contact de la terre, mais probablement dans un cercueil en bois pour les structures de type Balloy, voire parfois au sein de grands coffres en bois enterrés dans une fosse qui dispose alors d'une rampe d'accès, pour les structures de type Passy (Chambon, Leclerc, 2008a). 


\section{ESPACES CÉRÉMONIELS ET PLATES-FORMES SURÉLEVÉES}

La nécropole de Rots en Normandie est également composée de grands enclos allongés, souvent comparés aux structures de type Passy. Le monument 2 comporte deux sépultures individuelles en disposition axiale; l'une située à l'extrémité du dispositif et l'autre dans sa partie médiane (Desloges, 1997). Autour de cette dernière, le tracé du fossé périphérique semble contourner le fantôme d'un monument circulaire d'une dizaine de mètres de diamètre, aujourd'hui disparu. La disposition axiale des sépultures ne garantit pas une stricte contemporanéité avec l'enclos qui isole cet espace de celui des vivants. La nécropole de la Jardelle en Poitou est composée d'enclos courts de type Balloy, sur lesquels viennent parfois se superposer des enclos circulaires (Pautreau et al., 2006). L'espace sépulcral du monument B est un coffre en pierre, enterré dans une fosse desservie par une rampe d'accès. Sur ce site arasé, les fossés servaient à l'implantation d'une simple palissade. Plus profonds, les fossés qui entourent les monuments construits en élévation de Lannec-er-Gadouer dans le Morbihan ou de Sarceaux en Normandie, présentent un plan similaire (Chancerel, Desloges, 1998; Cassen dir., 2000). En revanche, aucune de ces nécropoles ne peut être attribuée au groupe de Cerny.

Beaucoup plus au sud, mais également au cours du troisième quart du $\mathrm{V}^{\mathrm{e}}$ millénaire av. J.-C., sur le plateau des Agriates en Corse, de petits monuments circulaires contenant de larges coffres en pierre sont associés spatialement à de grandes constructions quadrangulaires. Celles-ci sont interprétées comme autant de structures domestiques (Léandri et al., 2007), mais elles pourraient tout aussi bien correspondre à des plates-formes cérémonielles basses. L'hypothèse d'une plate-forme surélevée est celle finalement retenue par $\mathrm{R}$. Joussaume pour restituer l'élévation de la partie orientale du tumulus A de Champ-Châlon (Joussaume, Cadot, Gilbert, 2006), sur le littoral atlantique (fig. 6). Vers la fin du V $V^{\mathrm{e}}$ millénaire av. J.-C., l'intégration de formes architecturales multiples, aux fonctions initialement distinctes, est désormais provisoirement achevée. Exceptionnellement conservé sur toute son élévation, le long tumulus $\mathrm{C}$ de Péré à Prissé-la-Charrière comportait assurément un tel cheminement au sommet de sa construction, sur un peu moins de $100 \mathrm{~m}$ de long (Laporte et al., 2002). L'espace sépulcral n'occupe alors qu'une place très réduite dans la construction monumentale.

\section{ESPACES SÉPULCRAUX ET MONUMENTAUX}

Espaces cérémoniels délimités selon une forme allongée et constructions circulaires ceinturant étroitement l'espace sépulcral coexistent très tôt sur la façade atlantique. À Fleury-sur-Orne en Normandie, le faisceau d'enclos fossoyés converge vers une petite nécropole mégalithique plus récemment identifiée par une opération de diagnostic en archéologie préventive (Desloges, 1997). Un «cairn» circulaire à chambre elle-même circulaire a de plus été identifié par J. Desloges au centre de la nécropole; le tracé des enclos semble l'éviter. Les rares études extensives de nécropoles exclusivement mégalithiques comme celles de Champ-Châlon (Joussaume, Cadot, Gilbert, 2006), de Prissé-la-Charrière ou de Bougon en Poitou (Laporte et al., 2002; Mohen, Scarre, 2002), comme probablement celle d'Er Grah en Bretagne (Le Roux dir., 2006), révèlent une dynamique comparable. Dans une étape ancienne, elles associaient de grands monuments allongés, souvent isolés par un fossé périphérique, avec des dolmens à couloir seulement inclus dans une petite construction circulaire et généralement dépourvus de carrières adjacentes (Laporte, à paraître b).

À Mané-Ty-ec ou à Lannec-er-Gadouer en Bretagne, comme à Sarceaux en Normandie ou à Prissé-la-Charrière en Poitou, tous ces monuments allongés étaient initialement ceinturés par un parement en pierres sèches, construit en élévation. Au Cruchaud dans le sud des Charentes, la masse interne est structurée par des empilements de mottes de gazon (Burnez et al., 2003). À la différence des «dolmens à couloir », fonctionnement funéraire et constructions monumentales sont ici différés dans le temps. La construction du monument occulte et scelle l'espace cérémoniel précédemment circonscrit. Cela ne préjuge ni du nombre de défunts déposés dans la chambre, ni de la durée pendant laquelle les structures d'accès correspondantes sont fonctionnelles (Laporte et al., 2002). Ces dernières sont toujours présentes, comme à Er Grah ou pour le caveau du tumulus Saint-Michel, et probablement à Tumiac (Laporte, 2005). L'aménagement d'un accès couvert, ou «couloir», permet en revanche d'intégrer ces deux aspects au sein d'un même projet architectural. On anticipe alors sur l'usage qu'en feront de nombreuses générations à venir (Joussaume, 2003a). 

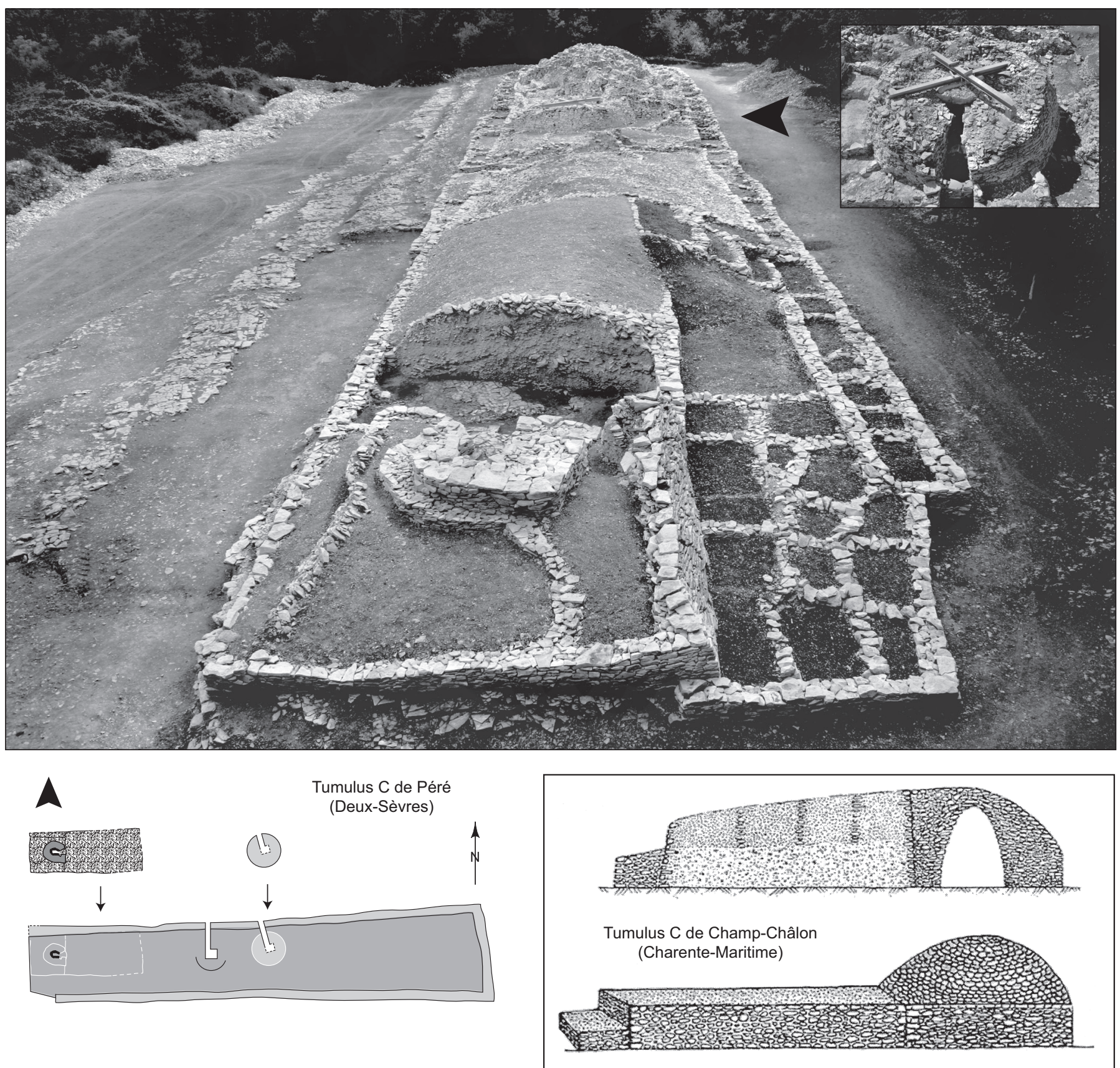

Fig. 6 - Architectures monumentales: tumulus allongés du centre-ouest de la France (d'après Laporte et al., 2002; Joussaume et al., 2006). Le tumulus C de Péré, pourvu d'une plate-forme sommitale, comme peut-être à Champ-Châlon, recouvre un monument allongé et un autre de forme circulaire (cliché: L. Laporte, R. Joussaume, CNRS).

\section{CONSTRUCTIONS MONUMENTALES ET FORMES DE L'HABITAT}

La découverte de grands bâtiments en bois du Néolithique moyen tend aujourd'hui à relancer les discussions sur un lien indirect entre la maison rubanée d'Europe continentale et certaines des constructions mégalithiques qui leur sont postérieures, sur la façade atlantique (fig. 7). De récentes études génétiques sur les restes de trois des individus inhumés dans la chambre III du tumulus $\mathrm{C}$ de 

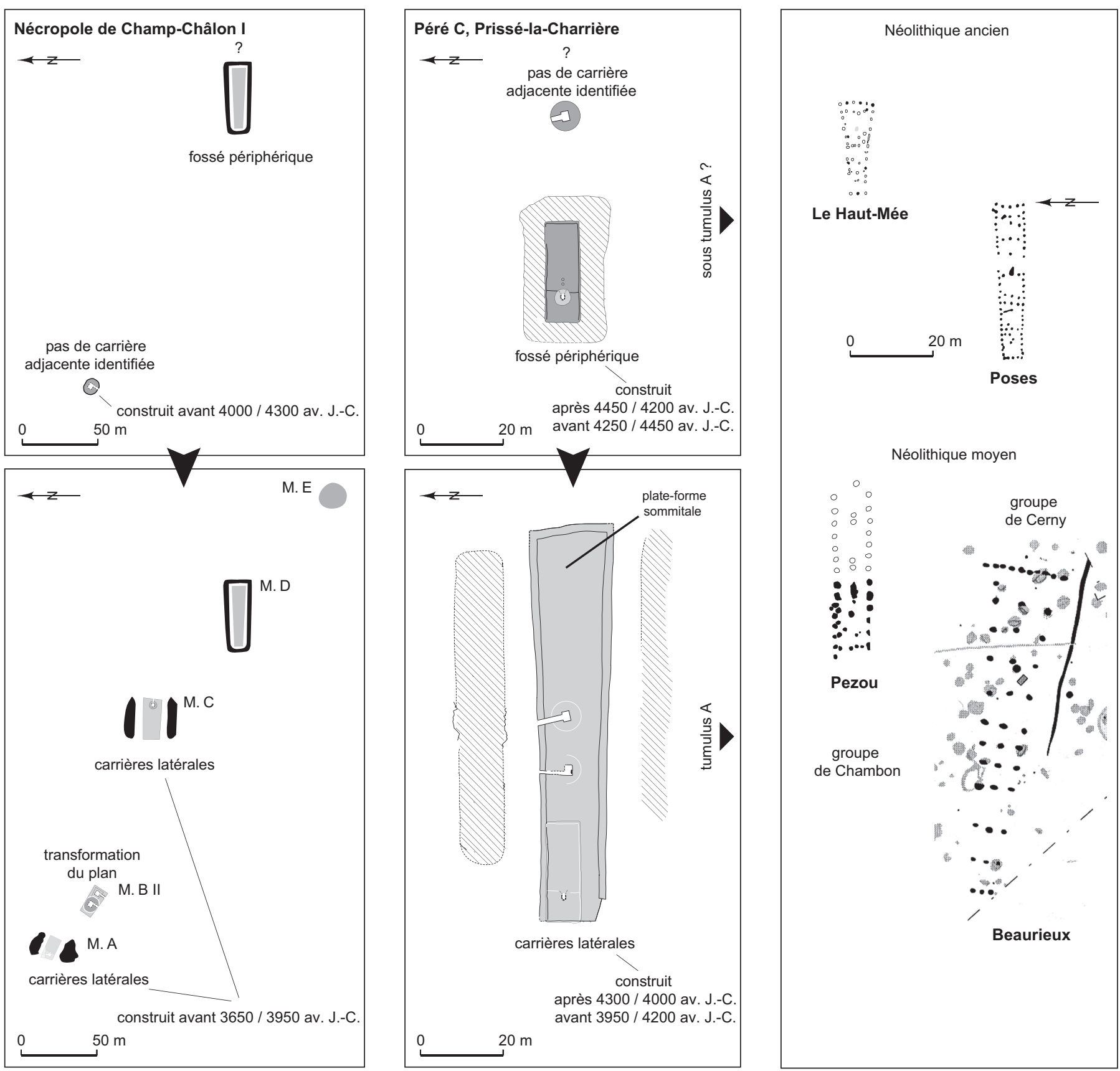

Fig. 7 - Architectures monumentales: monuments mégalithiques et bâtiments en bois sur poteaux porteurs allongés du Néolithique ancien et moyen dans l'ouest et le nord de la France (sauf mentions contraires, les dates radiocarbone indiquées sont sur matériel osseux) d'après Cassen et al., 1998; Laporte et al., 2002; Bostyn et al., 2003; Joussaume, Cadot, Gilbert 2006; Leroy et al., 2006; Colas et al., 2008 (DAO: L. Laporte, CNRS).

Péré ajoutent à ce débat une dimension biologique, qu'il faut toutefois éviter d'extrapoler trop rapidement en termes d'influences culturelles (Deguilloux et al., 2010). Le bâtiment de Pezou en région Centre est attribué au groupe de Chambon (Leroy et al., 2006). Cette longue construction quadrangulaire à deux nefs mesure plus de $40 \mathrm{~m}$ de long pour 9 à $10 \mathrm{~m}$ de large. À Beaurieux dans l'Aisne, un enclos en épingle à cheveux est bordé de fosses latérales, comme celles de la maison rubanée. Au centre de l'espace ceinturé, deux sépultures individuelles en fosse, l'une en pleine terre 
et l'autre dans un coffre de pierre et de bois, sont attribuées au Michelsberg ancien (Colas et al., 2007). Cent mètres plus loin, une construction sur poteaux mesurant plus de $80 \mathrm{~m}$ de long est attribuée au groupe de Cerny (Colas et al., 2008). Elle jouxte trois enclos très arasés de type Balloy. Les poteaux y sont disposés en tierce comme dans le modèle rubané. En Bretagne, la présence d'une tierce en Y à mi-longueur du bâtiment BVSG du Haut-Mée induit une dissymétrie latérale qui trouvera plus tard une étrange correspondance dans le plan de nombreux monuments mégalithiques allongés de cette même région (Laporte, Joussaume, Scarre, 2001). Ceux de Barnenez ou de la pointe du Souc'h en Bretagne, de Colombier-sur-Seulle en Normandie, comme de Bougon F ou de Péré C en Poitou, présentent effectivement une forme trapézoïdale, généralement plus haute et plus large à leur extrémité orientale. La plupart recouvrent des monuments antérieurs aux formes parfois très variées, initialement indépendants les uns des autres. Dans les plaines calcaires, de telles constructions sont les seules qui soient également bordées de carrières latérales. Leur morphologie est très différente de celle du fossé périphérique des enclos précédemment décrits. Ces carrières participent pleinement à la monumentalisation du paysage, contribuant parfois à créer un effet de perspective que C.-T. Le Roux (1997) - à nuancer par Sellier, 1995; Mens, 2008 - avait déjà souligné pour les alignements de Carnac.

\section{MÉGALITHISMES ATLANTIQUES : UN PROGESSUS ORIGINAL D'INTÉGRATION}

La présence d'une façade périphérique souvent construite en pierres sèches, tout comme la discrétion de structures d'entrée soigneusement murées ou occultées, contribuent désormais à forger globalement l'originalité de ce mégalithisme dans l'ouest de la France. La première de ces caractéristiques l'oppose à nombre de monuments parfois contemporains sur la péninsule Ibérique, qui semblent seulement couverts par une carapace de pierres. Sur sa façade atlantique notamment, la disposition en oblique (verticalement) et en écaille (latéralement) des dalles qui composent la chambre polygonale de nombreux dolmens à couloir, dessine un volume interne qui est finalement plus proche de celui d'un encorbellement ou d'un silo, que d'un coffre parallélépipédique. La seconde de ces caractéristiques, ou tendances, est illustrée par de très nombreux monuments où l'entrée du couloir est seulement obturée par une murette dont l'appareillage se fond avec celui des portions de façade attenantes. Ils se distinguent, sur ce point également, des mégalithismes plus récents comme celui des court tombs en Irlande ou des allées des géants en Sardaigne, qui magnifient l'architecture des espaces précédant l'entrée au tombeau; entrée parfois purement symbolique comme dans quelques monuments de type Costwold-Severn, en Angleterre.

\section{PROCESSUS D'INTÉGRATION POUR LA MASSE MONUMENTALE}

Longtemps, de tels monuments ont été considérés, si ce n'est comme des instantanés, du moins comme la ruine d'un nombre très limité de projets architecturaux seulement juxtaposés. Le principe d'accrétion fut même un temps proposé par P.-L. Van Berg (1996) comme l'un des éléments susceptibles de caractériser la pensée de leurs bâtisseurs. Pourtant, seule la séquence continue des multiples ajustements qui ont permis, à chaque génération successivement, une nécessaire réappropriation de ce que de telles réalisations contiennent de plus essentiel à leurs yeux, confèrent à ces lieux une histoire et toute leur monumentalité (Joussaume, 2003b; Laporte, 2010a). L'un des deux monuments allongés construits sur la pointe du Souc'h en Bretagne est ainsi le fruit d'au moins une dizaine d'états successifs, rendant compte de plus de trois ou quatre projets architecturaux largement indépendants (fig. 8). Ce n'est qu'en fin de cycle, que ces différentes réalisations ont été finalement regroupées au sein d'une seule et même masse tumulaire (Le Goffic, 2006).

Un tel processus d'intégration peut conduire à occulter certaines réalisations antérieures comme pour l'imposant monument circulaire de la Hougue Bie (Patton et al., 1999). Il peut tout aussi bien garder la mémoire des réalisations précédentes, d'une façon qui ne saurait se limiter à la juxtaposition de chambres funéraires dont les couloirs d'accès débouchent tous sur une même façade. À Barnenez en Bretagne, comme au Pey de Fontaines en Vendée, la succession de deux projets architecturaux distincts est soulignée par la couleur différente des matériaux utilisés (L'Helgouach, 1995; Joussaume dir., 1999). L'étude des carrières et des techniques d'extraction connait un véritable renouveau (Mens, 2008; Scarre, 2009). On a aussi beaucoup sous-estimé l'ampleur comme la fréquence des réfections: régularisation d'une façade comme à Champ-Châlon $\mathrm{B}$, ou nivellement des élévations comme pour le «cairn primaire» d'Er Grah, reprise en sous-œuvre des espaces internes comme cela est attesté au Danemark, ou plus proche de 

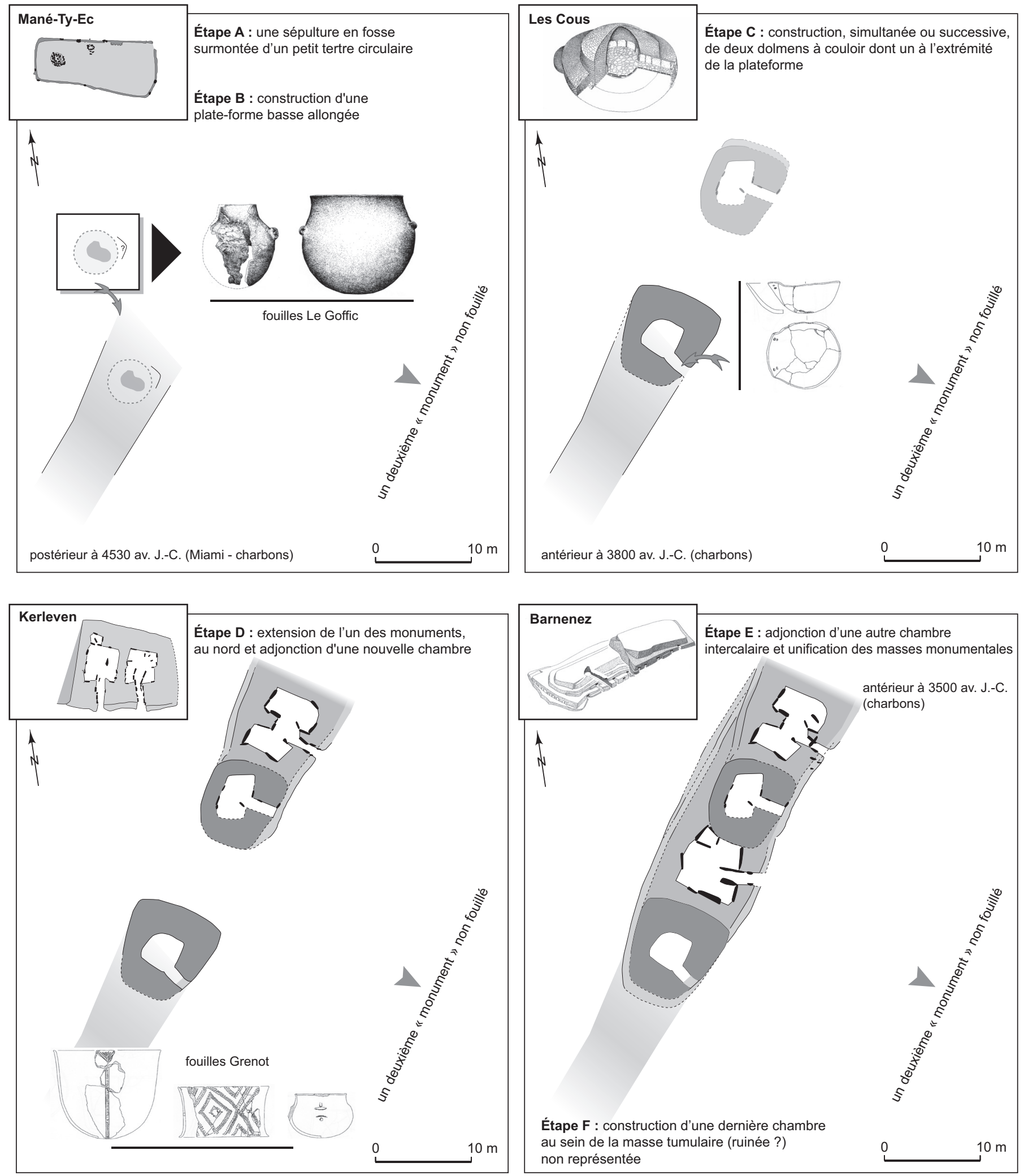

Fig. 8 - Intégration des masses monumentales. À chaque étape de sa transformation, la nécropole mégalithique du Souc’h (Plouhinec, Finistère) associe différents types de monuments qui sont tous également répertoriés de façon indépendante. Plan du monument d'après Le Goffic, 2006; dessin du mobilier d'après Hamon, 2003; dates radiocarbone in Cassen dir., 2009, p. 753 (DAO: L. Laporte, L. Quesnel, CNRS). 
nous pour la chambre II du Petit Mont à Arzon (Lecornec, 1994; Laporte, 2010a), voire sans doute destruction de certains monuments antérieurs, en fonction des besoins en matériaux ou au fur et à mesure d'une transformation de la nécropole dans son ensemble.

\section{PROCESSUS D'AGRÉGATION POUR LES ESPACES SÉPULCRAUX}

L'existence d'un accès couvert participe de ce processus d'intégration. Présent très tôt dans les petits monuments circulaires exclusivement construits en pierres sèches, il ne se généralisera que progressivement au cours de la seconde moitié du Ve millénaire av. J.-C. Les structures d'accès non couvertes liées à de petits coffres dits «fermés", car piégés sous d'immenses masses tumulaires, prennent également un tout autre sens (fig. 9). Les mobiliers funéraires qu'ils contiennent ne sont pas plus des ensembles clos que ceux provenant de dolmens à couloir (fig. 10). En dehors des zones circum-alpines, plus de $90 \%$ des haches en roche verte d'origine alpine proviennent de contextes mal assurés. À tenter alors de conforter cette sériation typologique, par une typologie évolutive des architectures funéraires par ailleurs contestée (Pétrequin et al., 2005), on risque fort de tomber dans le piège d'un raisonnement circulaire (Laporte, 2010a et b), pour ce qui est de l'ouest de la France (fig. 11).

Occasionnellement par la suite, la démultiplication des espaces sépulcraux pourrait être devenue l'une des normes guidant la réalisation d'un unique projet architectural; il semble que ce soit le cas pour les grands monuments circulaires de la Hogue et de la Hoguette, en Normandie (Lepaumier et al., 2007), comme peut-être pour le monument allongé très arasé récemment fouillé à Saint-Nicolas-Du-Pélem en Côtes-d'Armor (Tinévez et al., 2008). L'alternative, dans ce sens, est une compartimentation accrue de l'espace interne alors desservi par un unique accès couvert, comme dans les monuments de Colpo en Bretagne (L'Helgouach, 1964), ou du château d'Angers dans la vallée de la Loire (Marcigny et al., 2008). Le monument allongé de Kélarn illustre l'accrétion successive de grandes chambres compartimentées à couloir axial, puis de chambres transeptées dont le plan au sol s'inscrit dans un rectangle aux dimensions comparables (Giot, 1983). Une tendance inverse privilégie parfois l'accroissement des espaces internes au détriment de la masse monumentale, notamment au sein de cette grande famille des monuments du Néolithique moyen à chambre allongée et couloir axial.
Les dolmens à portique de type angevin, comme peut-être les dolmens en allée couverte de type aquitain, s'inscrivent dans cette tendance plus générale (Joussaume et al., 2008). Un peu comme si une nouvelle phase de diversification des architectures, à l'œuvre au cours de la première moitié du $I^{\mathrm{e}}$ millénaire av. J.-C., succédait à l'achèvement provisoire du processus d'intégration qui eut lieu tout au long du millénaire précédent.

\section{ASSOCIATIONS AVEC LES PIERRES DRESSÉES}

L'intégration des pierres dressées au sein des masses tumulaires participe sans doute d'une dynamique similaire à celle que nous venons de décrire pour les espaces sépulcraux. Cela n'est d'ailleurs pas propre au seul domaine funéraire. À Lillemer et probablement vers le début du IV e millénaire av. J.-C., l'un des passages pavés perçant le talus qui ceinture le pied de cette butte naturelle est bordé de pierres dressées. De larges blocs de dolérite de couleur verte y sont disposés d'un côté, et de grandes dalles de schiste de couleur bleue s'appuient contre l'autre paroi (Laporte et al., 2007). On retrouvera un tel jeu de couleurs dans nombre de monuments funéraires et mégalithiques. En Bretagne, une grande pierre effilée se dresse isolément entre la chambre coiffée par une grande dalle et le vestibule couvert en encorbellement de la chambre $\mathrm{H}$ du tumulus de Barnenez (fig. 12; Giot, 1987). Parfois, on peut s'interroger sur le rôle architectonique des orthostates lorsqu'ils sont seulement plaqués contre une paroi en pierres sèches, comme à Bougon E, ou lorsqu'ils ne mesurent guère plus de $20 \mathrm{~cm}$ d'épaisseur, comme à la Motte-de-la Jacquille (qui dispose d'une porte en pierre...), par exemple. Les dalles dressées à intervalle régulier le long des parois internes du dolmen à couloir et chambre en encorbellement de l'île Longue, en Bretagne, créent un cheminement qui n'est pas sans rappeler ceux des alignements de la région de Carnac, tous proches (fig. 13). Au Ménec, les blocs disposés le long de deux files, plus espacées que les autres, semblent présenter des faces d'affleurement systématiquement opposées, comme c'est effectivement le cas dans nombre de dolmens à couloir (Burl, 1993; Boujot, Pinet, 2007). De tels alignements participent à une monumentalisation du paysage environnant au même titre que la masse des constructions tumulaires les plus imposantes. Comme pour les tumulus allongés les plus monumentaux du centre-ouest de la France (Joussaume et al., 1998) ou d'autres dispositifs funéraires du Chasséen de la vallée du Rhône (Beeching, 2003), ils rendent compte également d'une capacité à ordonner 


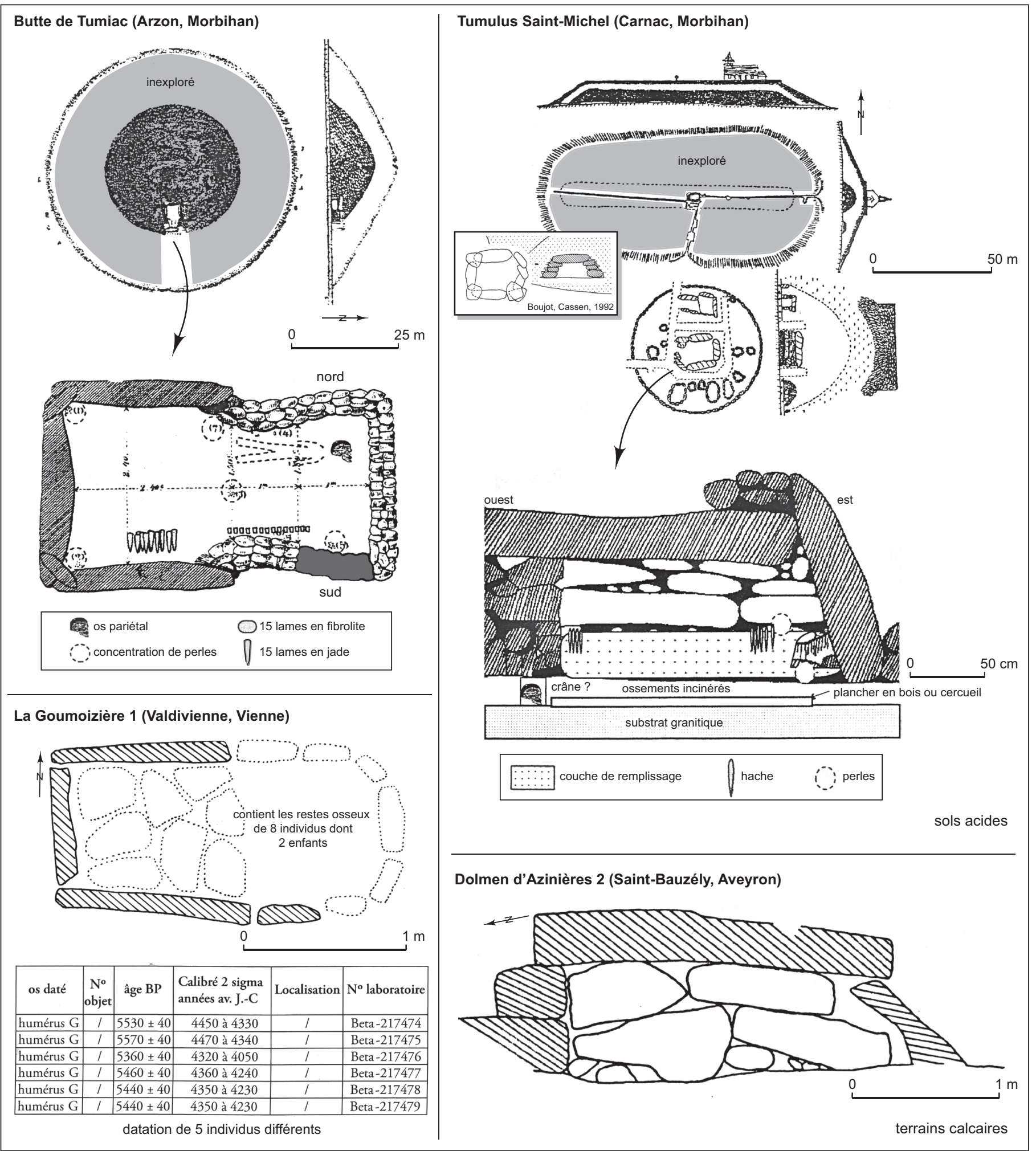


1 Fig. 9 - Intégration des espaces sépulcraux. Sur les terrains acides de la Bretagne, ces espaces sépulcraux seraient censés ne contenir que des sépultures individuelles. En terrain calcaire, comme à la Goumoizière, les mêmes formes architecturales des espaces sépulcraux se révèlent contenir les ossements d'un nombre d'individus similaire à ceux présents dans les dolmens à couloir du Néolithique moyen. Leur originalité architecturale doit également être relativisée par quelques exemples d'architectures tout à fait comparables, comme celles du dolmen d'Azinières 2 dans l'Aveyron, indépendantes des grands tumulus armoricains. On remarquera que l'illustration proposée par C. Boujot et S. Cassen (1992) a fait opportunément disparaître toute trace de la structure d'accès au caveau du tumulus Saint-Michel d'après Lourdou, 1998; Herbaut, 2001 ; Solers, 2007 (DAO: L. Laporte, CNRS).

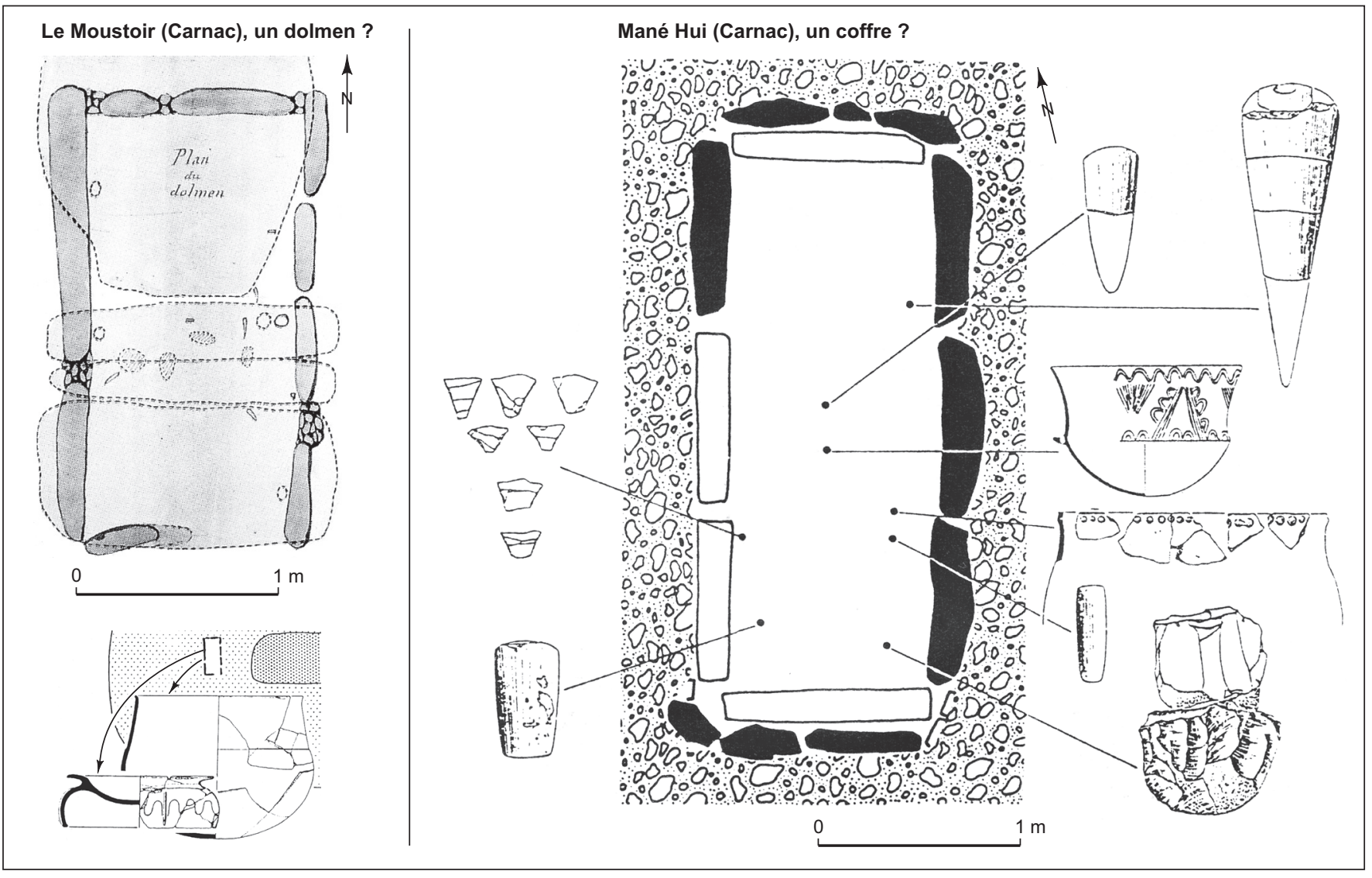

- Fig. 10 - Intégration des espaces sépulcraux et dépôts funéraires. L'espace sépulcral situé à l'extrémité occidentale du tumulus du Moustoir à Carnac a été associé (de par les objets quỉl recèle) aux dolmens à couloir (alors qu'il n'en possède pas). Pour les mêmes raisons, celui du Mané Hui - pourtant très proche architecturalement - appartiendrait à une phase antérieure (d'après Boujot, Cassen, 1992).

l'espace sur de vastes superficies, d'une façon qui n'est pas toujours directement perceptible pour un observateur situé au niveau du sol, au point que seuls des outils comme la photographie aérienne ou la cartographie nous permettent aujourd'hui d'en percevoir toute la cohérence (Boujot, Lorho, 2005).
Tous ces processus d'intégration, d'agrégation ou d'association d'éléments toujours combinés de façon singulière participent d'abord d'une séquence locale et continue d'ajustements successifs. En l'état de nos connaissances, ils n'autorisent que rarement, ou difficilement, une mise en phase des éléments de séquences différentes entre eux. Le processus semble en revanche récurrent. 


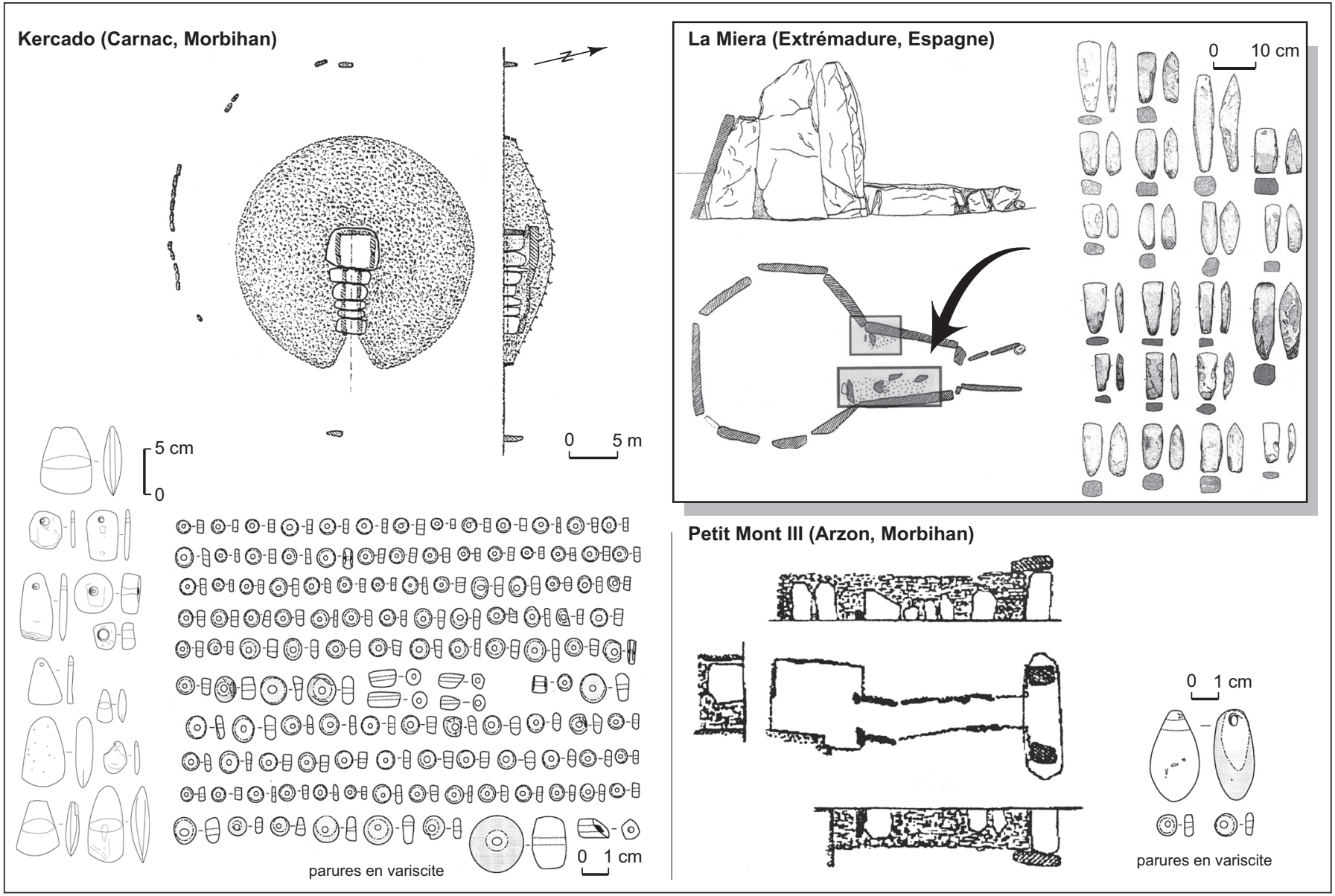

Fig. 11 - Intégration des espaces sépulcraux et dépôts funéraires. Quelques rares dépôts exceptionnels présentant notamment de nombreuses parures en variscite probablement d'origine ibérique, sont placés tant dans les «caveaux» de monuments carnacéens que dans des dolmens à couloir, comme celui de Kercado à Carnac ou du Petit Mont à Arzon dans le Morbihan. Parallèlement, quelques dépôts tout aussi exceptionnels de lames de hache sont également présents dans quelques dolmens à couloir de la péninsule Ibérique, d’après Le Rouzic, 1927; Lecornec, 1994; Enriquez, Carasco, 2000; Herbault, 2001; Sohn, 2009 (DAO: L. Laporte, CNRS).

\section{DIVERSITÉ DES MÉGALITHISMES AU COURS DES IV ${ }^{\mathrm{e}}$ ET III ${ }^{\mathrm{e}}$ MILLÉNAIRES} AV. J.-C.

Autour du milieu du IV millénaire av. J.-C., de profonds changements vont concerner tant les gestes funéraires ou la nature des dépôts associés aux défunts, que l'architecture des monuments correspondants. En France, pour un millénaire encore, différentes formes de mégalithisme vont s'étendre à de très larges régions où elles étaient précédemment particulièrement discrètes, voire totalement inconnues. Cette période est aussi celle qui va connaître la plus grande diversité de constructions mégalithiques sur le territoire français, notamment dans le sud de la France où elles sont si nombreuses. Les allées couvertes enterrées du Bassin parisien sont souvent comparées à celles construites au-dessus du sol sur le Massif armoricain, mais leur nombre est ici beaucoup plus restreint que celui des réalisations antérieures. Tout au long de ce millénaire, de telles réalisations seront pratiquement absentes entre Loire et Gironde, où elles furent pourtant si fréquentes au cours de la période précédente. Dans tous les cas, on assiste à maintes réutilisations des espaces funéraires construits par de prestigieux prédécesseurs.

En plusieurs points de l'Europe occidentale, au cours de la seconde moitié du IVe millénaire av. J.-C., on assiste en effet à un véritable renouvellement des formes architecturales. Nombre de «passage graves» du Danemark, du 

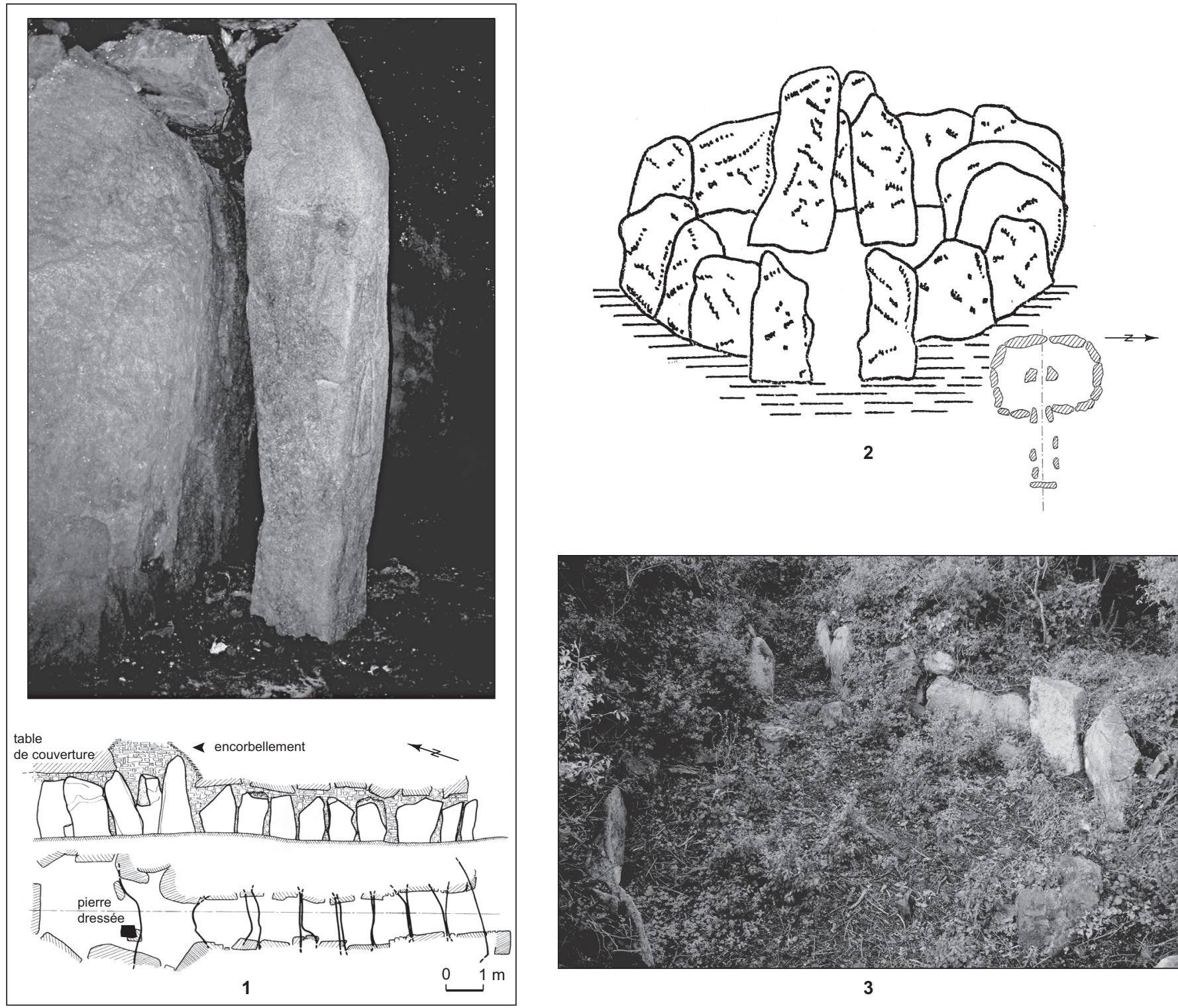

3

Fig. 12 - Intégration des pierres dressées. Au XIXe siècle, nombre de dolmens à couloir ruinés ont été décrits comme autant de petits "cromlechs». D'autres pierres sont parfois dressées isolément dans la chambre d'un dolmen: 1, pierre dressée dans la chambre (Barnenez H, Finistère); 2, la Haye (Saint-Gravé, Morbihan); 3, la Ville-Pichard (Côtes-d'Armor) d'après L'Helgouach, 1964; Giot, 1987 (cliché:L. Laporte, CNRS; DAO: L. Laporte, L. Quesnel, CNRS).

nord de l'Allemagne et des Pays-Bas ont ainsi été construits autour ou à partir de 3300 av. J.-C. (Dehn, Hansen, 2006; Bakker, 2009), alors que la mode des chambres circulaires à encorbellement, souvent partiellement enterrées, tend à se généraliser dans le sud-est de l'Espagne (Aguayo de Hoyos, Garcia Sanjuan, 2006). Au même moment, le Bassin parisien et l'ouest de l'Allemagne (Westphalie et Thuringe) voient apparaître une floraison d'allées sépulcrales à antichambre axiale (Chambon, Salanova, 1996; Raetzel-Fabian, 2002).
Enfin, le sud de la France se dote d'une impressionnante variété de monuments mégalithiques ou semi-mégalithiques (Chevalier, 1984; Guilaine, 1994). Parallèlement, on assiste à de profondes transformations dans le traitement des corps, ou dans la nature des dépôts qui leur sont plus ou moins étroitement associés. En France, la pratique des sépultures collectives se généralise. Cette pratique, qui se définit par un apport successif de cadavres, devient quasiment exclusive dans une grande partie de l'Europe occidentale pendant près 

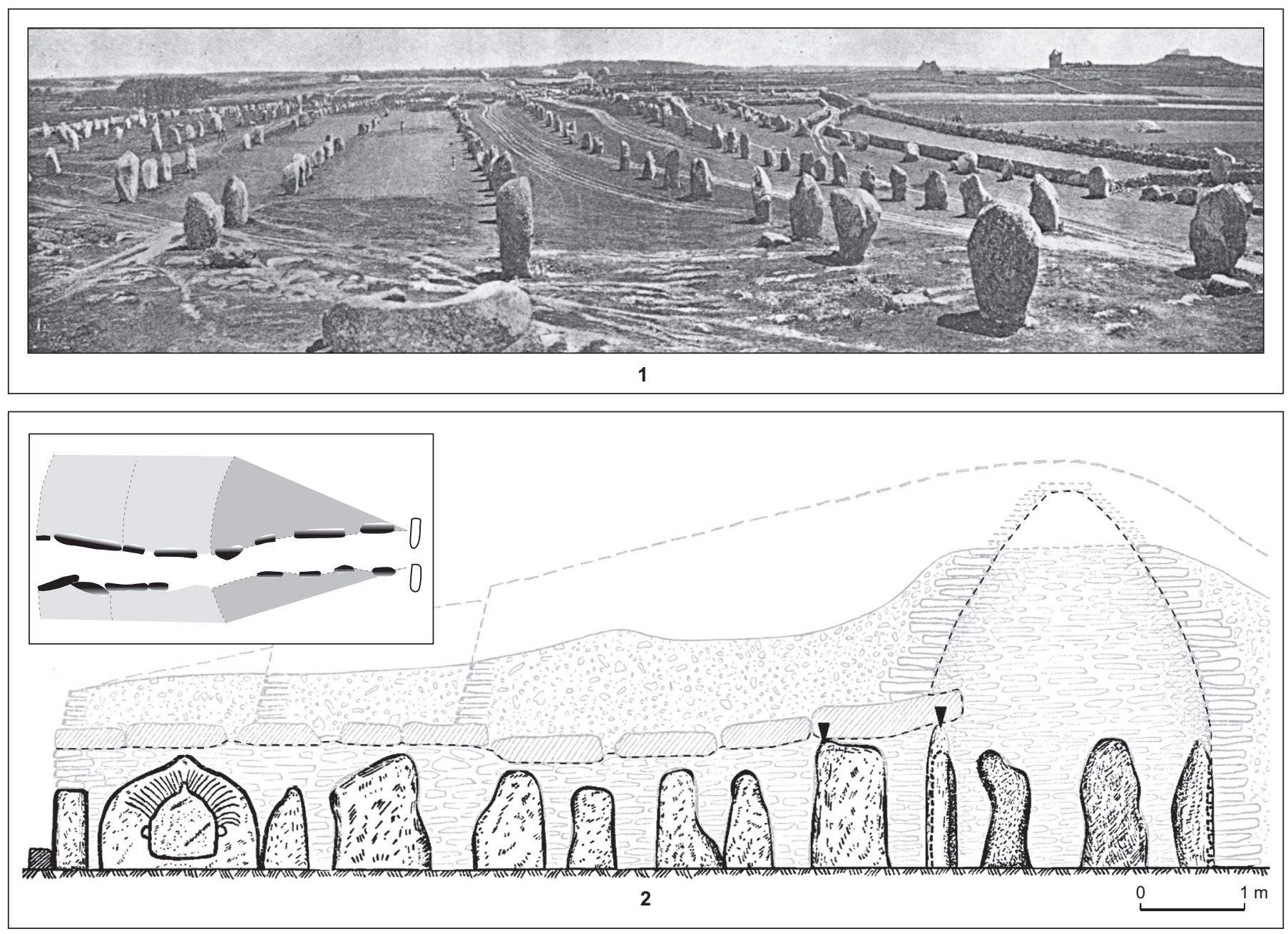

Fig. 13 - Intégration des pierres dressées. Organisées en files de pierres dressées isolément, implantées dans la chambre d'un monument mégalithique ou le long de ses parois, comme souvent de part et d'autre du couloir, elles sont toutes intégrées dans un dispositif monumental où, dans le cas ici cité comme pour ceux de la planche précédente, elles ne jouent qu'un rôle architectonique des plus réduits: 1 , l'une des toutes premières photographies de l'alignement du Ménec à Carnac; 2, pierres dressées le long du couloir (L'île Longue, Morbihan) d'après L'Helgouach, 1964; Giot, 1987 (DAO: L. Laporte, L. Quesnel, CNRS).

d'un millénaire et demi. Elle est attestée dès le Néolithique moyen, en Normandie (Dron et al., 2003) comme dans la tombe inviolée du tumulus C de Péré dans les Deux-Sèvres (Scarre et al., 2003; Solers et al., 2003). Au Néolithique récent et final, le nombre de corps déposés augmente considérablement, parfois dans des espaces sépulcraux au volume inchangé; en conséquence, les manipulations y sont beaucoup plus fréquentes, et l'intégrité corporelle de chaque défunt y est bien moins préservée qu'au Néolithique moyen.

Au moins depuis G. Daniel (1960), nous trouvons fréquemment dans la littérature française l'idée d'une évolution linéaire ou buissonnante des monuments méga- lithiques, surtout abordés à partir de l'étude architecturale des seuls espaces sépulcraux. L'ériger en principe pour l'évolution des constructions «primitives» revient à nier un peu qu'ils sont d'abord le fruit de véritables projets architecturaux, soigneusement conçus à l'avance et souvent dans le cadre de pratiques funéraires et cérémonielles complexes. Peut-être alors n'est-il pas absolument nécessaire d'attribuer aux quelques allées en V de Bretagne ou de l'Aude, comme aux allées d'Aquitaine ou du Pays basque, une place chronologique qui soit à tout prix compatible avec le rôle de châ̂non manquant qu'on leur prête si souvent, entre «dolmens à couloir» et «allées couvertes». 


\section{COFFRES, GROTTES ET DOLMENS : LES NOMBREUX MÉGALITHISMES DU SUD DE LA FRANCE}

Dans le sud de la France, on a coutume d'insister sur l'existence d'un lien étroit et récurrent entre sites d'habitats et milieux sépulcraux du Néolithique ancien et moyen. Au moins dès le Chasséen ancien, quelques coffres dérogent à cette tendance générale; ils sont parfois regroupés, comme le seront plus tard nombre de monuments mégalithiques. Ils contiennent généralement un seul corps mais on y dépose aussi jusqu'à cinq individus, et parfois successivement comme dans le «coffre» ${ }^{\circ} 2$ de Najac dans l'Hérault (Mahieu, 1992). Ils se distinguent toutefois par des pratiques moins standardisées que dans les cistes Chamblandes dont la seule nécropole de Thonon-les-Bains en Savoie en comprend près de 200 (Gatto et al., 2007). Au Chasséen récent, la sépulture A 185 de Saint-Michel-du-Touch en Haute-Garonne pourrait avoir été pourvue d'infrastructures en bois, scellées par une masse de galets. La mise en scène des dépôts comprend la restitution symbolique du squelette de deux individus, disposés sur le sol de cette très large fosse couverte (Méroc, Simonet, 1979).

Mégalithismes atlantiques et méridionaux offrent ainsi l'image d'une évolution décalée dans le temps, mais dont les précurseurs semblent se mettre en place à peu près au même moment, dès le milieu du V $V^{e}$ millénaire av. J.-C. Si les masses monumentales les plus imposantes de l'ouest de la France gardent souvent quelques stigmates d'un processus d'intégration globalement étalé sur plus d'un millénaire, la combinaison toujours originale de ces mêmes éléments pourrait ne pas cristalliser dans le sud avant le dernier tiers du IV ${ }^{e}$ millénaire av. J.-C. Le plus souvent, elle prendrait ici la forme de très nombreuses unités seulement juxtaposées.

\section{LA QUESTION DES ORIGINES}

J. Arnal (1963) n'excluait pourtant pas que certains des dolmens à couloir, du Languedoc en particulier, puissent avoir été construits au cours du Néolithique moyen, l'abondant mobilier du Néolithique récent et final que l'on y trouve n'étant alors perçu que comme le fruit d'une réutilisation systématique. Depuis, cette dernière hypothèse a été fermement rejetée (Clottes, 1970; Gutherz, 1998), l'étalement chronologique de la période néolithique au cours des années 1960-1980-faisant le reste (Guilaine, 2006).

Dans les régions méridionales, nombre de chambres mégalithiques prennent effectivement l'apparence de «coffres géants", avec une seule dalle par paroi et une superficie interne souvent restreinte, de l'ordre de 3 à $3,5 \mathrm{~m}^{2}$ en moyenne si l'on en croit Y. Chevalier (1984). À l'exception notable des dolmens «caussenards» (Ardèche, Aveyron, Lozère et Quercy), elles ouvrent plutôt dans le cadran sudouest, opposé donc à l'orientation que tend à privilégier le mégalithisme du Néolithique moyen sur la façade atlantique de la France. En outre, les monuments circulaires à chambre circulaire en pierres sèches y sont presque totalement absents, si ce n'est quelques exemples isolés comme celui de la Lauze à Salernes qui se rattacherait au petit groupe des tombes en blocs dans le Var (Sauzade, 1983). Les tombes ovales, quant à elles, évoquent par leurs petites chambres allongées et parementées le plan en réduction et le mode de construction des habitations contemporaines du groupe de Fontbouisse de l'arrière-pays de Montpellier. En Corse, la construction d'un petit coffre semble effectivement précéder celle du dolmen de Casa di l'Orcu (Léandri et al., 2007), mais la datation de la vingtaine de monuments de ce type actuellement répertoriés dans l'île fait encore débat (Lanfranchi, 2000; Tramoni et al., 2007; Costa, 2008).

La question présente cependant deux aspects distincts. L'un à peine plus consensuel tient à l'ancrage de ce mégalithisme méridional dans le Néolithique moyen régional; l'autre, nettement plus controversé, découle de l'ancienneté des mégalithismes atlantiques ou ibériques. La proposition de créer, dans l'ouest de la France, une grande famille de monuments à chambre quadrangulaire allongée, et accès axial inclus dans un tumulus à l'extrémité arrondie, n'est pas étrangère à ces discussions (fig. 14; Joussaume et al., 2008, p. 50). Un jalon vers le Quercy avait déjà été posé lors de la publication du dolmen à chambre piriforme de Marsac, dont la construction peut être datée du second quart du IVe millénaire av. J.-C. (Joussaume et al., 2002). Si les très nombreux dolmens caussenards livrent un mobilier largement attribué au $\mathrm{III}^{\mathrm{e}}$ millénaire av. J.-C., des dates radiocarbones font remonter au moins un dolmen à long tumulus au dernier tiers du IVe millénaire av. J.-C. (Azémar, 2008). Le problème de l'origine atlantique du mégalithisme caussenard reste donc d'actualité.

Des dates hautes ont également été proposées pour les cistes mégalithiques et dolmens à couloir du Alt Empordà près de Girone (Tarrus i Galter, 1987 et 1990), qui ont parfois livré des vases de style Montbolo (El Padro). En Languedoc occidental, de petits caissons de dalles, parfois pourvus de dispositifs de fermeture (coffres de Najac à Siran dans l'Hérault), livrent un mobilier attribué au Chasséen méridional. L'espace sépulcral de Coste Rouge à Beaufort 

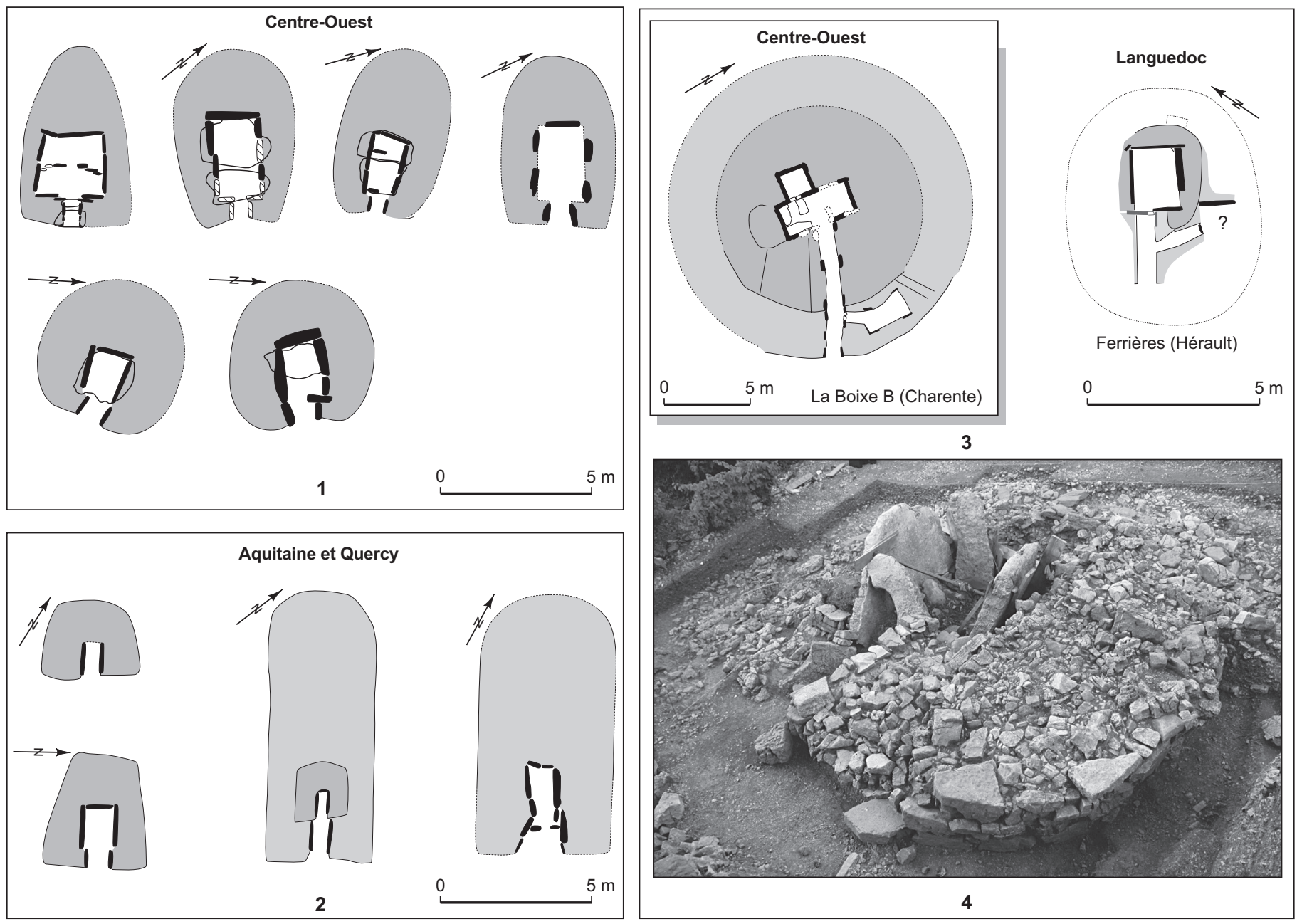

Fig. 14 - 1 et 2, exemples de classification des monuments funéraires mégalithiques. Monuments à chambre allongée et entrée axiale (d'après Joussaume et al., 2008); 3, chambre annexe du dolmen de Ferrières comparée à celle du monument B de la nécropole de la Boixe (Charente). Cette dernière est la seule à avoir livré un petit peu de mobilier du Néolithique moyen, alors que chacun des deux monuments a été largement fréquenté au cours du III millénaire av. J.-C.; 4, fouilles récentes sur le site de la Planquette (d'après Arnal, 1963; Joussaume, Laporte, 2006). Le cliché du dolmen de la Planquette est pris en cours de fouilles sous la direction de A.-L. Rivière et J.-P. Cros (DAO: L. Quesnel, L. Laporte, CNRS).

(Hérault), bordé de dalles dressées, à vestibule d’accès et enterré, pourrait constituer une transposition de la «cambra solsonienne», avec cependant une entrée orientée vers l'est (Vaquer et al., 2007 et communication personnelle). Toutefois, rien ne démontre qu'il existerait une continuité architecturale entre les différents styles: la nécropole du Camp del Ginèbre (Caramany, Pyrénées-Orientales) associe des coffres de dalles, à couronne de pierres, avec des aménagements parfois partiellement enterrés supportant des crémations - crémations sur place ou regroupements secondaires d'ossements incinérés - (Vaquer, 1998). Cependant, la durée séparant la construction des monuments centraux de celle des espaces funéraires périphériques reste à définir (Vignaud, 1995).

\section{DIVERSITÉ DES MÉGALITHISMES EN FRANCE MÉRIDIONALE}

Pour illustrer la diversité des mégalithismes du sud de la France nous parlerons de style. Concernant les dolmens, la plupart des auteurs en distingue trois (Chevalier, 1984; Gutherz, 1998; Beyneix, 2003; Sauzade, 2008). Du bas Languedoc à la Provence, le style languedocien se caractérise par une chambre rectangulaire haute à entrée axiale, 
et un long couloir parfois précédé d'une antichambre (Bordreuil, 1998; Sauzade, 1998). Dans sa variante dite bas-rhôdanienne, les murs en pierres sèches remplacent les parois de dalles dressées (Bordreuil et al., 2006). Le style caussenard localisé sur toute la bordure méridionale du Massif central se rapporte à des chambres courtes, parfois précédées d'un couloir généralement peu développé (Jaubert, Leduc, 1998; Azémar, 2008; Bories, 2008). Signalées de longue date (Arnal, Balsan, 1980), quelques masses tumulaires plus allongées existent également en Quercy (Pajot, 1999; Lagasquie et al., 2006). Enfin, le style pyrénéen - beaucoup plus hétérogène - s'étend des Pyrénées à la plaine de l'Aude (Abélanet, 1970; Claustre, 1998). Il comprend notamment les dolmens à vestibule ou à chambre prolongée (Ambert, 1990; Guilaine, Guilaine, 1998). Chacun de ces styles présente toutefois des variations importantes-et les exceptions à cette règle sont fréquentes : dolmens à chambre carrée ou semi-encavée, couloir en équerre ou décentré. On peut aussi différencier les monuments aux entrées orientées au levant, plutôt localisés dans les régions caussenardes, de ceux dont les accès sont ouverts dans le quart sud-ouest (fig. 15).

Ces architectures, dans leur état actuel, procèdent d'une histoire souvent complexe. Ainsi, le dolmen de Villedubert fut détruit avant d'être réinvesti par des populations de tradition campaniforme (Duday, 2003). Dans la chambre du dolmen de l'Ubac (Vaucluse), qui avait conservé l'intégralité de son remplissage, des dépôts essentiellement primaires alternent avec des phases d'abandon et des destructions partielles (Bizot et al., 2004). Quelques trop rares fouilles ont porté sur la structure du tumulus (Lagasquie, 1996; Pajot, Briois, 1996; Tchérémissinoff et al., 2002; Lagasquie et al., 2006; Bories, 2008; Rivière A.-L., Cros J.-P., fouilles en cours) et les nomenclatures se fondent essentiellement sur l'espace sépulcral. À ce titre, on remarquera que le caveau du tumulus Saint-Michel à Carnac, dépourvu de l'énorme masse tumulaire qui le surmonte, ressemblerait beaucoup au petit dolmen d'Azinières 2, dans l'Aveyron (Lourdou, 1998). Il faut donc rester prudent sur la définition du style architectural, comme l'a montré la fouille minutieuse des cairns des dolmens du Quercy (Pajot, 1990). De nombreux relevés restent imprécis et le démontage d'une architecture peut totalement en modifier la perception initiale (Joussaume, 1985; Poissonnier, 2008).

S'il est vraiment indispensable de rechercher une filiation entre les petits coffres prémégalithiques languedociens et les premiers dolmens véritables, la nécropole de ChâteauBlanc à Ventabren (Bouches-du-Rhône) pourrait jouer ce rôle. Elle comprend cinq tertres bordés d'une couronne de pierrailles renfermant en leurs centres des inhumations simples déposées dans des tombes à parement de pierres sèches. Des logettes périphériques au tumulus livrent de petites stèles de forme triangulaire. Les dates s'inscrivent en majorité dans le dernier tiers du IV millénaire. Un dolmen de style bas-rhodanien se surimpose à un tertre plus ancien (Hasler et al., 1998). Comme d'autres, cette nécropole rassemble des monuments de styles différents qui suggèrent des évolutions architecturales régionales, mais les chronologies locales restent floues. Les mobiliers ne reflètent pas nécessairement la période de construction, que des fouilles hâtives ont parfois contribué à vieillir ou à rajeunir. La construction des dolmens méridionaux est désormais attribuée, dans leur majorité, à la seconde moitié du IVe millénaire (Gutherz, 1998; Guilaine, 2003). Elle s'achèverait alors avec le début du Néolithique final 3, vers 2800 av. J.-C. Il n'est pas exclu toutefois que quelques monuments soient plus anciens ou plus tardifs, et certains de ces caveaux ont été utilisés jusqu'à l'âge du Fer (Dedet, 1982; Labriffe de, 2000), parfois pendant une durée considérable (Azémar, 1998).

\section{LA GROTTE ET L'INDIVIDU}

Dans le sud de la France, d'autres formes de mégalithisme permettent de faire le lien avec des types d'aménagement qui portent des valeurs a priori un peu opposées à celles que l'on voudrait associer à la plupart des monuments funéraires construits au-dessus du sol, ou à l'idée de l'effacement de l'individu au sein des sépultures collectives qu'ils contiennent.

\section{Grottes et hypogées}

La diversité des infrastructures mégalithiques fait écho aux aspects essentiels du Néolithique final du sud de la France, caractérisé par une démographie en hausse, une gestion complexe des ressources, une redistribution territoriale et un fort cloisonnement culturel dans un contexte de réorganisation des échanges et de renouvellement idéologique (Guilaine, 2006; Jallot, 2007). On assiste alors à l'éclosion de nouveaux modèles architecturaux: tombes ovales, tholos, coffres, tombes en bloc, tumulus non mégalithiques, tombelles en bois, caveaux-hypogées qu'accompagne une profusion de cavités et d'abris sous roche ou sous bloc qui reçoivent l'essentiel des restes humains (Claustre, 1998; Leduc, 1998). Les cavités artificielles, qualifiées d'hypo- 


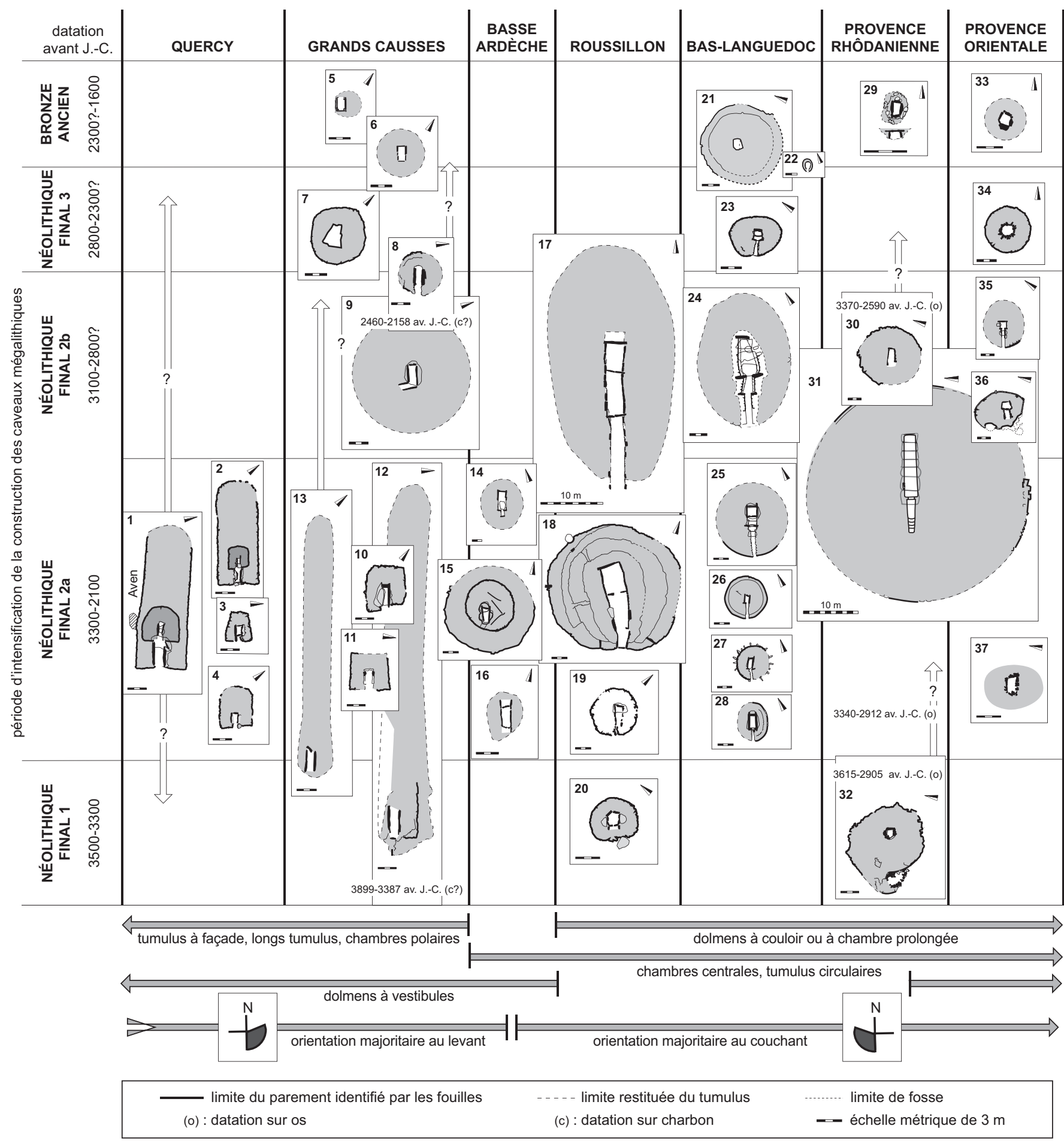

gées, comprennent des monuments disparates (Colomer, 1979; Guilaine, 2003). Celles de la montagne des Cordes, près d'Arles (fig. 16), s'apparentent aux dolmens à chambre allongée de Provence rhodanienne (Sauzade, 1990 et
1998). Il s'agit de longues, hautes et larges allées enterrées à couverture mégalithique. Ces hypogées comptent parmi les sépultures les plus grandes d'Europe (fig. 17). Leur aspect diffère beaucoup des cavités artificielles de plan 
1 Fig. 15 -Diversité des mégalithismes dans le sud de la France. Proposition de classement régional et d'attribution chronologique des coffres ou chambres mégalithiques sous tumulus dans le sud de la France, d'après les mesures radiométriques et les plus anciens mobiliers livrés (données de 2010). Des chambres non mégalithiques plus anciennes ou plus tardives sont figurées à titre de comparaison (DAO: L. Jallot, Inrap): 1, dolmens emboîtés de Saint-Antonin-Noble-Val (Tarn-et-Garonne) d'après Pajot, 1989; 2, dolmens embồtés de Rouzet (Larroque, Tarn) d'après Pajot, 1990; 3, dolmen de la Ferme du Frau à Cazals (Tarn-et-Garonne) d’après Pajot, Clottes, 1975; 4, dolmen de la Devèze de Barsalès (Penne, Tarn) d'après Pajot, 1988; 5, coffre de la Parade (Hures-la-Parade, Lozère) d'après Hugues, Lorblanchet, 1963; 6, coffre de l'Espital (Hures-la-Parade, Lozère) d'après Hugues, Lorblanchet, 1963; 7, tumulus du Devez Viel (Sainte-Enimie, Lozère) d'après Vaquer, 1994; 8, dolmen 2 de Saint-Martin-du-Larzac (Millau, Aveyron) $3850 \pm 50$ BP =-2460/-2158 av. J.-C. (d'après Azémar, 2008); 9, dolmen coudé de Gouziac-Frigas (Hures-la-Parade, Lozère) d'après Fagès, 1977; 10, dolmen de Peyrelebade 1 (Salles-la-Source, Aveyron) d'après Bories, 1995; 11, dolmen de Vialamontels (Lapanouse-de-Cernon, Aveyron) d'après Poissonnier, 2008; 12, dolmen du Devez de la Baume (Lapanouse-de-Cernon, Aveyron), GIF A 92246: $4880 \pm 80$ BP = -3899/-3387 av. J.-C; GIF A 99328: $5050 \pm 780$ BP=-3980/-3663 av. J.-C. (d'après Azémar, 1995 et 2008); 13, dolmen à long tumulus de Bagnolet (Meyrueis, Lozère) d'après Fagès, Roudil dir., 1979; 14, dolmen 1 des Géantes (Bourg-Saint-Andéol, Ardèche) d'après Chevalier, 1984; 15, dolmen 1 des Granges (Berriaset-Casteljau, Ardèche) d'après Lhomme, 1971 et 1974; 16, dolmen 17 des Granges (Berrias-et-Casteljau, Ardèche) d'après Lhomme, 1974; 17, dolmen à chambre prolongée des Fades (Pépieux, Aude) d'après Guilaine, 1998, p. 50; 18, dolmen à chambre prolongée en V de Saint-Eugène (Laure-Minervois, Aude) d'après Guilaine, 1998, p. 52; 19, dolmen du Moli del Vent (Belesta-de-la-Frontière, Pyrénées-Orientales) d'après Claustre, 1998; 20, dolmen 8 de la nécropole de la Clape (Laroque-de-Fa, Aude), d'après Guilaine et al., 1972, p. 56-68; 21, tumulus à tombelle centrale de Peirouse ouest (Marguerittes, Gard) d'après A. Vignaud, inédit; 22, tombe ovale 2 de Rubia Torte (Les Matelles, Hérault) d'après Arnal, 1963; 23, dolmen de la Sogne (Saint-Jean-du-Pin, Gard) d'après Salles, 1992; 24, dolmen bas-Rhôdanien du Pas de Gallardet (Pouget, Hérault) d'après Chevalier, 1984; 25, dolmen à antichambre du Lamalou (Rouet, Hérault) d’après Arnal, 1963; Chevalier, 1984; 26, dolmen de la Liquisse (Rouet, Hérault), d'après Arnal, 1963 révisé; 27, dolmen à péristalithe $n^{0} 1$ de la Grande Pallière ou de Panissière (Anduze, Gard) d'après Salles, 1988; 28, dolmen 1 de Grammont (Soumont, Hérault) d'après Chevalier, 1984; 29, ciste des Gouberts (Gigondas, Vaucluse) d'après Sauzade, Vital, 2002; 30, sépulture collective du tertre 4 de Château-Blanc (Ventabren, Bouches-du-Rhône). Lintervalle chronologique recouvre trois dates obtenues pour les os de la tombe multiple, soit: ETH-15730: $4495 \pm 75$ BP=-3370/-2925 av. J.-C.; ETH-15733: $4215 \pm 70$ BP=-3020/-2590 av. J.-C.; ETH-15731: $4430 \pm 70$ BP=-3335/-2920 av. J.-C. (d'après Hasler et al., 2002); 31, hypogée de Bounias (Fontvieille, Bouches-du-Rhône) d'après Cazalis de Fondouce, 1873; 32, tertre 2 de Château-Blanc (Ventabren, Bouches-du-Rhône). Lintervalle chronologique recouvre les dates obtenues pour les os des tombes centrales des tertres 1 et 5 considérés comme contemporains du tertre 2, soit: tertre 1: ETH-15260: $4385 \pm 60$ BP = -3320/-2905 av. J.-C.; tertre 5: ETH-15261: $4620 \pm 60$ BP =-3615/-3105 av. J.-C. (d'après Hasler et al., 2002); et au-dessus: datation du premier dépôt du dolmen de l'Ubac (Goult, Vaucluse), Ly11492: $4440 \pm 45$ BP=-3340/-2912 av. J.-C. (d'après Sauzade et al., 2003); 33, tombe en bloc des Puades (Saint-Cézaire-sur-Siagne, Alpes-Maritimes) d'après Sauzade, 1998; 34, tombe circulaire en bloc de la Lauze (Salernes, Var) d'après Courtin, 1974; 35, dolmen de Saint-Marcellin (Mons, Var) d'après Courtin, 1974; 36, dolmen de la Haute-Suane (Grimaud/Sainte-Maxime, Var) d'après Courtin et al., 1988; 37, tombe en bloc 5 des Canaux (Andon, Alpes-Maritimes) d'après Sauzade, 1998.

oblong de la Drôme et du nord du Vaucluse qui livrent des empilements de corps attribués à des décès simultanés: les fameuses «couches de guerre»(Courtin, 1974). Cette appellation s'accorde avec la multiplication relative à cette période des traces de violence sur les os des défunts. Il faut pourtant tempérer cette proposition en tenant compte de l'augmentation du nombre de restes humains étudiés à partir du Néolithique final. Le concept de «crise démographique» est aujourd'hui préféré à celui de «sépulture de catastrophe»(Chambon, 2003; Devriendt, 2004).

On souligne rarement que les dépôts multiples coexistent avec l'inhumation individuelle. D'anciens puits d'extraction de silex, des «caves» désaffectées, de simples fosses, des diaclases, des fosses à logette funéraires, comme celle du Cadereau d'Alès à Nîmes, livrent des corps isolés (Hasler, Noret, 2006; Cros et al., 2010). Parmi les trois cents ensembles funéraires déposés sur le sol du réseau profond de la grotte du Pas de Joulié (Trèves, Gard), beaucoup sont individuels (Costantini, 2002). Toutefois, la plupart des grottes naturelles ont servi d'ossuaires. Les dépôts multiples y sont attestés dès le Néolithique moyen; ils se généralisent au Néolithique final et se maintiennent au Bronze ancien (Janin, 2001). Les cavités ont été vidangées ou nettoyées en vue de l'arrivée de nouveaux défunts. L'aven de la Boucle à Corconne (Gard) ou la grotte des Truels II à Millau (Aveyron) illustrent des phénomènes de repositionnements, d'ajouts, de rangements des crânes, de regroupements des os (Duday, 1987). Des aménagements externes et internes ont reçu ces dépôts (Courtaud, Janin, 1994). Sous les abris rocheux, des sortes de bâtiments à murs de pierres élevés jusqu'à la voûte abritent les corps (Sauzade, 1983). La juxtaposition, plusieurs fois constatée, entre une cavité naturelle et un dolmen n'est peut-être pas fortuite (Pajot, 1988). On envisage parfois une complémentarité entre le fonctionnement funéraire des chambres mégalithiques et celui des cavités naturelles (Crubézy et al., 2004). Un parallèle est suggéré entre la diaclase d'accès de l'aven sépulcral de la Boucle partiellement couverte de dalles mégalithiques et le couloir surbaissé d'un dolmen. L'entrée des réseaux sépulcraux colmatée par des pierres, l'accès marqué par de 


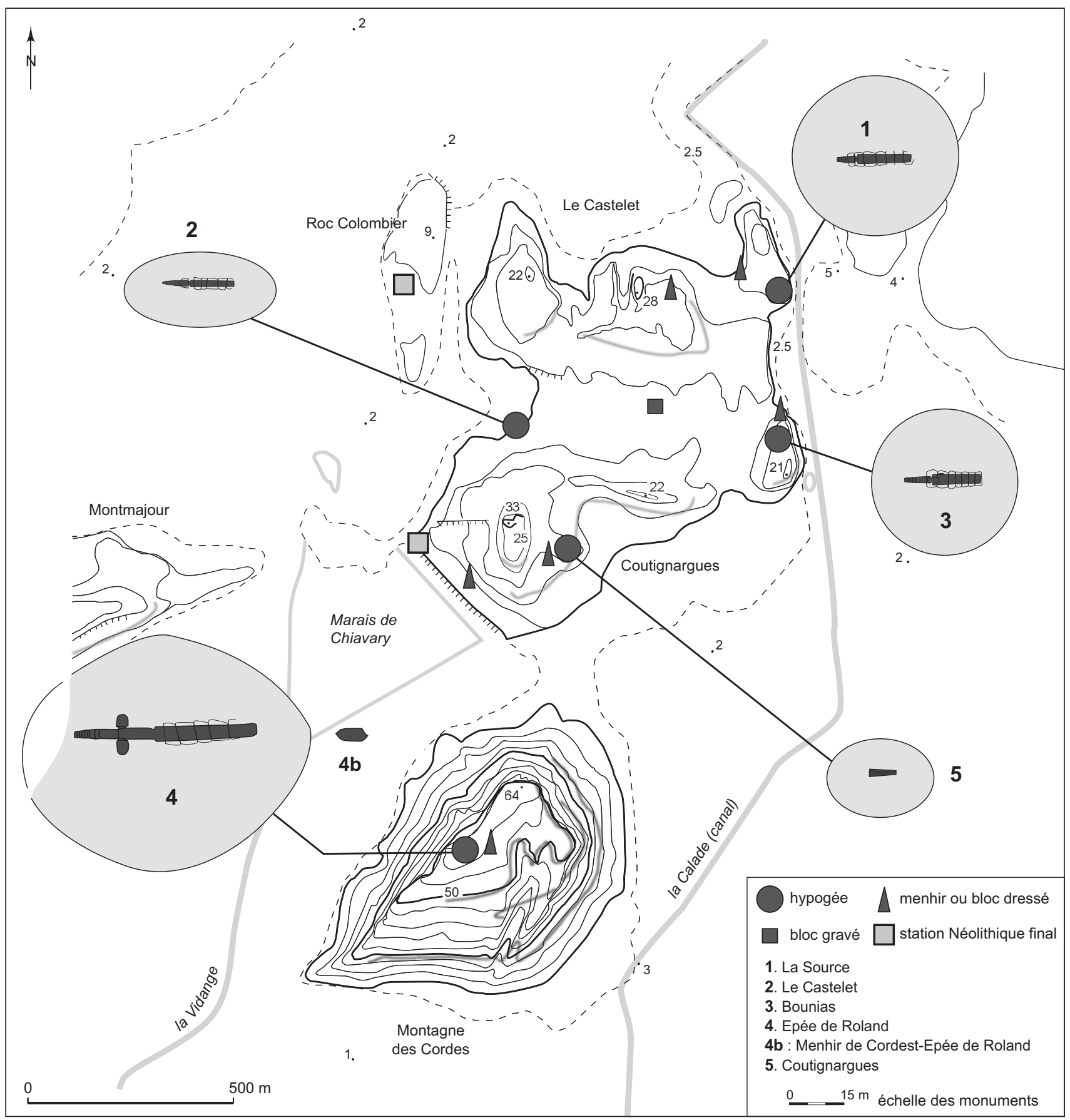

Fig. 16 - Les hypogées de Cordes. Localisation des cinq monuments funéraires du secteur de Cordes-Castelet (Fontvieille, Bouches-du-Rhône) (DAO: L. Jallot, Inrap).

lourdes dalles posées de chant et les galeries secondaires obturées de manière à permettre un cheminement confirment cette impression. Ces convergences répondent-elles à un projet architectural plus général ? La chambre d'un dolmen, placée sous un tertre de pierraille, aux parois et au plafond faits de lourdes dalles non mobiles, telles des parois naturelles, doit-elle évoquer la salle d'une grotte sépulcrale? 


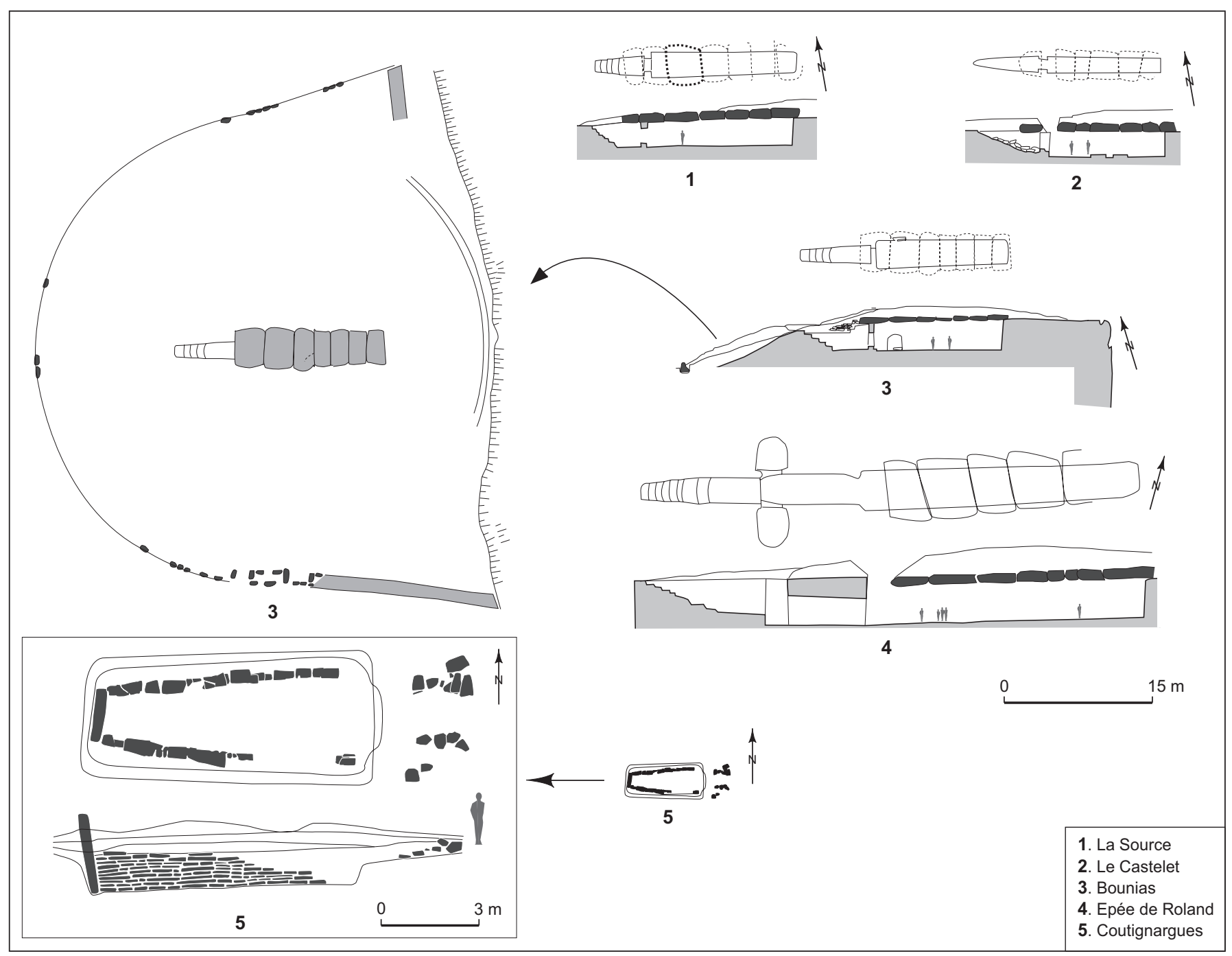

Fig. 17 - Les hypogées de Cordes. Relevé en plan et coupe des cinq monuments funéraires du secteur de Cordes-Castelet (Fontvieille, Bouches-du-Rhône) d'après Cazalis de Fontdouce, 1873 et 1878; Arnal, Latour, Riquet, 1953; Sauzade, 1976 (DAO: L. Jallot, Inrap).

\section{Les statues-menhirs}

On connaît le lien qu'entretiennent les statues-menhirs et les représentations anthropomorphes figurées sur les montants des allées couvertes du nord et de l'ouest de la France ou de la péninsule Ibérique. Elles adoptent peu ou prou la même organisation des motifs et l'absence de bouche souligne une parenté de convention (Octobon, 1931; Arnal, 1976). Plus qu'une véritable statuaire, elles prennent la forme de projections planes sur les deux grandes faces de larges dalles. Ces faces peuvent parfois être reliées entre elles par la sculpture des flancs (Philippon dir., 2002). Il en existe trois groupes stylistiques et géographiques (D’Anna,
1977). Les stèles à chevrons provençales, qui sont de petites stèles facilement transportables, dateraient du second tiers du IVe millénaire (D’Anna et al., 2004). Les motifs présents sur les lourdes statues-menhirs masculines ou féminines du Rouergue pourraient suggérer leur contemporanéité avec les stèles de Provence (Serres, 1997; Rodriguez, 2010). Les stèles languedociennes plus ou moins massives, en remploi dans des architectures domestiques ou incluses dans des constructions à caractère funéraire, sont bien datées de la seconde moitié du IV e millénaire à la fin du III ${ }^{\mathrm{e}}$ millénaire av. J.-C. (Gutherz, Jallot, 1987; Jallot, D’Anna, 1990; Gutherz et al., 1998; fig. 18). La fonction de cette statuaire et son lien avec les autres mégalithismes fait débat (Guilaine, 


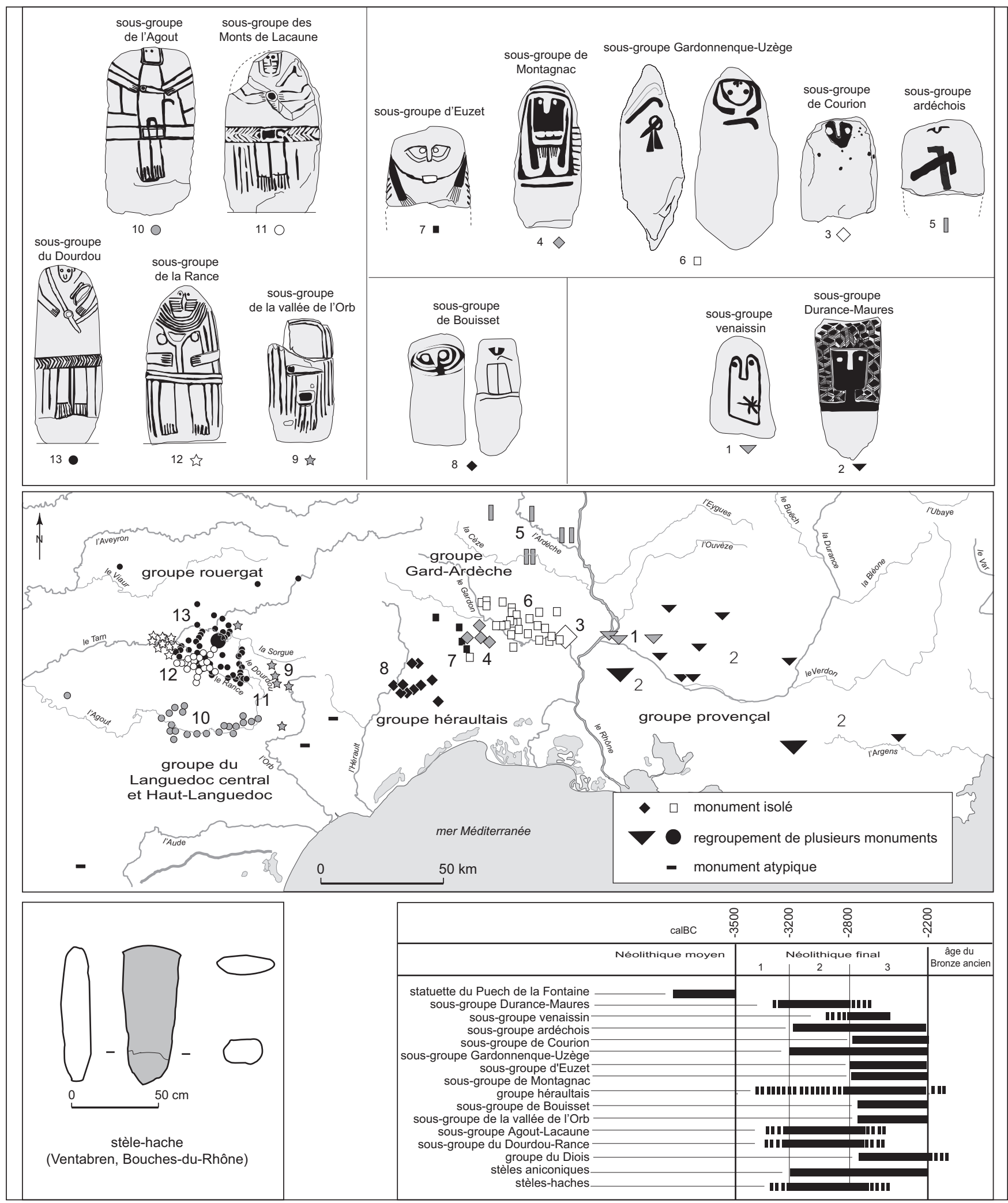


1 Fig. 18 -Distribution géographique des principaux groupes et sous-groupes stylistiques des stèles et statues-menhirs du sud de la France et tentative de classement chronologique d'après les affinités stylistiques et les contextes archéologiques: 1, rocher des Doms (Avignon, Vaucluse); 2 , la Lombarde 1 (Lauris/Puyvert, Bouches-du-Rhône); 3, Courion 1 (Collias, Gard); 4, Maison Aube (Montagnac, Gard); 5, Serre des Fourches (Lagorce, Ardèche); 6, Montaïon 1 (Sanilhac-Sagriès, Gard) et Mas de Teste 1 (Collorgues, Gard); 7, les Roumanis (Saint-Théodorit, Gard); 8, Serre de Bouissert 1 (Ferrières-les-Verreries, Hérault) et Montferrand (Saint-Mathieu-de-Tréviers, Hérault); 9, la Verrière (Montagnol, Aveyron); 10, Couffignet (La-Salvetatsur-Agout, Hérault); 11, les Vidals (Lacaune, Tarn); 12, Saint-Sernin 1 (Saint-Sernin-sur-Rance, Aveyron); 13, les Maurels (Camels-et-le-Viala, Aveyron). Tous les dessins sont d'après des relevés de l'auteur sauf noo 10 d'après Rodriguez, 2010 (DAO: L. Jallot, Inrap).

2003). Apparaissent-elles avec la métallurgie du cuivre? Illustrent-elles un culte du héros masculin armé que l'on prête plutôt à l'âge du Bronze finissant (Carozza, Mille, 2007) ? Synchrones du premier mégalithisme méridional, elles traduisent le renouvellement profond du rapport entre les agro-pasteurs et leur environnement naturel et humain tout au long des différents moments du Néolithique final méridional (Jallot, Sénépart, 2008).

\section{LES DOLMENS EN ALLÉE COUVERTE, LES ALLÉES SÉPULCRALES ENTERRÉES ET LES HYPOGÉES DU NORD DE LA FRANGE}

En Bretagne comme dans le Bassin parisien, peu de travaux récents ont porté sur l'architecture de ces monuments au cours de ces dix dernières années (nécropole de Wéris en Belgique, Toussaint et al., 2009; sépulture de SaintClaude à Bury dans l'Oise, fouilles L. Salanova). Le terme de «dolmen en allée couverte» est celui finalement retenu par R. Joussaume (2008) pour décrire les monuments mégalithiques construits en élévation, notamment sur le Massif armoricain où par ailleurs, les ossements ne sont que très rarement conservés. Le terme d'«allée sépulcrale», ou galeriegrab en allemand, a été proposé par C. Masset (1995) pour désigner des monuments enterrés qui n'ont pas toujours été recouverts par une dalle de couverture. Tous présentent une chambre quadrangulaire très allongée. L'usage de matériaux en pierre ou en bois a souvent été présenté comme une simple alternative technique, alors qu'il renvoie malgré tout à des aires culturelles nettement distinctes : celui de monuments en pierre construits en élévation, comme en Bretagne ou en Europe septentrionale; celui de maisons funéraires en bois partiellement enterrées, comme les Totenhütten de Saxe-Anhalt et de Thuringe. Par ailleurs, l'usage du bois dans les architectures du Bassin parisien a souvent été perçu comme antérieur à celui des dalles mégalithiques, ce qui paraît de moins en moins vraisemblable (Salanova, Sohn, à paraître).

La recherche sur les sépultures collectives du nord de la France, en particulier du Bassin parisien (fig. 19.1), est encore aujourd'hui fidèle héritière des travaux précurseurs d'A. Leroi-Gourhan sur l'hypogée des Mournouards (fouille 1960, Leroi-Gourhan et al., 1962). C'est également dans ces années que G. Bailloud (1964) s'est attaché à définir la «civilisation» Seine-Oise-Marne, dont l'essentiel du mobilier provient de contextes funéraires; unité géoculturelle qui sera rediscutée quarante ans plus tard dans le cadre du travail collectif de recherche sur la fin du Néolithique dans le centre-nord de la France (Chambon, Salanova, 1996; Langry-François, 2004; Renard, 2004; Augereau et al., 2007; Polloni, 2007). Sous l'impulsion de C. Masset, de J. Leclerc (Chaussée-Tirancourt, Somme; Bazochessur-Vesle, Aisne; Gours-aux-Lions, Seine-et-Marne) puis de P. Chambon, chaque monument est désormais perçu comme une structure funéraire au fonctionnement dynamique, de sa construction à sa condamnation parfois plus d'un millénaire plus tard (remaniements au fil du dépôt des corps, vidanges de la couche sépulcrale, organisations internes successives, réaménagements, zonations...). Dans ce cadre, l'étude des gestes funéraires concerne aussi bien l'architecture du monument que la gestion des restes humains ou du mobilier (Sohn, 2006a). Dans le Bassin parisien et l'ouest de l'Allemagne, les dépôts de vases, de haches et de gaines de haches dans l'entrée des monuments seraient anciens dans l'histoire des monuments (seconde moitié du IVe millénaire av. J.-C.), comme le prouvent plusieurs stratigraphies (Piningre, Bréart, 1985; Leclerc, Masset, 2006) et l'attribution chronoculturelle des objets (Sohn, 2002 et 2006b).

\section{ÉLÉMENTS DE CONTINUITÉ EN BRETAGNE}

Construits au-dessus du sol, les dolmens en allée couverte du Massif armoricain sont étroitement ceinturés par un petit tertre allongé à l'extrémité arrondie, comme pour les dolmens à chambre quadrangulaire allongée et entrée axiale de la fin du Néolithique moyen (Joussaume, 2008). Celui d'Arzon, dans le golfe du Morbihan, se distingue par des parois internes construites exclusivement en pierres sèches (Lecornec, 1996). J. L'Helgouach identifiait 


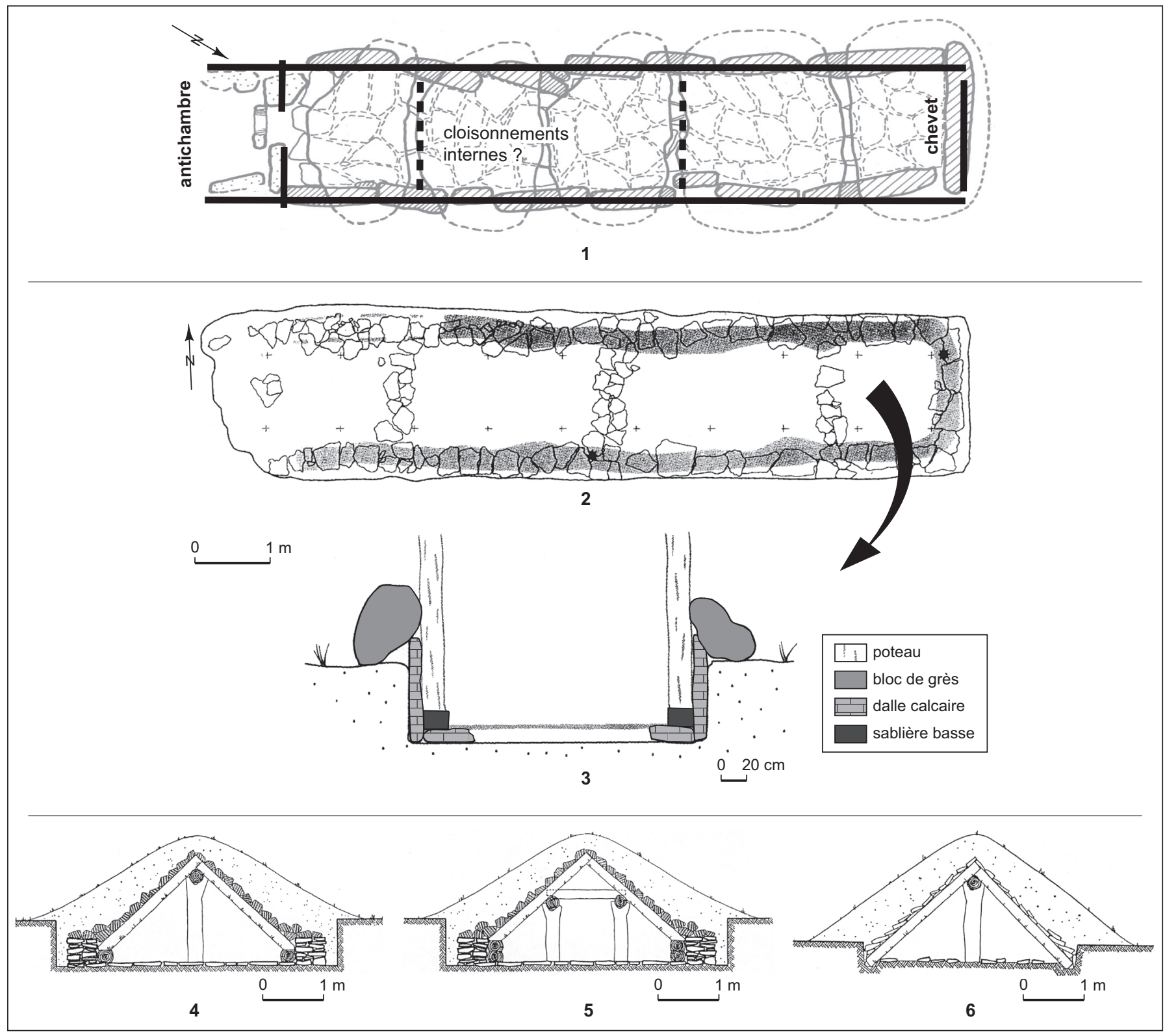

Fig. 19 - 1, allée sépulcrale «type» du Bassin parisien. En fond, sépulture des Mureaux, Yvelines (d'après Peek, 1975); 2-6, les allées sépulcrales en bois; 2-3, le Prieuré à Lacroix-Saint-Ouen (Oise), d'après Guillot et al., 1996; 2, plan de la sépulture et emplacement des parois en bois identifiées à la fouille; $\mathbf{3}$, restitution du système de montage des cloisons en bois sur sablière basse; 4-6, propositions de restitution des architectures en bois d'après des exemples comparables situés outre-Rhin; 4-5, Nordhausen, Kr. Nordhausen (d'après Feustel, Ullrich, 1965); 6, Niederbösa, Kr. Sondershausen (d'après Feustel, Ullrich, 1965).

plusieurs types de dolmens en allée couverte, notamment en fonction de la longueur de la chambre (Giot et al., 1998). Par sa porte d'entrée aménagée entre deux montants verticaux, celui à chambre courte de Champtocé-sur-Loire n'est pas sans rappeler certains dolmens angevins; parmi ces derniers, celui de la Roche-aux-Fées en Ille-et-Vilaine est effectivement très allongé. Les dolmens en allée couverte sont aussi les plus nombreux: la chambre du monument aujourd'hui détruit de Caro mesurait jusqu'à $25 \mathrm{~m}$ de long. Par son couloir débouchant à mi-longueur sur une chambre transversale allongée, le monument de Brécé en Mayenne est certainement celui qui se rapproche le plus des passage 
graves d'Europe septentrionale (Bouillon, 1989). Le cas le plus fréquent est toutefois celui d'un accès court et décalé vers l'une des extrémités de la chambre, comme au FourSarazin en Ille-et-Vilaine (Briard et al., 1995). Le dolmen en allée couverte à entrée latérale de Beaumont est implanté au centre d'un éperon ceinturé qui fut largement occupé au cours du Néolithique récent/final (Tinévez dir., 1988). Ce dernier type de monument pourrait être un peu plus récent que les dolmens en allée couverte à entrée axiale, avec lesquels il partage cependant nombre de caractéristiques communes (Laporte, Le Roux, 2004).

\section{LES ALLÉES SÉPULCRALES ENTERRÉES DU BASSIN PARISIEN}

Proches parentes des galeriegrab de Hesse et de Westphalie, les allées sépulcrales du Bassin parisien sont des monuments allongés et enterrés, mesurant 9 à $10 \mathrm{~m}$ de long et 2,5 à $3 \mathrm{~m}$ de large en général, mais pouvant aller exceptionnellement jusqu'à $20 \mathrm{~m}$. Situées à flanc de coteaux, la tranchée s'enfonçant perpendiculairement à la pente de manière à dégager une entrée monumentale visible de loin, les allées sépulcrales ne présentent pas vraiment d'orientation préférentielle (Bailloud, 1964). L'une de leurs principales caractéristiques est de posséder une antichambre axiale, clairement individualisée; l'entrée de la chambre sépulcrale étant matérialisée par une dalle hublot et par un système de feuillure, trous et gouttières destinés à maintenir une fermeture en bois (parfois en pierre: Guiryen-Vexin, Val-d'Oise). Les parois internes sont constituées de dalles mégalithiques en calcaire, de murets de pierres sèches ou en bois. Certaines couvertures mégalithiques auraient été mises en place lors de la fermeture définitive des monuments, comme l'atteste leur position au-dessus des couches de condamnation, sans fonction architectonique évidente (Leclerc, 1987; Masset, 1995; Leclerc, Tarrête, 2006). Quatre monuments livrent des figurations féminines gravées comme les seins et le collier de la Pierre Turquaise en Val-d'Oise.

Les fouilles préventives de sépultures qui semblent avoir connu un temps de fonctionnement assez court, comme celles de Vignely (Allard et al., 1998) ou de Souppessur-Loing (Pecqueur, 2002) attribuées au Néolithique récent, apportent des éléments complémentaires à ce débat. L'intégrité corporelle d'un nombre restreint d'individus a été largement respectée, sans que le caractère collectif des dépôts ne soit ici mis en cause (Chambon, 2008). Près de l'estuaire de la Seine, dans la boucle du Vaudreuil en
Normandie, la fouille préventive de cinq sépultures collectives enterrées, d'architectures différentes, a été l'occasion de comparer les caractéristiques biologiques des personnes inhumées dans chacune d'entre elles, ou la nature des dépôts mobiliers qui leur sont associés. L'hypothèse est formulée d'un recrutement socialement différencié entre sépultures à parois mégalithiques et celles construites en bois, d'une durée d'utilisation supposée plus courte (Billard, 1998; Billard et al., 2010).

\section{ESPACES SÉPULCRAUX AUX PAROIS DE PIERRE OU DE BOIS}

À l'exception d'un certain nombre de sépultures dites «en fosse», de dimensions réduites et certainement fort discrètes aux yeux de leurs contemporains (GermignyL'Évêque, les Gours-aux-Lions 1 et 2, Seine-et-Marne), les longues allées sépulcrales que nous venons de mentionner ont pu être réalisées entièrement en bois et en pierres sèches (systèmes de sablières basses comme à Lacroix-SaintOuen dans l'Oise; fig. 19.2, ou à Bazoches-sur-Vesles dans l'Aisne). Dans le cas des monuments «hybrides», qui allient bois et éléments mégalithiques (Vers-sur-Selle ou Bury, Somme), on constate que les deux types de matériaux ont pu coexister comme s'être succédés dans l'histoire du monument. Dans la sépulture de Saint-Claude à Bury (Oise) en effet, pierre et bois sont complémentaires du début à la fin de l'utilisation du monument (Salanova, Sohn, à paraître). Les rites de condamnation sont peut-être plus faciles à percevoir dans le cas de monuments en bois, comme celui de Bazoches-sur-Vesles (Leclerc, 1999), puisque le feu y joue un rôle prépondérant (Masset, 2002). Ils réintroduisent une dissociation dans le temps entre les dépôts de corps consécutifs aux funérailles, et l'effort collectif dont rend compte également la monumentalité du dispositif; phénomène que nous avions déjà observé au début du mégalithisme atlantique au travers de la discussion concernant les espaces sépulcraux dépourvus d'accès couverts, bien que désormais le caractère successif des dépôts ne saurait plus être mis en cause.

\section{LES HYPOGÉES DE LA MARNE}

Le département de la Marne compte plus de 150 hypogées creusés dans la pente de coteaux crayeux. Ils sont organisés en nécropoles. La nécropole du Razet à Coizard compte à elle seule quarante tombes creusées dans le rocher, dont l'organisation interne a souvent été comparée à celle 
des allées sépulcrales (chambre quadrangulaire simple ou double, antichambre axiale séparée de la chambre sépulcrale par une dalle hublot, rampe d'accès en pente, orientation indifférenciée). Le passage entre la chambre et le vestibule porte parfois des représentations de haches emmanchées ou des représentations féminines gravées, parfois les deux comme à l'hypogée 24 du Razet à Coizard (Bailloud, 1964). À l'intérieur de la chambre, la présence de banquettes latérales rappelle peut-être l'organisation des espaces internes de l'habitat domestique, comme c'est assurément le cas pour les exemples plus anciens des hypogées sardes (Tanda, 1992). En Champagne, la découverte toute récente d'un vaste enclos palissadé englobant deux grands bâtiments allongés du Néolithique récent à Pont-sur-Seine (fouilles V. Desbrosse, Inrap 2010) est troublante: sa forme oblongue, comme celle évasée du dispositif d'entrée axial, n'est pas sans rappeler le plan des hypogées que nous venons de décrire. Par ailleurs, quelques variantes aux hypogées «classiques» sont connues, comme à Arronville, où la tranchée creusée à flanc de coteaux s'engage sous une dalle du rocher naturellement en place. J. Tarrête (1999) y voit comme une solution intermédiaire ou une alternative aux hypogées de la Marne.

\section{MONUMENTS AUX MORTS, MONUMENTALITÉ POUR LES VIVANTS : MÉGALITHISMES DE LA FIN DU NÉOLITHIQUE}

Dès la seconde moitié du IV ${ }^{\mathrm{e}}$ millénaire av. J.-C. entre Loire et Gironde, les efforts collectifs se focalisent exclusivement sur de vastes habitats ceinturés. Au cours de la première moitié du $\mathrm{III}^{\mathrm{e}}$ millénaire av. J.-C., la monumentalité de bâtiments en bois construits sur toute la façade atlantique, comme plus ponctuellement jusque dans le nord de la France, éclipse assurément celle des quelques constructions mégalithiques contemporaines. À la même époque en Languedoc, les techniques de la construction en pierres sèches seront plus largement appliquées aux constructions domestiques.

Tous les éléments que le mégalithisme du Ve millénaire avait intégrés, de façon à chaque fois un peu singulière, reprennent désormais de leur autonomie. Chaque élément - très grosses pierres dressées ou simplement déplacées, espaces cérémoniels étroitement circonscrits voire ensuite occultés, ou plates-formes surélevées, masses monumentales exposées à la vue de tous ou mise en scène plus intime de l'espace sépulcral, corps déposés sur le sol de salles construites en élévation ou souterraines, etc. - pourra alors être décliné de façon de plus en plus indépendante. Des pierres assemblées à Stonehenge jusqu'aux «statuesmenhirs» de Corse, des caveaux mégalithiques des petits princes d'Armorique comme pour l'appareillage cyclopéen des navettes aux Baléares, c'est bien sous cette forme d'ailleurs que certains de ces mégalithismes trouveront un prolongement jusque dans les âges des Métaux.

À partir de 2800 av. J.-C., on assiste également à une compartimentation plus importante dans la gestion funéraire de l'espace sépulcral, et à une déshumanisation accrue des restes ultimes de chaque défunt individuellement (Chambon, Leclerc, 2008a). La stratigraphie des dépôts, dans le monument enterré aux parois mégalithiques de la Chaussée-Tirancourt, illustre de tels changements qu'accompagne ici l'aménagement d'une entrée latérale (Leclerc, Masset, 2006). C'est peut-être aussi, parfois, que l'essentiel du rituel funéraire n'est plus étroitement associé au lieu où l'on dépose le corps du défunt: dans le centreouest de la France, d'abondants dépôts céramiques en façade de dolmens à couloirs, construits précédemment et abondamment réutilisés au Néolithique final, participent à cette externalisation des rites funéraires, voire peut-être dans le cadre de cérémonies seulement commémoratives (Michel, 2009). De telles pratiques sont surtout attestées en Allemagne et en Europe du Nord avant 2900-2800 av. J.-C.

Au total, de l'ordre de 200 à 300 corps ont été parfois introduits successivement dans un espace restreint, sur une durée de plus d'un millénaire. Pour C. Masset (1999), la structure en classes d'âge des individus inhumés ne saurait toujours rendre compte de celle des populations correspondantes, impliquant une stricte sélection des premiers. L'étude des restes humains de quatre sépultures collectives d'architectures différentes, le Blanc Val à Presles, la Ferme Duport à Guiry-en-Vexin (Val-d'Oise), Essômes-sur-Marne (Aisne) et les Réaudins à Balloy (Seine-et-Marne), conclut à l'absence de caractères discriminants d'un point de vue démographique ou sanitaire en fonction du matériau employé pour la construction de la tombe (Deschamps et al., 1996). Ici, il ne paraît pas exister, du point de vue des populations, une hiérarchie sociale qui soit corrélée avec la nature du monument funéraire. Dans plusieurs autres sépultures du Bassin parisien, on s'est demandé si la zonation de l'espace était corrélée avec l'origine sociale des individus. À la Chaussée-Tirancourt (Somme), un système de cellules d'inhumation a été mis en évidence: certains caractères discrets suivent leur topographie mais ne s'échangent pas entre cellules, ce qui évoquerait la possibilité de groupes familiaux n'ayant pas de relations 


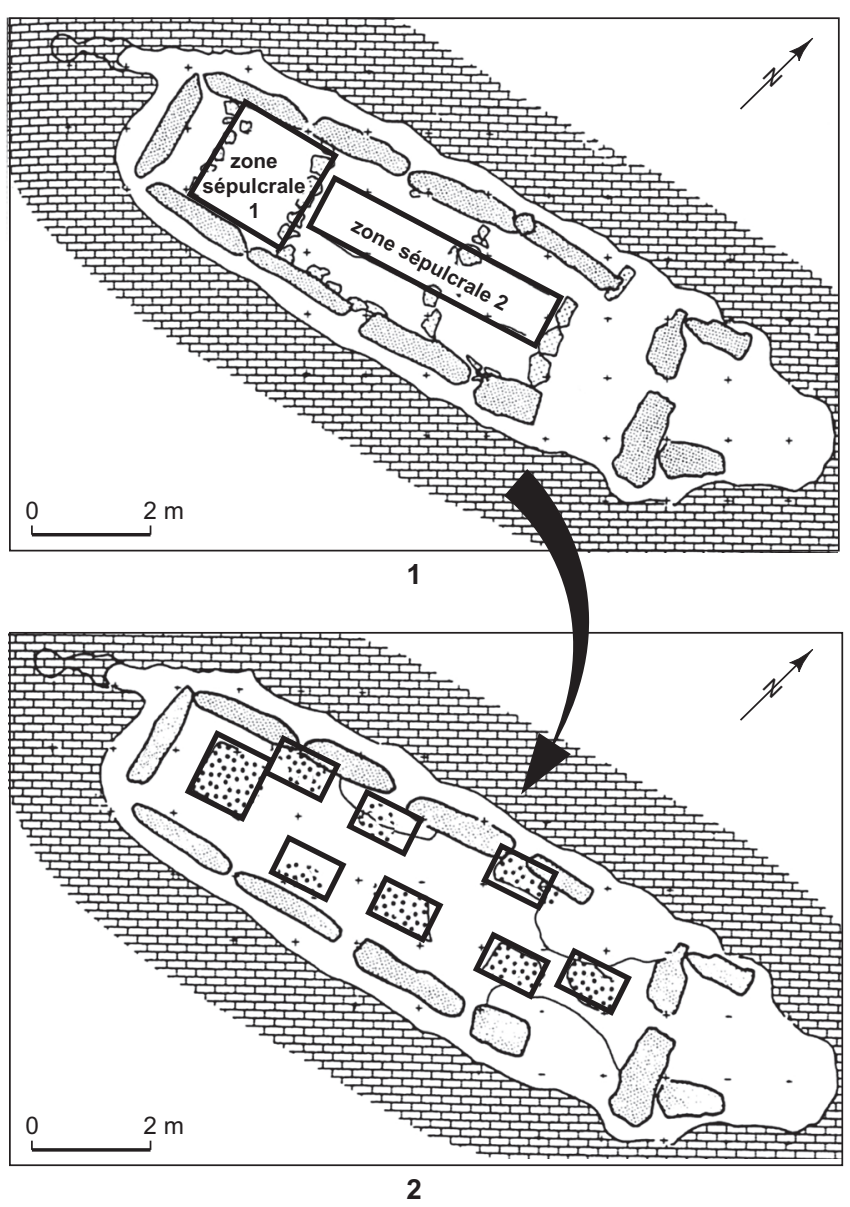

Fig. 20 - Compartimentation croissante de l'espace funéraire durant le III millénaire av. J.-C. Allée sépulcrale de la Chaussée-Tirancourt (Somme): 1, zonage des restes humains dans la couche V; $\mathbf{2}$, cellules d'inhumation dans la couche III, correspondant à la fin de la première moitié du III millénaire av. J.-C. (d'après Masset, 1979).

matrimoniales entre eux (fig. 20; Masset, 1979; Leclerc, Masset, 2006). Des résultats comparables ont été obtenus d'après la population inhumée dans la sépulture d'Éteauville en Eure-et-Loir (Bailloud et al., 1965). Enfin, deux groupes d'inhumés ont été différenciés par leurs caractères discrets dans la sépulture de Guiry-en-Vexin (Val-d'Oise). L'un des deux était dans un meilleur état sanitaire que le second... (Masset, Valentin, 1999).

\section{LA MAISON DES MORTS}

En Bretagne, le dolmen en allée couverte de Gâvres est pourvu d'une très longue entrée latérale. Son plan, les dimensions relatives de chacune de ses parties, comme son élévation interne, peuvent être rapprochés du plan des grands bâtiments domestiques fouillés à Pléchâtel (Laporte, Tinévez, 2004). La présence d'une cella adventice construite en arrière de la dalle de chevet de nombreux dolmens en allée couverte, parfois richement décorée comme à Trébeurden (Giot et al., 1998), rappelle le porche monumental de ces mêmes bâtiments de Pléchâtel (Tinevez, 2004). Dans le nord de la France, la présence d'un puits cuvelé au centre du porche d'entrée du grand bâtiment d'Houplin-Ancoisne (Praud et al., 2007), occupe la place de riches dépôts enterrés de céramiques et de haches polies dans le vestibule des dolmens en allée couverte enterrés de Picardie, construits en pierre ou en bois (Laporte, à paraître a). Le monument enterré en allée couverte de la Croix-Saint-Ouen (Oise), en bois comme le bâtiment d'Houplin-Ancoisne (Nord-Pas-de-Calais), ont tous deux été datés par la dendrochronologie de l'extrême fin du IV ${ }^{\mathrm{e}}$ millénaire av. J.-C. Les bâtiments à aile latérale de Pléchâtel appartiennent en revanche au second quart du III $^{\mathrm{e}}$ millénaire av. J.-C. (fig. 21).

\section{EXTERNALISATION DU RITUEL FUNÉRAIRE}

En partie construites au-dessus du sol, la sépulture 13 de Balloy ou celle de Pincevent, pourraient avoir présenté bien des similitudes avec un petit dolmen ou un coffre en bois. Elles sont toutes deux attribuées à l'extrême fin du Néolithique. Au nord de la Loire, en région Centre et en Île-de-France, comme dans la Marne, en Bourgogne ou en Champagne, quelques dolmens existent assurément, dont certains pourraient peut-être dater du Néolithique moyen (Soulier dir., 1998). Celui largement enterré de Sublaines n'a livré que du mobilier attribué à des périodes postérieures, mais rares sont ceux qui ont fait l'objet d'études récentes. De part et d'autre de la trouée de Belfort, les dolmens à dalle hublot de type Aesch-Schwörstadt sont ceinturés par un petit tumulus circulaire. Dans la première moitié du III ${ }^{\mathrm{e}}$ millénaire av. J.-C., il leur sera parfois adjoint une plate-forme triangulaire ou trapézoïdale dont ils occupent l'extrémité orientale, comme pour les dolmens partiellement enterrés de type Aillevans (Pétrequin, 1985), ou les grands coffres des nécropoles mégalithiques du Valais suisse et celles du Val d'Aoste en Italie.

\section{DISSOCIATION DES COMPOSANTES DU MÉGALITHISME}

La comparaison proposée entre la forme triangulaire de ces plates-formes et celle d'un travois en bois initialement tiré par des bœufs, comme celui récemment exhumé sur 


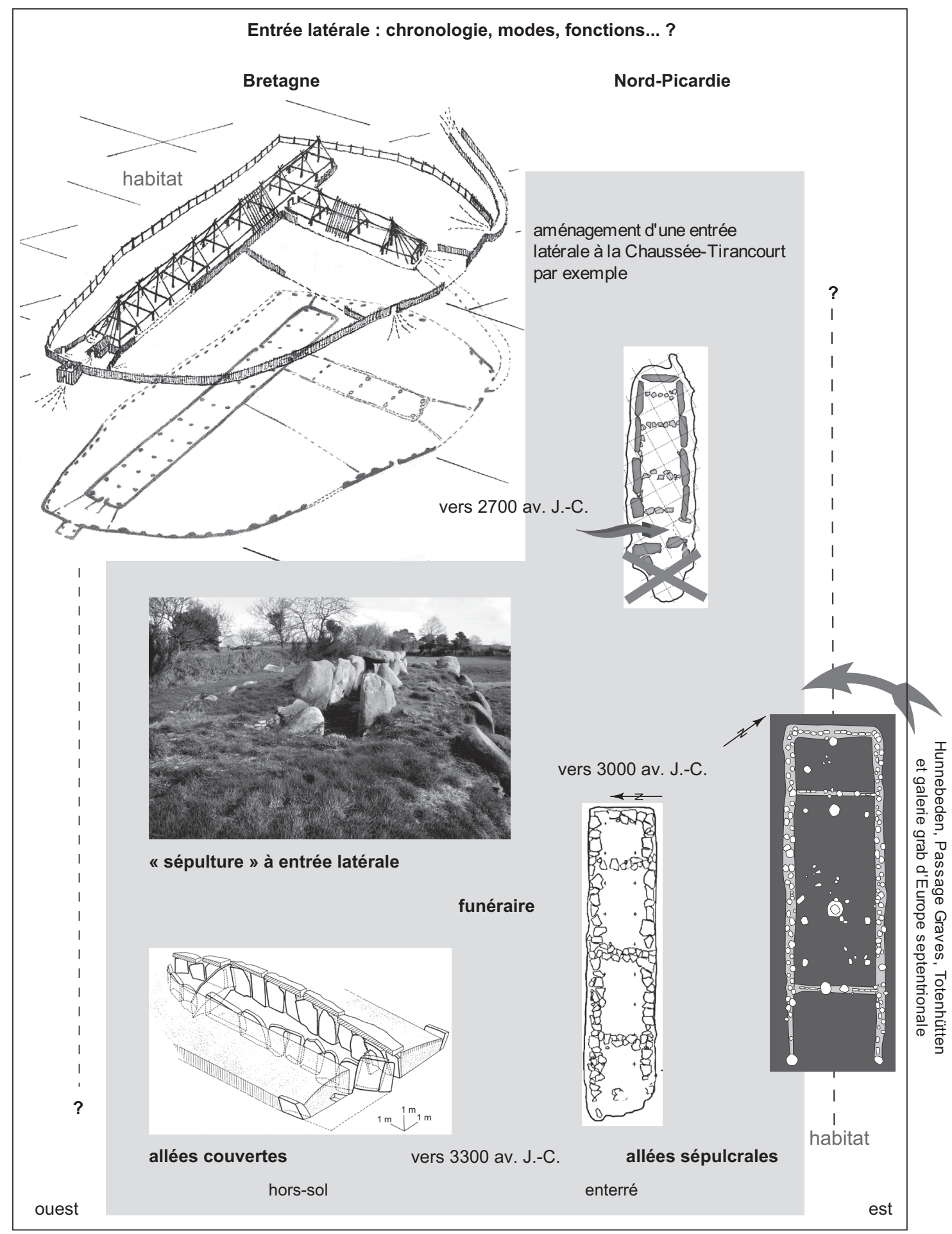

Fig. 21 - Constructions monumentales en bois (grandes maisons) et monuments mégalithiques de la fin du Néolithique dans la moitié nord de la France (d'après Laporte, à paraître). 
le site lacustre de Châlain, veut mettre l'accent encore une fois sur l'importance de rites qui accompagnent le mort vers sa dernière demeure, et (si l'on suit cette dernière hypothèse de travail) peut-être ici sous la forme d'une procession (Pétrequin et al., 2006). Espace sépulcral construit au-dessus du sol et plate-forme cérémonielle s'affichent alors séparément, selon un processus inverse à celui d'intégration que nous avions observé au début du mégalithisme atlantique. Dans ce cas également, l'espace cérémoniel de telles plates-formes peut être associé à différentes architectures pour ce qui est de l'espace sépulcral, comme dans l'exemple déjà cité de Xanton-Chassenon en Vendée (Joussaume, 1977), voire en être dissocié spatialement, comme à Villamontel sur les Causses. Dans le Sud, l'attribution au III $^{\mathrm{e}}$ millénaire av. J.-C. du coffre semi-enterré à tertre parementé de Peirouse-Ouest (Marguerittes, Gard) mérite d'être signalée (Vigneau, inédit). Ce modèle réapparaîtra au Bronze ancien, à l'image de la ciste des Goubert en Vaucluse (Sauzade, Vital, 2002). Le tumulus de PeirouseOuest appartient également à cette période. Quoique plus récent, il évoque l'architecture des tertres de ChâteauBlanc. Parallèlement, à Penvénan en Bretagne (Briard, Giot 1968; Lopez Romero, De la Aleja, 2008) comme à Silbury Hill en Angleterre, d'énormes efforts collectifs sont consacrés à la construction de très hautes buttes circulaires qui ne recouvrent plus forcément un espace sépulcral.

\section{LE RÔLE DU FEU DANS LES PRATIQUES FUNÉRAIRES}

Vers la fin du Néolithique également, le rôle du feu est à nouveau perceptible dans les pratiques funéraires, mais sous des formes parfois très diverses (Chambon, 2003). Il était déjà présent au $\mathrm{V}^{\mathrm{e}}$ millénaire av. J.-C., bien que de façon assez discrète, au travers de restes incinérés, recueillis dans certains dispositifs de la nécropole de Caramany par exemple (Vaquer, 1998), ou de quelques mentions plus anciennes concernant les «tertres» bas du Morbihan (Miln, 1883), avant de disparaître ensuite presque totalement. À moins bien sûr que les très nombreuses structures de pierres chauffées, que l'on rencontre dans l'ouest de la France pour cette période, ne rendent compte d'une autre forme d'association avec les pratiques funéraires en général et le mégalithisme en particulier, ce qui resterait à prouver. À partir de la fin du IVe millénaire av. J.-C., le feu peut jouer un rôle important dans les rituels de condamnation des monuments en bois, enterrés ou non, alors parfois qualifiés de crématoires, bien que ce terme ne soit que très rarement approprié (Masset, 2002). Dans le Bassin parisien, la men- tion de quelques sujets incinérés existe également dans de tels contextes; ce sont même souvent les seuls restes osseux qui nous soient parvenus dans les dolmens en allées couvertes de Bretagne. Beaucoup plus au sud, sur les Causses, le tumulus de Freyssinels (Lozère) a livré une sépulture multiple à incinération et un viatique spectaculaire (Morel, 1934; Beyneix et al., 2001). Ici, des tumulus de dimensions plus modestes, contenant des restes incinérés ou non, existent à la même époque. Ils sont plutôt associés aux porteurs de la céramique campaniforme. Les fouilles du tumulus de Dignas (Fagès, 1983), du tumulus 26 du Devèzes de Maymac (Gruat et al., 2004) suggèrent qu'ils pouvaient parfois abriter des chambres en bois, qualifiées de «maison des morts». Souvent réutilisés à une époque tardive, certains de ces monuments pourraient toutefois s'inscrire dans la continuité des tertres des Grands Causses attribués au Néolithique moyen (Gruat, 2006).

\section{CONCLUSION}

Cet article n'a pas pour prétention de résumer l'immense complexité du Mégalithisme en France et près de trois millénaires d'histoire, mais plutôt d'ouvrir la réflexion aux innombrables pistes de recherche qu'il suscite. Il insiste d'abord sur l'importance de faire enfin table rase d'un certain nombre d'idées reçues; parmi les plus fréquentes, la tendance à la classification systématique de l'architecture des seuls espaces sépulcraux en fonction de leur complexité «apparente», du plus simple au plus élaboré. Un grand nombre d'exemples anciens et récents présentés ici montrent à quel point le phénomène mégalithique est complexe, non linéaire, et combien il convient de rester humble en attendant que s'étoffent les corpus de données de qualité. Mais n'est-ce pas là un point commun à toute recherche en cours, dès lors qu'elle est quelque peu novatrice? Nous avons souhaité également mettre l'accent sur la nécessité d'aborder le mégalithisme aussi bien sous l'angle des architectures, que sous celui des mobiliers funéraires et des restes humains (lorsqu'ils sont conservés), ces trois aspects étant souvent intimement imbriqués. Chaque groupe de pierres dressées ou simplement déplacées, chaque monument mégalithique et chaque nécropole méritent d'être abordés comme le fruit d'un ou plusieurs "projets", et non comme la simple juxtaposition de modifications architecturales aux motivations purement pratiques. Que ce soit par le biais de la culture matérielle, de l'architecture domestique ou de l'anthropologie sociale, parmi d'autres exemples, ces études spécifiques gagnent toujours à être confron- 
tées à d'autres sphères. Parallèlement, la mise en œuvre du chantier suppose une succession d'actes techniques qui méritent également d'être étudiés en détail, un peu à l'image de ce que nos collègues médiévistes nomment «l'archéologie du bâti». Bon nombre d'exemples nous prouvent que la notion d'intégrité d'un monument, et des «morts» ou des «ancêtres», a pu perdurer sur plus de deux millénaires, ce qui est parfois difficile à admettre dans nos sociétés modernes. Au même titre que l'effort investi pour sa construction, la pérennité de l'attention qu'il requiert au fil des générations ne concourt-elle pas à la notion même de monument ? Enfin, le monument mégalithique doit être compris dans son espace, l'espace funéraire au sens large (emprise dans le paysage, lien avec les habitats, espaces cérémoniels extérieurs ou intérieurs, aménagements et dépôts annexes, carrières...), mais aussi l'espace sépulcral (gestion des inhumations, zonations, population inhumée, mobiliers funéraires, évolution de la pratique au sein de la même structure...). Dès lors, une multitude d'interrogations et de nombreuses nouvelles pistes de recherche apparaissent. Le mégalithisme n'est pas un sujet désuet mais novateur, où beaucoup reste à faire.

En Europe occidentale, ces monuments mégalithiques constituent les vestiges préhistoriques les plus nombreux et parmi les plus anciens des constructions en élévation qui nous soient parvenus. Il s'agit là d'une source d'information au potentiel considérable sur les sociétés du passé, mais - il est vrai - qui laisse un peu moins de liberté à l'imagination, que l'interprétation de vestiges totalement arasés. Au cours des dix dernières années en France, l'intérêt suscité par ce type d'études comme les investissements consentis dans ce domaine restent très inégaux suivant les régions. Entre ceux de nos collègues qui semblent un peu effrayés par la complexité d'un phénomène auquel ils n'ont pas forcément eu l'occasion d'être confrontés, et ceux qui estiment que tout a été dit en la matière, se dégage parfois l'impression erronée d'un certain essoufflement des recherches. Peut-être faut-il aussi un peu de temps pour que l'abondante bibliographie spécialisée produite ces dernières années soit pleinement digérée par l'ensemble de la communauté scientifique. De plus, étudier un dolmen prend désormais, en principe, beaucoup plus de temps que les deux à trois semaines requises dans les années soixante. L'exigence de la fouille fine et sereine, comme l'intervention d'anthropologues et de spécialistes compétents en matière d'archéologie funéraire préhistorique (notamment), mériterait assurément d'être maintenue. Il s'agit d'investissements lourds sur le long terme qui, à quelques exceptions près, échappent largement au renouvellement des connaissances induit par le développement de l'archéologie préventive. Enfin, la protection et la préservation des mégalithes sont étroitement liées aux problématiques scientifiques. Étudier un monument mégalithique c'est aussi ne pas l'oublier. Le mettre en valeur avec tous les partenaires locaux ou régionaux de la recherche archéologique, contribue souvent aux efforts de développement territoriaux. 


\section{BIBLIOGRAPHIE}

\begin{tabular}{ll}
\multicolumn{2}{c}{ ABRÉVIATIONS } \\
ADALR & Association pour le développement de l'archéologie en Languedoc-Roussillon. \\
ADRAHP & Association pour le développement de la recherche archéologique et historique en Périgord. \\
APDCA & Association pour la promotion et la diffusion des connaissances archéologiques. \\
APRAIF & Association pour la promotion de la recherche archéologique en Île-de-France. \\
ARALO & Association pour la recherche archéologique en Languedoc oriental. \\
BAR & British Archaeological Reports. \\
BSPF & Bulletin de la Société préhistorique française. \\
BSR & Bilan Scientifique Régional. \\
CeRAA & Centre régional d'archéologie d'Alet. \\
CNRS & Centre national de la recherche scientifique. \\
EHESS & École des hautes études en sciences sociales. \\
PAR & Patrimoine archéologique de Bretagne. \\
SPF & Société préhistorique française. \\
SRA & Service régional de l'archéologie.
\end{tabular}

Abélanet J.

1970: "Les dolmens du Roussillon», in Les Civilisations du Néolithique du Midi de la France, Actes du colloque de Narbonne, 15-17 févr. 1970, Carcassonne, Laboratoire de préhistoire et de palethnologie (coll. Atacina, 5), p. 74-79.

Aguayo de Hoyos P., Garcia Sanjuan L., 2006: «Le phénomène mégalithique en Andalousie (Espagne) : une synthèse", in JOUSSAUME R., LAPORTE L., SCARRE C. (DIR.), Origine et développement du mégalithisme de l'ouest de l'Europe, Actes du colloque international de Bougon, 26-30 oct. 2002, Bougon, Musée des tumulus de Bougon, p. 451-472.

\section{Allard P., ANDRÉ M.-F., Chambon P.,} LAFAGE F., PRAUD Y.

1998: «La sépulture collective de Vignely, la Porte aux Bergers (Seine-et-Marne)», in GUTHERZ X., JOUSSAUME R. (DIR.), Le Néolithique du centre-ouest de la France, Actes du XXI colloque interrégional sur le Néolithique, Poitiers, 14-16 oct. 1994, Chauvigny, Association des publications chauvinoises (coll. Mémoire, XIV), p. $395-401$

\section{AMbert P}

1990: "Réflexion concernant l'architecture des dolmens larges de l'aire pyrénaïque», in Guilaine J., GUTHERZ X. (DIR.), Autour de Jean Arnal: recherches sur les premières communautés paysannes en Méditerranée occidentale, Montpellier, Laboratoire de paléobotanique de l'université des sciences et techniques du Languedoc de Montpellier-II, p. 291-299.
ARNAL J.

1956: «Petit lexique du mégalithisme », $B S P F$ 53,9 , p. 518-531.

1963: Les Dolmens du département de l'Hérault, Paris, Presses universitaires de France (coll. Préhistoire, XV), $250 \mathrm{p}$.

1976: Les Statues-menhirs, hommes et dieux, Toulouse, éd. des Hespérides (coll. Archéologie, Horizons neufs), 1976, 238 p.

\section{ARNAL J., BALSAN L.}

1980 : «Les longs tumulus à dolmen décentré du département de l'Aveyron", Gallia Préhistoire, 23, 1, p. 183-207.

ARNAL J., LATOUR J., RiQUeT R.,

1953: «Les monuments et stations néolithiques de la région d'Arles en Provence », Études roussillonnaises, 3, 1, p. 27-69.

AUgereaU A. ET AL.

2007: «Le Néolithique récent dans le centrenord de la France (3400/3300-2800/2700 av. J.-C.) : l'avenir du Seine-Oise-Marne en question", in ÉVIN J. (DIR.), Un siècle de construction du discours scientifique en Préhistoire: des idées d'hier aux conceptions d'aujourd'hui, Actes du XXVI congrès préhistorique de France, congrès du centenaire de la SPF, Avignon, 21-25 sept. 2004, Paris, SPF vol. 1, p. 165-184.

\section{AzÉMAR R.}

1995: «Aveyron, Lapanouse-de-Cernon, Dolmen de la Baume", BSR Midi-Pyrénées 1994, Paris, Ministère de la Culture et de la Communication, p. 53-54.

1998: «Réemplois et recomposition architecturale des dolmens: l'exemple de la nécropole de Saint-Martin-du-Larzac
(Aveyron)", in SOUlIER P. (DIR.), La France des dolmens et des sépultures collectives (4500-2000 av. J.-C.): bilans documentaires régionaux, Paris, Errance, p. 232-236.

2008: "Nouveaux enjeux, nouveaux acquis autour des dolmens et des territoires de la Préhistoire récente des Grands Causses », in GASCO J., LEYGE F., GRUAT P. (DIR.), Hommes et passé des Causses: hommage à Georges Costantini, Actes du colloque de Millau, 16-18 juin 2005, Toulouse, EHESS (coll. Archives d'écologie préhistorique), p. 351-364.

\section{BAILLOUD G.}

1964: Le Néolithique dans le Bassin parisien, Paris, éd. du CNRS (coll. Suppl. à Gallia Préhistoire, II), p. 433

Bailloud G., Boujot C., Cassen S., LE ROUX C.-T.

1995: Carnac: les premières architectures de pierre, CNRS Éditions, Paris, 126 p.

BaIlloud G., DAUVOIS M., horemans P., Nouel A., Planchais N., POULAIN-JOSIEN T., RIQUET R.

1965: «L'ossuaire néolithique d'Éteauville, commune de Lutz-en-Dunois (Eure-etLoir) », BSPF (coll. Études et Travaux, 62 , 3), p. 576-648.

BAILlOUd G., MIEG DE BOOFZHEIM P.

1955: Les Civilisations néolithiques de la France dans leur contexte européen, Paris, Picard, $244 \mathrm{p}$

BAKKER J. A.

2009: The TRB West Group: Studies in the Chronology and Geography of the Makers of 
Hunebeds and Tiefstich Pottery, Amsterdam,

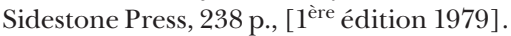

\section{BEECHING A.}

2003: «Organisation spatiale et symbolique du rituel funéraire chasséen en moyenne vallée du Rhône: première approche", in CHAmbon P., LECLERC J. (DIR.), Les Pratiques funéraires néolithiques avant 3500 av. J.-C. en France et dans les régions limitrophes, Paris, SPF (coll. Mémoires de la SPF, 33), p. 231-240.

\section{Beeching A., Grubézy É.}

1998: «Les sépultures chasséennes de la vallée du Rhône», in GUILAINE J. (DIR.), Sépultures d'occident et genèses des mégalithismes (9000-3500 avant notre ère), Paris, Errance, p. 147-164.

\section{BEYNEIX A.}

2003: Traditions funéraires néolithiques en France méridionale, 6000-2200 av. J.-C., Paris, Errance, 288 p.

\section{BeyneiX A., Moulherat C.} BERTRAND L.

2001: «À propos du niveau néolithique final du tumulus X du Freyssinel (SaintBauzile, Lozère) », BSPF, 98, 4, p. 663-674.

\section{BILLARD C.}

1998: «Les architectures funéraires du Néolithique final», Catalogue d'exposition Au bout du couloir, les mégalithes en Normandie et dans les îles anglo-normandes, Musée des Mégalithes, Wéris, Musée des Mégalithes, p. 49-56.

BILlaRd C., GUILlon M.,

VERRON G. (DIR.)

2010: Les Sépultures collectives du Néolithique récent-final de Val-de-Reuil et Porte-Joie (Eure, France), Liège, Université de Liège (coll. ERAUL, 123), 404 p.

Bizot B., Michel J., SAuzade G.

2004: «Dépôts funéraires et sédimentation dans le dolmen de l'Ubac à Goult", in BUisson-Catil J., GUIlcheR A., Hussy C., Olive M., PAGNi M. (DIR.), Vaucluse préhistorique: le territoire, les hommes, les cultures et les sites, Le Pontet, éd. Barthélémy, DRAC de ProvenceAlpes-Côte d'Azur, p. 238-244.

\section{BORDREUIL M.}

1998: «Recherches sur le monumentalisme funéraire et les sépultures mégalithiques en Languedoc oriental ", in SOULIER P. (DIR.), La France des dolmens et des sépultures collectives (4500-2000 av. J.-C.): bilans documentaires régionaux, Paris, Errance, p. 135-157.

\section{BORDREUIL M., BORDREUIL M.-C.,}

JALLOT L.

2006: «Dolmens à murs latéraux en pierre sèche en Languedoc oriental (France): étude préliminaire", in JOUSSAUME R., LAPORTE L., SCARRE C. (DIR.), Origine et développement du mégalithisme de l'ouest de l'Europe, Actes du colloque international de Bougon, 26-30 oct. 2002, Bougon, Musée des Tumulus de Bougon, p. 283-304.

\section{BORIES G.}

1995: «Le dolmen de Peyrelebade à Limouze, Salles-la-Source: vivre en Rouergue", Cahiers d'archéologie aveyronnaise, 9, p. $97-120$.

2008: «La structure de protection des chambres mégalithiques des dolmens du nord Aveyron: l'exemple des dolmens I et II de Peyrelevade à Limouze, commune de Salles-la-Source », in GASCO J., LEYGE F., GRUAT P. (DIR.), Hommes et passé des Causses: hommage à Georges Costantini, Actes du colloque de Millau, 16-18 juin 2005, Toulouse, EHESS (coll. Archives d'écologie préhistorique), p. 365-372.

BOSTyN F., BEURION C., BILlaRd C., Guillon M., HACHEM L., HAMON C., LANCHON Y., PRAUD I., RECKINGER F., Ropars A., MUNAUT A.-V.

2003: Néolithique ancien en Haute-Normandie: le village Villeneuve-Saint-Germain de Poses "Sur la Mare" et les sites de la boucle du Vaudreuil, SPF (coll. Travaux, 4), 342 p.

\section{BOUILLON R.}

1989: «La sépulture mégalithique à entrée latérale du Petit Vieux-Sou à Brécé (Mayenne)", Revue archéologique de l'Ouest, 5, p. 51-70.

\section{BOUIN F., JOUSSAUME R.}

1998: «Le tumulus du Planti à Availles-surChizé (Deux-Sèvres) », in GUTHERZ X., JOUSSAUME R. (DIR.), Le Néolithique $d u$ centre-ouest de la France, Actes du XXI colloque interrégional sur le Néolithique, Poitiers, 14-16 oct. 1994, Chauvigny, Association des publications chauvinoises (coll. Mémoire, XIV), p. 169-182.

\section{Boujot C., Cassen S.}

1992: «Le développement des premières architectures funéraires monumentales en France occidentale ", in LEROUX C.-T. (DIR.), Paysans et bâtisseurs : l'émergence du Néolithique atlantique et les origines du mégalithisme, Actes du XVII colloque interrégional sur le Néolithique, Vannes, 29-31 oct. 1990, Rennes, (Suppl. à la Revue archéologique de l'Ouest, 5), p. 195-211.

\section{BOUJOT C., LORHO T.}

2005: "Champs de menhirs à Carnac (Morbihan) comme champs d'expérimentation d'approches spatiales: le recours au SIG ? ", in BERGER J.-F., BERTONCELLO F., BRAEMER F., DAVTIAN G., GAZENBEEK M. (DIR.), Temps et espaces de l'homme en société: analyses et modèles spatiaux en archéologie, Actes des $X X V^{e}$ rencontres internationales d'archéologie et d'histoire d'Antibes, 21-23 oct. 2004, Antibes, APDCA, p. 259-262.

\section{Boujot C., Pinet L.}

2007: «Mégalithes et pierres dressées, matériau du discours scientifique en Préhistoire: évolutions et perspectives d'après les exemples de Carnac (Bretagne) et du plateau de Cauria (Corse) ", in ÉvIN J. (DIR.), Un siècle de construction du discours scientifique en Préhistoire: des idées d'hier aux conceptions d'aujourd'hui, Actes du XXVI congrès préhistorique de France, congrès du centenaire de la SPF, Avignon, 21-25 sept. 2004, Paris, SPF, vol. 1, p. 185-197.

\section{Briard J., Gautier M., Leroux G.}

1995: Les Mégalithes et les tumulus de SaintJust (Ille-et-Vilaine), Paris, éd. du Comité des travaux historiques et scientifiques, $176 \mathrm{p}$.

\section{BRIARD J., GIOT P.-R}

1968: «Le tumulus de Tossen Kelern en Penvénan (Côtes d'Armor) ", L'Anthropologie, 72, p. 5-40

\section{BRIARD J., LANGOUËT L., ONNÉE Y.}

2004: Les Mégalithes du département d'Ille-etVilaine, Rennes, Institut culturel de Bretagne (coll. Patrimoine archéologique de Bretagne), 122 p.

BURL A.

1993: From Carnac to Callanish: the Prehistoric Stone Rows and Avenues of Britain, Ireland and Brittany, New-Haven/London, Yale University Press, 320 p.

BURneZ C., LOUboutin C., Kinnes I

2003: «Le tumulus du Cruchaud à SainteLheurine (Charente-Maritime): étude archéologique », BSPF, 100, 2, p. 293-314.

\section{Carozza L., Mille B.}

2007: «Chalcolithique et complexification sociale: quelle place pour le métal dans la définition du processus de mutation des sociétés de la fin du Néolithique 
en France ?", in GUILAINE J. (DIR.), Le Chalcolithique et la construction des inégalités -1- Le continent européen, Séminaire du Collège de France, Paris, Errance, p. 154189.

\section{CASSEN S.}

2005: «Pigeon-vole! Re-connaissance d'une gravure armoricaine du $V^{\mathrm{e}}$ millénaire», $B S P F, 102,2$, p. 299-334.

2007: «Le Mané Lud en images: interprétations de signes gravés sur les parois d'une tombe à couloir mégalithique (Locmariaquer, Morbihan) », Gallia Préhistoire, 49, p. 197-258.

2009: Exercice de stèle: une archéologie des pierres dressées, réflexion autour des menhirs de Car$n a c$, Paris, Errance, $160 \mathrm{p}$.

\section{CASSEN S. (DIR.)}

2000: Éléments d'architecture, exploration d'un tertre funéraire à Lannec er Gadouer (Erdeven, Morbihan), Chauvigny, Association des publications chauvinoises (coll. Mémoire, XIX), 813 p.

2009: Autour de la table: explorations archéologiques et discours savants sur des architectures néolithiques à Locmariaquer, Morbihan (Table des Marchands et Grand Menhir), Nantes, Laboratoire de recherches archéologiques LARA du CNRS/Université de Nantes, 915 p.

\section{Gassen S., Audren C., Hinguant S.,} LANNUZEL G., MARCHAND G.

1998: «L'habitat Villeneuve-Saint-Germain du Haut-Mée (Saint-Étienne-en-Coglès, Ille-et-Vilaine) », $B S P F, 95$, 1, p. 41-76.

\section{Cassen S., VaQuero J.}

2003: Les Marches du Palais: recherches archéologiques sur alignements de stèles et tertres funéraires néolithiques autour de la baie de Quiberon (Morbihan, 2000-2002), Nantes, Université de Nantes/Laboratoire de Préhistoire récente et Protohistoire de l'ouest de la France du CNRS, 166 p.

\section{CaUne N., Dolukhanov P.,}

\section{KOZLOWSKI J., VAN BERG P.-L.}

2007: Le Néolithique en Europe, Paris, Armand Colin, 382 p.

\section{CAZALIS DE FONDOUCE P.}

1873: Les Temps préhistoriques dans le sudest de la France: allées couvertes de Provence, Montpellier/Paris, C. Coulet/ A. Delahaye, vol. 1, 32 p.

1878: Les Temps préhistoriques dans le sudest de la France: allées couvertes de Provence, Montpellier/Paris, C. Coulet/ A. Delahaye, vol. 2, 64 p.
Chambon P.

2003: Les Morts dans les sépultures collectives néolithiques en France: du cadavre aux restes ultimes, Paris, CNRS Éditions (coll. Suppl. à Gallia Préhistoire, 35), 395 p.

2008: «Les rangements dans les sépultures collectives mégalithiques: une utopie archéologique?", in BROCHIER J.-E., GuilcherA., PAGNi M. (DIR.), Archéologies de Provence et d'ailleurs: mélanges offerts à Gaëtan Congès et Gérard Sauzade, Aix-enProvence, Association Provence archéologie (Suppl. au Bulletin archéologique de Provence, 5), p. 87-93.

\section{CHAMbON P., LECLERC J.}

2007: «Les tombes multiples dans le Néolithique français : aléa statistique ou pratique institutionnalisée », BSPF, 104, 2, p. 289-306.

2008a: "Les pratiques funéraires", in TARRÊTE J., LE ROUX C.-T. (DIR.), Le Néolithique, Paris, Picard (coll. Archéologie de la France), p. 308-324.

2008b: «Encore les tombes multiples néolithiques », $B S P F, 105,2$, p. 424-426.

\section{Chambon P., Salanova L.}

1996: «Chronologie des sépultures du III $^{\mathrm{e}}$ millénaire dans le bassin de la Seine », BSPF, 93, 1, p. 103-118.

\section{Chancerel A., Desloges J.}

1998: «Les sépultures pré-mégalithiques de Basse-Normandie», in GUILAINE J. (DIR.), Sépultures d'occident et genèses des mégalithismes (9000-3500 avant notre ère), Paris, Errance, p. 89-106.

\section{GHEVALIER Y.}

1984: L'Architecture des dolmens entre Languedoc et centre-ouest de la France, Bonn, Rudolf Habelt, 287 p.

\section{CHILde V.-G.}

1949: "The origin of Neolithic Culture in Northern Europe», Antiquity, 23, 91, p. 129-135.

\section{Claustre F.}

1998: «Monuments mégalithiques et grottes sépulcrales en Roussillon », in SOULIER P. (DIR.), La France des dolmens et des sépultures collectives (4500-2000 av. J.-C.): bilans documentaires régionaux, Paris, Errance, p. 159-174.

\section{Clottes J.}

1970: «Rapport général sur le mégalithisme méridional», in GUILAINE J. (DIR.), Les Civilisations néolithiques du midi de la France, Actes du colloque de Narbonne
15-17 févr. 1970, Carcassonne, Laboratoire de préhistoire et de palethnologie (coll. Atacina, 5), p. 65-68.

\section{Colas C., Baillieu M., NAZE Y.}

2008: «Un bâtiment monumental Cerny à Beaurieux-La Plaine (Aisne) », Internéo 7, p. 59-70.

\section{Colas C., Manolokakis L.,}

\section{THEVENET C. ET AL.}

2007: «Le monument funéraire Michelsberg ancien de Beaurieux-La Plaine (Aisne, France) ", in BESSE M. (DIR.), Sociétés néolithiques: des faits archéologiques aux fonctionnements socio-économiques, Actes du 270 colloque interrégional sur le Néolithique, Neuchâtel, 1-2 oct. 2005, Lausanne, Bibliothèque historique vaudoise (coll. Cahiers d'archéologie romande, 108), p. 329-334.

\section{Colomer A.}

1979: Les Grottes sépulcrales artificielles en Languedoc oriental, Toulouse, EHESS (coll. Archives d'écologie préhistorique), 117 p.

Costa L.-J.

2008: Mégalithismes insulaires en Méditerranée, Paris, Errance, 128 p.

\section{Costantini G.}

2002: «La vie quotidienne au temps des statues-menhirs», in PHILLIPON A. (DIR.), Statues-menhirs: des énigmes de pierres venues $d u$ fond des âges, Rodez, éd. du Rouergue, p. 114-145.

\section{Courtaud P., JANin T.}

1994: «La grotte sépulcrale chalcolithique du Rec d'Aigues Rouges à Saint-Pons-deThomières (Hérault) ", Gallia Préhistoire, 36, p. 329-356.

\section{CoURTIN J.}

1974: Le Néolithique de la Provence, Paris, Klincksieck (coll. Mémoires de la SPF, 11), $359 \mathrm{p}$.

\section{Courtin J., Sauzade G., Chabaud G.}

1988: «Le Dolmen de la Haute-Suane (Grimaud-Sainte-Maxime, Var) et la tombe circulaire en blocs de l'Amourié (Grimaud) », BSPF, 85, 5, p. 148-160.

Cros J.P., Garnotel A., Jallot L.

2010: «Des morts dans les structures de stockage : exemple dans la plaine montpelliéraine », in BARAY L., BOULESTIN B. (DIR.), Morts anormaux et sépultures bizarres: les dépôts en fosses circulaires et en silos du Néolithique à l'âge du Fer, Actes de 
la $I I^{e}$ table ronde interdisciplinaire, Sens, 29 mars- $1^{\text {er }}$ avr. 2006, Dijon, éd. universitaires de Dijon, p. 69-96.

Crubézy É., POUJOL J., Ludes J.-B. (DIR.) 2004: Pratiques et espaces funéraires: les Grands Causses au Chalcolithique, Lattes, ADALR (coll. Monographie d'archéologie méditerranéenne, 17), $162 \mathrm{p}$.

DAIRE M.-Y.

2005: Les Stèles de l'âge du Fer dans l'ouest de la Gaule: réflexions sur le monde des morts et le monde des vivants, CeRAA (coll. Dossiers du CeRAA, AB), 172 p.

D'ANNA A.

1977: Les Statues-menhirs et stèles anthropomorphes du midi de la France, Paris, éd. du CNRS, 277 p.

D'Anna A., RENAult S., GUENDON J.-L., MASE J.-P., INET L., WALTER P.

2004: Stèles anthropomorphes néolithiques de Provence, Catalogue, Musée Calvet d'Avignon, Avignon, Musée Calvet, 96 p.

DANIEL G.

1960: The Prehistoric Chamber Tombs of France, London, Thames and Hudson, 282 p.

\section{DEDET B.}

1982: «La réutilisation des sépultures mégalithiques des garrigues de l'Hérault à la fin du Bronze final et du premier âge du Fer », Revue archéologique de la Narbonnaise, 15 , p. $1-17$

DEgUillouX M.-F., SOlER L.,

PEMONGE M.-H., SCARRE C., JOUSSAUME R., LAPORTE L.

2010: «News from the West: Ancien DNA from a French Megalithic Burial Chamber", American Journal of Physical Anthropology, 44, 1, p. 108-118.

\section{DEHN T., HANSEN S}

2006: «Architecture mégalithique en Scandinavie ", in JOUSSAUME R., LAPORTE L., SCARRE C. (DIR.), Origine et développement du mégalithisme de l'ouest de l'Europe, Actes du colloque international de Bougon, 26-30 oct. 2002, Bougon, Musée des Tumulus de Bougon, p. 39-62.

Delattre W. avec la collab. de BULARD A., Gouge A., Pihuit P.

2000: «De la relégation sociale à l'hypothèse des offrandes: l'exemple des dépôts en silos protohistoriques au confluent SeineYonne (Seine-et-Marne)", Revue archéologique du Centre de la France, 39, p. 5-30.
DEMOULE J.-P. (DIR.)

2007: La Révolution néolithique en France, Paris, éd. La Découverte, $180 \mathrm{p}$

\section{DeSCHAMPS N., GUY H., MASSET C.} VALENTIN F.

1996: «Hiérarchie sociale et architecture funéraire au III $^{\mathrm{e}}$ millénaire d'après des séries anthropologiques du Bassin parisien ", BSPF, 93, 3, p. 403-407.

\section{DESLOGES J.}

1997: «Les premières architectures funéraires de Basse-Normandie ", in CONSTANTIN C. MORDANT D., SIMONIN D. (DIR.), La Culture de Cerny: nouvelle économie, nouvelle société au Néolithique, Actes du colloque international de Nemours, 9-11 mai 1994, APRAIF (coll. Mémoires du musée de Préhistoire d'île-de-France, 6), p. 515-539.

\section{DEVRIENDT W.}

2004: «Les hypogées vauclusiens : vers une meilleure connaissance des populations du Néolithique final", in BUISSONCatil J., Guilcher A., Hussy C. Olive M., PAGNI M. (DIR.), Vaucluse préhistorique: le territoire, les hommes, les cultures et les sites, Le Pontet, éd. Barthélémy, DRAC de Provence-Alpes-Côte d'Azur, p. 245-247.

\section{DRON J.-L., LE GOFF I., LEPAUMIER H.}

ET AL.

2003: «Le fonctionnement des tombes à couloir de Basse-Normandie", in Chambon P., LEClerC J. (DIR.), Les Pratiques funéraires néolithiques avant 3500 av. J.-C. en France et dans les régions limitrophes, Paris, SPF (coll. Mémoires de la SPF, 33), p. 259-286.

\section{DUDAY H.}

1987: «Organisation et fonctionnement d'une sépulture collective, l'aven de la Boucle à Corconne (Gard)", in MASSET C., DUDAY H. (DIR.), Anthropologie physique et archéologie, Paris, éd. du CNRS, p. 89-104.

2003: «De la réflexion anthropologique à l'archéologie funéraire, ou l'approche globalisante d'une sépulture collective: le dolmen des Peirières à Villedubert (Aude, France)", in Pirineus $i$ Veïns al 3r Milleni AC. De la fin del neolitic a l'edat del bronze entre l'Ebre i la Garona, Homenatge al prof. Dr. Domènec Campillo, XII Col.loqui Internacional d'Arqueologia de Puigcerdà, 10-12 nov. 2000, Puigcerdà, Insitut d'Estudis Ceretans, $751 \mathrm{p}$.

2005: Lezioni di archeotanatologia, archeologia funeraria $e$ antropologia di campo, Rome, Arti grafiche Mengarelli, $230 \mathrm{p}$
Duday H., Courtaud P.

1998: «La nécropole mésolithique de La Vergne (Charente-Maritime)", in GUILAINE J. (DIR.), Sépultures d'Occident et genèses des mégalithismes (9000-3500 avant notre ère), Paris, Errance, p. 27-37.

\section{DUHAMEL P.}

1997: «La nécropole monumentale Cerny de Passy (Yonne): description d'ensemble et problèmes d'interprétation", in CONSTANTIN C., MORdanT D., SIMONIN D., (DIR.) : La Culture de Cerny: nouvelle économie, nouvelle société au Néolithique, Actes du colloque international de Nemours, 9-11 mai 1994, APRAIF (coll. Mémoires du musée de Préhistoire d'Îlede-France, 6), p. 397-448.

\section{DUPONT C.}

2006: La Malacofaune de sites mésolithiques et néolithiques de la façade atlantique de la France: contribution à l'économie et à l'identité culturelle des groupes concernés, Oxford, Archaeopress (coll. BAR International Series, 1571), 439 p

ENRIQUEZ J.-J., CARASCO M.-J.

2000: «Sobre los dolmenes de corredor corto de Valencia de Alcantara», Revista Cultural do Concelho de Marvão (coll. Ibn Maruan, 9-10), p. 271-301.

FAGÈS G.

1977: «Consolidation du dolmen de Gouziac, Drigas, commune de Hures-la-Parade", in Fagès G., Hugues C., Marolle C. (DIR.), Cinq années de recherches archéologiques sur le Causse Méjan et ses abords immédiats 1969-1974, Travaux du Dépôt de fouilles préhistoriques d'Anilhac, Aurillac, Parc national des Cévennes, p. 70-75.

1983: «Le tumulus de Dignas, commune de Sainte-Énimie (Lozère)», Bulletin de la Société des lettres, sciences et arts de la Lozère, 1, p. $5-25$

FAGÈS G., ROUDIL J.-L. (DIR.)

1979: Les Causses au temps des premiers hommes, Aurillac, Parc national des Cévennes, $101 \mathrm{p}$.

FeUSTEL R., ULLRICH H.

1965: «Totenhütten der neolithischen Walternienburger Gruppe », Alt-Thüringen, 7, p. 105-202.

GALLAY A.

2006: Les Sociétés mégalithiques: pouvoir des hommes, mémoire des morts, Genève, Presses polytechniques et universitaires romandes (coll. Le savoir suisse, 37), 139 p. 
GATTO E. avec la collab. de GISCLON J.-L. 2007: «La gestion de l'espace sépulcral dans les coffres de Genevray (Thononles-Bains, Haute-Savoie, France) », in MOINAT P., CHAMBON P. (DIR.), Les Cistes de Chamblandes et la place des coffres dans les pratiques funéraires du Néolithique moyen occidental, Actes du colloque de Lausanne, 12-13 mai 2006, Paris/Lausanne, SPF (coll. Mémoires de la SPF, 43)/Bibliothèque historique vaudoise (coll. Cahiers d'archéologie romande, 110), p. 177-194.

GIOT P.-R.

1959: «Une station du Néolithique primaire armoricain : le Curnic en Guisseny (Finistère) ", $B S P F, 56,5-6$, p. 292-293.

1983: «Chronique de Préhistoire et de Protohistoire finistériennes ", Bulletin de la Société archéologique du Finistère, CXII, p. 11-16.

1987: Barnenez, Carn, Guennoc, Rennes, Équipe de recherche $n^{\circ} 27$ du CNRS/ Université de Rennes-I (coll. Travaux du Laboratoire anthropologie, préhistoire, protohistoire, quaternaire armoricains), $232 \mathrm{p}$.

1990: «Petit lexique du mégalithisme: vingt ans après », in GUILAINE J., GUTHERZ X. (DIR.), Autour de Jean Arnal: recherches sur les premières communautés paysannes en méditerranée occidentale, Montpellier, Laboratoire de paléobotanique de l'université des sciences et techniques du Languedoc de Montpellier-II, p. 251-255.

\section{GIOT P.-R., MONNIER J.-L.,}

\section{L'HELGOUACH J.}

1998: Préhistoire de la Bretagne, Rennes, OuestFrance, $580 \mathrm{p}$

\section{GIOT P.-R., MORZADEC $\mathbf{H}$}

1992: «Des dolmens à couloir au péril des mers actuelles", Revue archéologique de l'Ouest, 9, p. 57-66.

\section{GOMEZ DE SOTO J.}

1998: "La nécropole de la Boixe à Vervant, Maine-de-Boixe, Cellettes (Charente) : nouvelles recherches sur le monument $\mathrm{C}$ », in GUTHERZ X., JOUSSAUME R. (DIR.), Le Néolithique du centre-ouest de la France, Actes du XXI colloque interrégional sur le Néolithique, Poitiers, 14-16 oct. 1994, Chauvigny, Association des publications chauvinoises (coll. Mémoire, XIV), p. 183-191

\section{GoUÉzIN P.}

2007: Les Mégalithes du Morbihan littoral (au sud des Landes de Lanvaux, de Guidel à Quiberon), Rennes, CeRAA/Institut culturel de Bretagne, $135 \mathrm{p}$.
GRUAT P., HÉROUIN S., MARTY G., RAKOTONDRAMASY T.

2004: «Le tumulus 26 du Devèzes de Maymac (Bertholène, Aveyron) ", in CRUBÉZY E. Ludes B., POUjOls J. (DIR.), Pratiques et espaces funéraires: les Grands Causses au Chalcolithique, Lattes, ADALR (coll. Monographie d'archéologie méditerranéenne, 17), p. 126-137.

GRUAT P. avec la collab. de VERNHET A. 2006: «Contribution à la connaissance des tumulus non mégalithiques de la Préhistoire récente des Causses de l'Aveyron », in GASCO J., LEYGE F., GRUAT P. (DIR.), Hommes et passé des Causses: hommage à Georges Costantini, Actes du colloque de Millau, 16-18 juin 2005, Toulouse, EHESS (coll. Archives d'écologie préhistorique), p. 395-413.

\section{Gruet M., LE RouX C.-T.}

2005: Mégalithes en Anjou, Inventaire mégalithique, Cheminements, $421 \mathrm{p}$.

\section{GUILAINE J.}

1994: La Mer partagée: la Méditerranée avant l'écriture 7000-2000 av. J.-C., Paris, Hachette, $450 \mathrm{p}$.

1998: Au temps des dolmens: mégalithes et vie quotidienne en France méditerranéenne il y a 5000 ans, Toulouse, Privat, $167 \mathrm{p}$.

2000: Au temps des dolmens: la France méridionale au temps des mégalithes, Toulouse, Privat, $160 \mathrm{p}$.

2003: De la vague à la tombe: la conquête néolithique de la Méditerranée, Paris, Le Seuil, $375 \mathrm{p}$.

2006: «Le phénomène dolménique en Méditerranée nord-occidentale», in JOUsSAUME R., LAPORTE L., SCARRE C. (DIR.), Origine et développement du mégalithisme de l'ouest de l'Europe, Actes du colloque international de Bougon, 26-30 oct. 2002, Bougon, Musée des tumulus de Bougon, p. 253-282.

GUILAINE J. avec la collab. de DUDAY H., LAVERGNE J.

1972: La Nécropole mégalithique de la Clape (commune de Laroque-de-Fa, Aude), Carcassonne, Laboratoire de préhistoire et de palethnologie (coll. Atacina, 7), $184 \mathrm{p}$.

\section{Guilaine C., Guilaine J.}

1998: «Les dolmens de l'Aude », in SOULIER P. (DIR.), La France des dolmens et des sépultures collectives (4500-2000 av. J.-C.): bilans documentaires régionaux, Paris, Errance, p. $175-194$
GUILlOT H., BILLAND G., LE GOFF I.

1996: «Les éléments en bois du monument funéraire du Prieuré à Lacroix-SaintOuen (Oise) », BSPF, 93, 3, p. 408-412.

\section{GUTHERZ X}

1998: «Les dolmens en LanguedocRoussillon: introduction ", in SOULIER P. (DIR.), La France des dolmens et des sépultures collectives (4500-2000 av. J.-C.): bilans documentaires régionaux, Paris, Errance, p. 131-133.

\section{GUTHERZ X., JALLOT L.}

1987: «Statue-menhir et habitat du Néolithique final à Montaïon (Sanilhacet-Sagriès, Gard) ", in Actes des Journées d'étude des statues-menhirs, Saint-Pons-deThomières, 5-6 mai 1984, Saint-Pons-deThomières, Fédération des associations et usagers du Parc naturel régional du Haut-Languedoc, p. 15-36.

GUTHERZ X., JALLOT L., GARNIER N.

1998: «Le monument de Courion (Collias, Gard) et les statues-menhirs de l'Uzège méridionale", in Actes du $2^{e}$ colloque international sur la statuaire mégalithique, SaintPons-de-Thomières, 10-14 sept. 1997, Lattes, Fédération archéologique de l'Hérault (coll. Archéologie en Languedoc, 22), p. 119-134.

\section{HAMON G.}

2003: Les Productions céramiques au Néolithique ancien et moyen dans le nord-ouest de la France, Thèse de Doctorat, Université de Rennes-I, 329 p.

Hasler A., Chevillot P., Collet H., DURAND C., RENAUlt S., Richier A.

1998 : «La nécropole tumulaire néolithique de Château-Blanc (Ventabren, Hérault) ", in D'ANNA A., BINDER D. (DIR.), Production et identité culturelle: actualité de la recherche, Actes des II rencontres méridionales de Préhistoire récente, Arles, 8-9 nov. 1996, Antibes, APDCA, p. 403-414.

hasler A., Collet H., Durand C., Chevillot P., Renault S., Richier A.

2002: «Ventabren-Château Blanc: une nécropole tumulaire néolithique», in GUTHERZ X. (DIR.), Archéologie du TGV Méditerranée, fiches de synthèse -1- La Préhistoire, Lattes, ARALO (coll. Monographies d'archéologie méditerranéenne, 8), p. 227-238.

\section{HASLER A., NORET C.}

2006: «Habitats et structures funéraires néolithiques sur le tracé du cadereau d'Alès à Nîmes (Gard) ", in FOUÉRÉ P., 
Chevillot C., Courtaud P., Ferullo O., Leroyer C. (DIR.), Paysages et peuplement: aspects culturels et chronologiques en France méridionale, Actes des $V I^{2}$ rencontres méridionales de Préhistoire récente, Périgueux, 14-16 oct. 2004, Périgueux, ADRAHP (coll. Suppl. à Préhistoire du Sud-Ouest, 11), p. 171-190.

\section{HeRbault F.}

2001: La Parure néolithique dans l'ouest de la France, Thèse de Doctorat, Université de Nantes, $270 \mathrm{p}$.

\section{HINGUANT S., BOUJOT C.}

2010: «Les pierres couchées de Beltz (Morbihan) ou la découverte d'un ensemble mégalithique", in DEMOULE J.-P. (DIR.), La Révolution néolithique dans le monde, Paris, CNRS Éditions, p. 383-398.

\section{HUGUES C., LORBLANCHET M.}

1963: "Contribution à l'étude de la Préhistoire du causse Méjean central et oriental», Revue du Gévaudan, 9, p. 5-35.

\section{JALLOT L.}

2007: «Les sociétés néolithiques», in Demoule J.-P. (DIR.), La Révolution néolithique en France, Paris, éd. La Découverte, p. 28-41

\section{JALlot L., D'ANNA A.}

1990: «Statues-menhirs et stèles anthropomorphes: état de la question et perspectives », in GUILAINE J., GUTHERZ X. (DIR.), Autour de Jean Arnal: recherches sur les premières communautés paysannes en Méditerranée occidentale, Montpellier, Laboratoire de paléobotanique de l'université des sciences et techniques du Languedoc de Montpellier-II, p. 359384.

\section{JALLOT L., SÉNÉPART I.}

2008: «Haches-marteaux et statues-menhirs dans le sud de la France: de l'objet à la représentation", in BROCHIER J.-E., Guilcher A., PAGNi M. (DIR.), Archéologie de Provence et d'ailleurs: mélanges offerts à Gaëtan Congès et Gérard Sauzade, Aix-enProvence, Association Provence archéologie (Suppl. au Bulletin archéologique de Provence, 5), p. 215-255.

\section{JANIN T.}

2001: «Sépultures, nécropoles, archéologie funéraire et sociétés de l'âge du Bronze dans le sud-ouest de la France: résultats récents, programmes et tendances», Documents d'archéologie méridionale, 24, p. 230-237.

\section{JAUBERT J., LEDUC M.}

1998: «Les sépultures mégalithiques en Midi-Pyrénées: potentiel et tendances actuelles de la recherche», in SOULIER P. (DIR.), La France des dolmens et des sépultures collectives (4500-2000 av. J.-C.): bilans documentaires régionaux, Paris, Errance, p. $197-198$.

\section{JOUSSAUME R.}

1977: «Le mégalithe de la Pierre-Virante à Xanton-Chassenon (Vendée): étude archéologique ", L'Anthropologie, 81, 1 p. 5-62.

1981: Le Néolithique de l'Aunis et du Poitou occidental dans son cadre atlantique, Rennes, Équipe de recherche $\mathrm{n}^{\mathrm{o}} 27 \mathrm{du}$ CNRS/ Université de Rennes-I (coll. Travaux du Laboratoire anthropologie, préhistoire, protohistoire, quaternaire armoricains), $625 \mathrm{p}$.

1985: Des dolmens pour les morts: les mégalithismes à travers le monde, Paris, Hachette, $398 \mathrm{p}$.

1997: «Les longs tumulus du centre-ouest de la France», in RODRIGUEZ CASAL A. (DIR.), O Neolitico e as orixes do megalithismo, Actes du colloque de Saint-Jacques de Compostelle, avril 1996, Santiago de Compostela, Consello da Cultura Gallega, p. 279-298.

2003a: Les Charpentiers de la pierre: monuments mégalithiques dans le monde, Paris, éd. La Maison des Roches, 126 p.

2003b: «Du réaménagement des monuments funéraires néolithiques dans le centreouest de la France", in Sens dessus dessous, la recherche du sens en Préhistoire: recueil d'études offert à Jean Leclerc et Claude Masset, numéro spécial de la Revue archéologique de Picardie, 21, p. 157-172.

2008: “L'habitat des morts dans l'Ouest et le Nord», in TARRÊTE J., LE ROUX C.-T. (DIR.), Le Néolithique, Paris, Picard (coll. Archéologie de la France), p. 325-335.

\section{JOUSSAUME R. (DIR.)}

1990: Mégalithisme et société, Table ronde CNRS des Sables-d'Olonne (Vendée), 2-4 novembre 1987, La Roche-sur-Yon, Groupe vendéen d'études préhistoriques, 235 p.

1999: «Le tumulus du Pey de Fontaine au Bernard (Vendée) ", Gallia Préhistoire, 41, p. $167-222$.

Joussaume R., Cadot R., Gilbert J.-M. 2006: Les Tumulus de Champ-Châlon à Benon (Charente-Maritime), La Roche-sur-Yon, Groupe vendéen d'études préhistoriques, $42,90 \mathrm{p}$.
Joussaume R., Crédot R., GiRaud C. 2008: «Le dolmen des Goudours à Folles (Haute-Vienne) et les dolmens à chambre axiale allongée dans le centre-ouest de la France", Préhistoire du Sud-Ouest, 16, p. 3-54.

Joussaume R., Fouéré P., CRÉdot R. avec la collab. de ROGER J.

2002: "Dolmens des quatre routes et de Bois Neuf III à Marsac (Creuse) ", BSPF, 99, 1, p. $49-80$.

JOUSSAUME R., LAPORTE L.,

2006: «Monuments funéraires néolithiques dans l'ouest de la France», in JOUSSAUME R., LAPORTE L., SCARRE C. (DIR.), Origine et développement du mégalithisme de l'ouest de l'Europe, Actes du colloque international de Bougon, 26-30 oct. 2002, Bougon, Musée des tumulus de Bougon, p. 319-344.

Joussaume R., Laporte L., SGarre C.

1998: «Longs tumulus néolithiques et organisation de l'espace dans l'ouest de la France", Anthropologie et Préhistoire, 109, p. $259-275$.

JOUSSAUME R., LAPORTE L., SCARRE C. (DIR.)

2006: Origine et développement du mégalithisme de l'ouest de l'Europe, Actes du colloque international de Bougon, 26-30 oct. 2002, Bougon, Musée des tumulus de Bougon, $830 \mathrm{p}$.

\section{JOUSSAUME R., RAUX P.}

2006: «Sculpture serpentiforme sur le menhir de la Bretellière à Saint-Macaire-enMauges (Maine-et-Loire, France)", in JOUSSAUME R., LAPORTE L., SCARRE C. (DIR.), Origine et développement du mégalithisme de l'ouest de l'Europe, Actes du colloque international de Bougon, 26-30 oct. 2002, Bougon, Musée des tumulus de Bougon, p. 727-731.

\section{LABRIFFE P.A. DE}

2000: "Villedubert, Les Peirières", BSR Languedoc-Roussillon 1999, SRA Languedoc-Roussillon, Paris, Ministère de la Culture et de la Communication, p. 57-58.

\section{LAGASQUIE J.-P.}

1996: Dolmens et tumulus du Quercy: premières architectures, Martel, éd. Laquet, 11 p.

LAGASQUie J.-P., BARREAU D., Rocher A. 1996: «Le dolmen de la Devèze-sud à Marcilhac-sur-Célé (Lot): approche 
méthodologique et résultats de la fouille », BSPF, 93, 3, p. 425-433.

2006: «Le dolmen des Aguals ou de la Combe de l'ours: communes de GréalouMontbrun (Lot, France) ", in JOUSSAUME R., LAPORTE L., SCARRE C. (DIR.), Origine et développement du mégalithisme de l'ouest de l'Europe, Actes du colloque international de Bougon, 26-30 oct. 2002, Bougon, Musée des tumulus de Bougon, p. 293-303.

\section{LANFRANCHI F. DE}

2000: Le Secret des mégalithes, Aiacciu, Albania, $164 \mathrm{p}$.

\section{LANGOUËT L.}

2004: Les Mégalithes de l'arrondissement de Dinan, Rennes, PAR/Institut culturel de Bretagne, $62 \mathrm{p}$.

2005: Les Mégalithes de l'arrondissement de Saint-Brieuc, Rennes, PAR/Institut culturel de Bretagne, $89 \mathrm{p}$.

2006: Les Mégalithes de l'arrondissement de Guingamp, Rennes, PAR/Institut culturel de Bretagne, 92 p.

\section{LANGRY-FRANCOIS F.}

2004: «Le mobilier lithique des sépultures en hypogée du département de la Marne», in VANDER LINDEN M., SALANOVA L. (DIR.), Le Troisième Millénaire dans le nord de la France et en Belgique, Paris/Bruxelles, SPF (coll. Mémoires de la SPF, 35)/ Société royale belge d'anthropologie et de Préhistoire (coll. Anthropologica et Praehistorica, 1155), p. 91-102.

\section{LAPORTE L.}

2005: "Néolithisation de la façade atlantique du centre-ouest de la France", in MARChAND G., TRESSET A. (DIR.), Unité et diversité des processus de néolithisation sur la façade atlantique de l'Europe (VI'-IVe millénaires av.J.-C.), Paris, SPF (coll. Mémoires de la SPF, 36), p. 99-125.

2009: «La parure néolithique dans le centreouest de la France: approches stylistiques, technologiques et fonctionnelles du mobilier", in LAPORTE L. (DIR.), Des premiers paysans aux premiers métallurgistes sur la façade atlantique de la France (35002000 av. J.-C.), Chauvigny, Association des publications chauvinoises (coll. Mémoire, XXXIII), p. 455-469.

2010a: «Restauration, reconstruction, appropriation: évolution des architectures mégalithiques dans l'ouest de la France, entre passé et présent", Munibe, Suppl. $\mathrm{n}^{\circ} \mathrm{XX}, \mathrm{p} .15-46$

2010b: "Innate and/or Expressed Identities: their Conceptualization trough Monu- mentality, Funerary Practices and Grave Goods: Some Examples from the Megalithic Tradition of Western France", en ligne sur: http://www.jungsteinsite.de/

À paraître a: «Dépôts de mobilier, architectures et pratiques funéraires dans le centre-ouest de la France au cours du Néolithique récent et final dans son contexte atlantique", in SOHN M., VAQUER J. (DIR.), La Fin du Néolithique en Europe de l'Ouest: valeurs sociales et identitaires des dotations funéraires (3500-2000 av. J.-C.), Actes du colloque de Carcassonne, 26-28 sept. 2008, Paris, EHESS.

À paraître b: «Les carrières fournissant le petit appareil employé dans la construction des masses tumulaires: mégalithismes de l'ouest de la France, projets architecturaux, stratégies d'approvisionnement et techniques mises en œuvre pour l'extraction", in MENS E., GUYODO J.-N. (DIR.), Technologie des premières architectures en pierre en Europe occidentale $d u V^{e}$ au II $I^{e}$ millénaire av. J.-C, Actes du colloque de Nantes, 2-4 oct. 2008, Rennes, Presses Universitaires de Rennes.

\section{Laporte L., CAemerlynck C.,}

FLORSCH N., LEVÊQUE F., NÉRAUdEAU D., OBERLIN C. avec la collab. de QUESNEL L.

2009: «Occupations préhistoriques et variation des lignes de rivage: l'exemple des marais charentais» in LAPORTE L. (DIR.), Des premiers paysans aux premiers métallurgistes sur la façade atlantique de la France (3500-2000 av. J.-C.), Chauvigny, Association des publications chauvinoises (coll. Mémoire, XXXIII), p. 16-28.

\section{LAPORTE L., GOMEZ J.}

2001: «Lamérac et Germignac: perles et anneaux-disques dans le centre-ouest de la France », Revue archéologique de l'Ouest, 18 , p. 13-26.

LAPORTE L., GUYODO J.-N., BIZIEN-JAGLIN C., BERNARD V., BERTIN F., BLANCHET S., DIETCH-SELLAMI M.-F., GUITTON V., HAMON A.-L., HAMON G., LEMOULAND Q., LUCQUIN A., NOSLIER A., QUESNEL L.

2007: «Nouvelles découvertes en milieu humide autour de l'habitat ceinturé du Néolithique moyen à Lillemer (Ille-etVilaine, France)», in BESSE M. (DIR.), Sociétés néolithiques: des faits archéologiques aux fonctionnements socio-économiques, Actes $d u 27^{e}$ colloque interrégional sur le Néolithique, Neuchâtel, 1-2 oct. 2005, Lausanne, Bibliothèque historique vaudoise (coll. Cahiers d'archéologie romande, 108), p. 341-351.
LAPORTE L., JOUSSAUME R., SCARRE C.

2001: «Megalithic Monuments of westcentral France in their Relationship to the Landscape", in SCARRE C. (DIR.) : Monumentality and Landscape in Atlantic Europe, Londres, Routledge, p. 73-83.

2002: «Le tumulus C de Péré à Prissé-laCharrière (79) : état des recherches après 6 années d'intervention", Gallia Préhistoire, 44, p. 167-214

\section{LAPORTE L., LE ROUX C.-T.}

2004: Bâtisseurs du Néolithique: mégalithisme de la France de l'Ouest, Paris, éd. La Maison des Roches (coll. Terres mégalithiques), $126 \mathrm{p}$

\section{LAPORTE L., MARCHAND G.}

avec la collab. de QUESNEL $L$.

2004: «Une structure d'habitat circulaire dans le Néolithique ancien du centreouest de la France », $B S P F, 101,1$, p. 55-73.

\section{LAPORTE L., TINEVEZ J.-Y.}

2004: «Neolithic Houses and Chambered Tombs of Western France", Cambridge Archaeological Journal, 14, p. 217-234.

LARGE J.-M., MENS E.

2008: "L'alignement du Douet à Hoëdic (Morbihan, France)", L'Anthropologie, $112,4-5$, p. 544-571.

LÉANDRI F., GILABERT C., DEMOUCHE F. 2007: «Les chambres funéraires des Ve et IV $^{e}$ millénaires av. J.-C.: le cas de la Corse", in MOINAT P., CHAMBON P. (DIR.), Les Cistes de Chamblandes et la place des coffres dans les pratiques funéraires $d u$ Néolithique moyen occidental, Actes du colloque de Lausanne, 12-13 mai 2006, Paris/ Lausanne, SPF (coll. Mémoires de la SPF, 43)/Bibliothèque historique vaudoise (coll. Cahiers d'archéologie romande, $110)$, p. 41-60.

\section{LECLERC J.}

1987: «Procédures de condamnation dans les sépultures collectives Seine-OiseMarne ", in DUDAY H., MASSET C. (DIR.), Anthropologie physique et archéologie: méthodes d'étude des sépultures, Paris, éd. du CNRS, p. 76-88.

1999: «Un phénomène associé au mégalithisme: les sépultures collectives», in Guilaine J. (DIR.), Mégalithismes de l'Atlantique à l'Éthiopie, Paris, Errance, p. $23-40$

\section{LECLERC J., MASSET C.}

2006: "L'évolution de la pratique funéraire dans la sépulture collective néolithique 
de la Chaussée-Tirancourt (Somme)", $B S P F, 103,1$, p. 87-116.

\section{LECLERC J., TARRÊTE J.}

2006: «Du Bassin parisien à la Suisse», in JOUSSAUME R., LAPORTE L., SCARRE C. (DIR.), Origine et développement du mégalithisme de l'ouest de l'Europe, Actes du colloque international de Bougon, 26-30 oct. 2002, Bougon, Musée des tumulus de Bougon, p. 381-406.

\section{LECORNEC J.}

1994: Le Petit Mont: Arzon, Morbihan, Rennes, Documents archéologiques de l'Ouest, $109 \mathrm{p}$.

1996: "L'allée couverte de Bilgroix à Arzon, Morbihan", Bulletin de la Société polymathique du Morbihan, 122, p. 15-64.

\section{LEDUC $M$.}

1998: «Les grottes utilisées comme lieu sépulcral en Midi-Pyrénées au cours du III ${ }^{\mathrm{e}}$ millénaire », in SOULIER P. (DIR.), $L a$ France des dolmens et des sépultures collectives (4500-2000 av. J.-C.): bilans documentaires régionaux, Paris, Errance, p. 198-216.

\section{LE GOFFIC M.}

2006: «La nécropole mégalithique du Souc'h en Plouhinec", in Journée de civilisations atlantiques et archéosciences, Rennes, 9 mars 2002, Rennes, Université de Rennes-I/ UMR 6566 du CNRS, p. 24-25.

\section{LEPAUMIER H., MARCIGNY C.,}

Clément-Sauleau S., GHeSQuière E.

2007: «Histoire et déboires d'un mégalithe: l'exemple du monument de la Hogue à Fontenay-le-Marmion (Calvados)", in ÉVIN J. (DIR.), Un siècle de construction $d u$ discours scientifique en Préhistoire: des idées d'hier aux conceptions d'aujourd'hui, Actes du XXVI congrès préhistorique de France, congrès du centenaire de la SPF, Avignon, 21-25 sept. 2004, Paris, SPF, vol. 2, p. 249264.

\section{LE QUELLEC J.-L.}

2006: "L'art mégalithique en France», in Joussaume R., Laporte L., SCARRE C. (DIR.), Origine et développement du mégalithisme de l'ouest de l'Europe, Actes du colloque international de Bougon, 26-30 oct. 2002, Bougon, Musée des tumulus de Bougon, p. 687-717.

\section{LEROI-GOURHAN A., BAILLOUD G.,} BRÉZILLON M.

1962: «L'hypogée II des Mournouards (Mesnil-sur-Oger, Marne)», Gallia Préhistoire, 5, 1, p. 23-134.

\section{LE ROUX C.-T.}

1985: «New Excavations at Gavrinis", Antiquity, 59, p. 183-187.

1997: «Aspects non funéraires du mégalithisme armoricain", in RODRIGUEZ CASAl A. (DIR.), O Neolitico $e$ as orixes do megalithismo, Actes du colloque de SaintJacques de Compostelle, avril 1996, Santiago de Compostela, Consello da Cultura Gallega, p. 233-244.

LE ROUX C.-T. (DIR.)

2006: Monuments mégalithiques à Locmariaquer (Morbihan): le long tumulus d'Er Grah dans son environnement, Paris, CNRS Éditions (coll. Suppl. à Gallia Préhistoire, 38), 308 p.

LEROY D., LECGUVRE J.-M. avec la collab. de Creusillet M.-F., Irribaria R.

2006: «Une maison dans le Chambon: le site du clos des gués à Pezou (Loir-et-Cher), résultats préliminaires», in DUHAMEL P. (DIR.), Impacts interculturels au Néolithique moyen: du terroir au territoire, sociétés et espaces, Actes du $25^{e}$ colloque interrégional sur le Néolithique, Dijon, 20-21 oct. 2001 (Suppl. à la Revue archéologique de l'Est, 25), p. 303-317.

\section{LE ROUZIC Z}

1927: «Dépôts rituels de haches en pierre polie découverts dans la région de Carnac », BSPF, 24, 5, p. 156-160.

1932: Tumulus du Mont St-Michel, Vannes, Imprimerie Lafolye \& J. de Lamarzelle (coll. Carnac: fouilles faites dans la région), $50 \mathrm{p}$.

\section{L'HELGOUACH J.}

1962: «Le dolmen de Conguel en Quiberon (Morbihan) », BSPF, 49, 5-6, p. 371-381.

1964: Les Sépultures mégalithiques en Armorique, Thèse de Doctorat, Université de Rennes-I, 329 p.

1983: «Des idoles qu'on abat... (ou les vissicitudes des grandes stèles de Locmariaquer)», Bulletin de la société polymathique du Morbihan, 110, p. 57-68.

1995 : «Les manifestations artistiques», in MASset C., SOUlier P. (DIR.), Allées couvertes et autres monuments funéraires $d u$ Néolithique dans la France du Nord-Ouest. allées sans retour, Paris, Errance, p. 83-95.

1997: «Les premiers monuments mégalithiques de l'ouest de la France", in RODRIGUEz CASAL A. (DIR.), O Neolitico $e$ as orixes do megalithismo, Actes du colloque de Saint-Jacques de Compostelle, avril 1996, Santiago de Compostela, Consello da Cultura Gallega, p. 191-210.

\section{L'Helgouach J., Le RouX C.-T.,} LECORNEC J.

1997: Arts et symboles du mégalithisme européen

(Suppl. à la Revue archéologique de l'Ouest, 8), $248 \mathrm{p}$.

\section{LHOMME G.}

1971: «Deux campagnes de fouilles dans un dolmen de Berrias (Ardèche)", Études préhistoriques, 1, p. 9-23.

1974: «Le dolmen $\mathrm{n}^{\circ} 17$ des Granges à Berrias (Ardèche) ", Études préhistoriques, 8, p. 1-12.

\section{LOISON G.}

1998: «La nécropole de Pontcharraud en Basse Auvergne», in GUILAINE J. (DIR.), Sépultures d'occident et genèses des mégalithismes (9000-3500 avant notre ère), Paris, Errance, p. 189-206.

\section{LOISON G., SCHMITT A.}

2009: «Diversité des pratiques funéraires et espaces sépulcraux sectorisés au Chasséen ancien sur le site de Crès à Béziers (Hérault) : croisement de données archéologiques et anthropologiques", Gallia Préhistoire, 51, p. 245-272.

\section{LOPEZ ROMERo E., DE LA ALEJA G.}

2008: "Monuments néolithiques de la région de Lorient (Morbihan, Bretagne): à propos des modes d'organisation des territoires ", L'Anthropologie, 112, 4-5, p. $572-597$.

\section{LOURDOU J.}

1998: Inventaire des mégalithes du centre de l'Aveyron, numéro spécial aux Cahiers d'archéologie aveyronnaise, $173 \mathrm{p}$.

\section{MAHIEU E.}

1992: «La nécropole de Najac à Siran (Hérault): réflexion sur les sépultures chasséennes ", Gallia Préhistoire, 34, p. 141-164.

MARCIGNY C., GUAMÉ E., GHESQUIÈRE E. 2008: «Le cairn du château d'Angers (Maineet-Loire) », $B S P F, 105,4$, p. 813-848.

\section{MASSET C.}

1979: «La population de la ChausséeTirancourt: approche méthodologique ", Archives suisses d'anthropologie générale, 43 , 2, p. 223-230.

1995: "Sur la stratigraphie de la ChausséeTirancourt (Somme) », Actes du $19^{e} \mathrm{col}$ loque interrégional sur le Néolithique, Amiens, 1992, numéro spécial de la Revue archéologique de Picardie, 9, p. 135-139. 